University of Louisville

ThinkIR: The University of Louisville's Institutional Repository

Electronic Theses and Dissertations

$5-2012$

\title{
Job embeddedness theory : can it help explain employee retention?.
}

Jeffery A. Young

University of Louisville

Follow this and additional works at: https://ir.library.louisville.edu/etd

\section{Recommended Citation}

Young, Jeffery A., "Job embeddedness theory : can it help explain employee retention?." (2012). Electronic Theses and Dissertations. Paper 1625.

https://doi.org/10.18297/etd/1625

This Doctoral Dissertation is brought to you for free and open access by ThinkIR: The University of Louisville's Institutional Repository. It has been accepted for inclusion in Electronic Theses and Dissertations by an authorized administrator of ThinkIR: The University of Louisville's Institutional Repository. This title appears here courtesy of the author, who has retained all other copyrights. For more information, please contact thinkir@louisville.edu. 


\title{
JOB EMBEDDEDNESS THEORY: CAN IT HELP EXPLAIN EMPLOYEE RETENTION?
}

\section{By}

\section{Jeffery A. Young}

B.S., University of Kentucky, 1985

M.P.A., University of Louisville, 1995

\author{
A Dissertation \\ Submitted to the Faculty of the \\ College of Education and Human Development \\ of the University of Louisville \\ in Partial Fulfillment of the Requirements \\ for the Degree of
}

\section{Doctor of Philosophy}

Department of Leadership, Foundations

and Human Resource Education

University of Louisville

Louisville, KY

May 2012 
Copyright 2012 by Jeffery A. Young

All rights reserved 


\section{JOB EMBEDDEDNESS THEORY: CAN IT HELP}

EXPLAIN EMPLOYEE RETENTION?

By

Jeffery A. Young

B.S., University of Kentucky, 1985

M.P.A., University of Louisville, 1995

A Dissertation Approved on

April 4, 2012

by the following Dissertation Committee:

Dr. James Stone

Dissertation Director

Dr. Oscar Aliaga Abanto

Dr. Brad Shuck

Dr. Ann M. Herd

Dr. Pradeep Kotamraju 


\section{ACKNOWLEDGMENTS}

I want to express my deepest appreciation to my family, friends, colleagues, and fellow doctoral students, without whose support I would not have been able to accomplish this daunting task. Thanks especially to my wife, Sheila, for her understanding and support. Thanks to my children for their patience when I was gone, though in the same room. A special thanks to my parents who instilled in me a love for learning.

In addition, I want to express my appreciation to the members of my dissertation committee. Your professionalism is matched only by your enthusiasm and generosity. Thank you, Dr. James Stone, for agreeing to walk this road with me. I have realized many times throughout this process how fortunate I was to have you on my team. Thank you, Dr. Oscar Aliaga Abanto, for your patience and willingness to share your wisdom, knowledge, and experience regarding the dissertation process. Thank you, Dr. Brad Shuck, for serving as "methodologist" and for being a reliable source of enthusiasm and support whenever I needed either. Thank you, Dr. Pradeep Kotamraju and Dr. Ann Herd, for agreeing to serve on my dissertation committee and for providing valuable feedback and advice.

Thanks to Dr. Jimmy Henning, Associate Dean for the Extension and Director of the University of Kentucky Cooperative Extension Service, and Dr. Daryl Buchholz, Associate Director of Extension and Applied Research at Kansas State University, for 
agreeing to support this study. It goes without saying that without your support, this work would not have happened.

Thanks to Stacey Warner (Kansas State University), Dr. Kenneth Jones

(University of Kentucky), Dr. Charlene Jacobs (University of Kentucky), and Martha

Thompson (University of Kentucky) for serving as my panel of experts. Your insight into shaping the data-collection instrument was extremely helpful.

Most important, thank you Father, God in Heaven. I could never have imagined the life You have blessed me with, the opportunities You have brought my way, and the wonderful, healthy family You have given me. Thank You. 


\title{
ABSTRACT \\ JOB EMBEDDEDNESS THEORY: CAN IT HELP EXPLAIN EMPLOYEE RETENTION?
}

\author{
Jeffrey A. Young
}

April 4, 2012

Job embeddedness theory, as introduced by Mitchell, Holtom, Lee, Sablynski, and Erez (2001), offers a method of discovering why people stay in an organization. By analyzing the construct's three dimensions (links, fit, and sacrifice) within community and workplace contexts, an overall level of embeddedness was determined and then used to examine retention among Extension agents $(N=454)$ in the Kansas and Kentucky Extension Services systems. An Internet-based survey was used to gather background data and responses to various scales (embeddedness, job satisfaction, organization commitment, engagement, intent to stay, and discretionary effort). Research questions were examined through the use of correlations, analyses of variance, and linear regression analyses.

This dissertation is divided into five chapters. Chapter 1 gives a historical overview of the problem of retention. Chapter 2 examines the major theories that scholars have used to explain retention and the factors that influence it; particular attention is given to job embeddedness theory. Chapter 3 contains a discussion of the research design, study population and sample, sampling procedure, instrumentation, and datacollection procedures. Chapter 4 presents the results of the study. The chapter presents the main analysis and more specific analyses by the study population's demographics 
(including comparisons of nonrespondents, respondents, and late respondents). Chapter 5 provides a summary of the study; a discussion of the results; implications for theory, research, and practice; and a discussion of the study's limitations.

In summary, Kansas and Kentucky Extension agents reported significantly different levels of job embeddedness over the study period. Regression analyses showed that job embeddedness was significantly correlated with and predicted unique variance in intent to stay. An examination of the participants' background characteristics showed that age, education level, and geographic state of employment significantly influenced certain components of job embeddedness. 


\section{TABLE OF CONTENTS}

PAGE

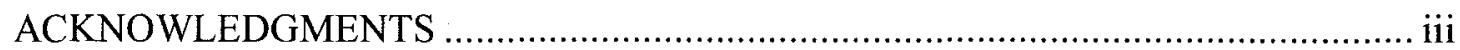

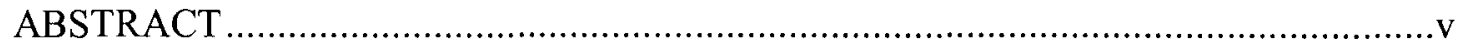

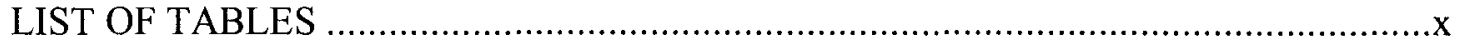

INTRODUCTION

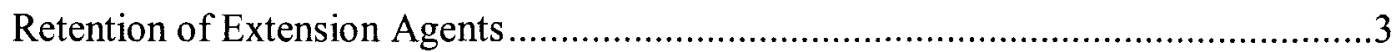

Retention Rates in Kansas and Kentucky ...........................................................

Extension Agents' Retention Rates Compared to Other Sectors .................................4

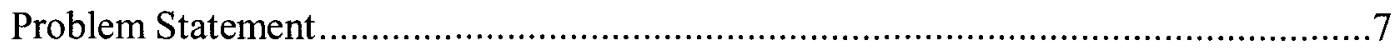

Purpose

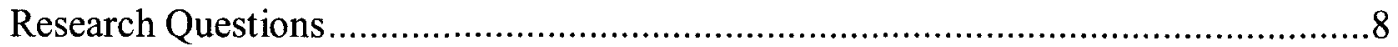

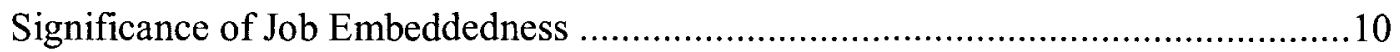

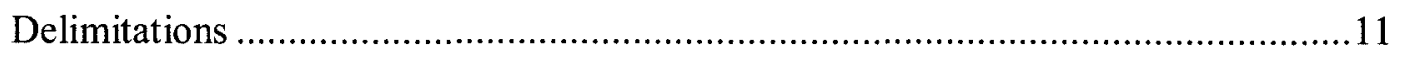

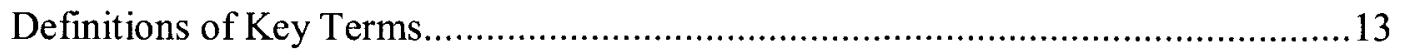

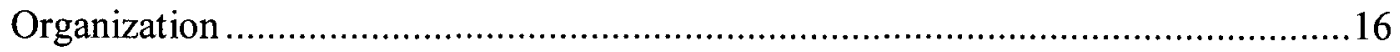

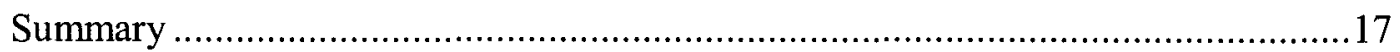

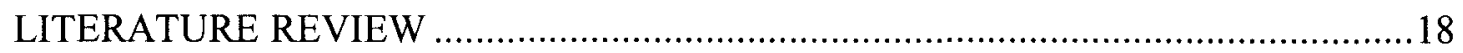

The Land-Grant University System and Cooperative Extensions..............................18

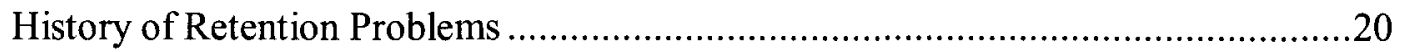

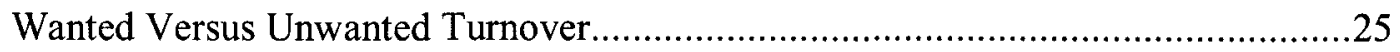

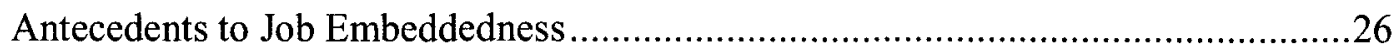

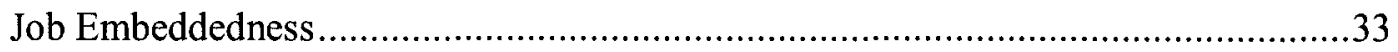




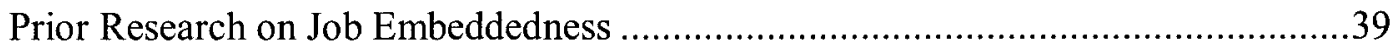

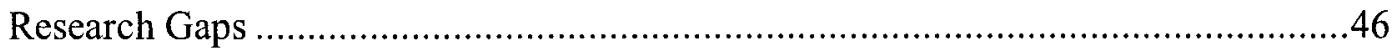

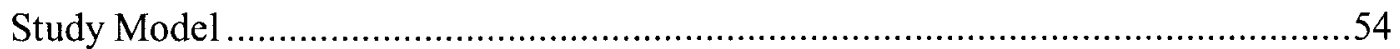

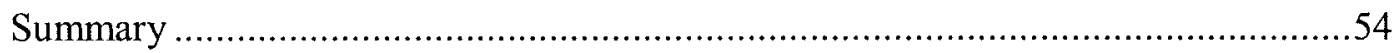

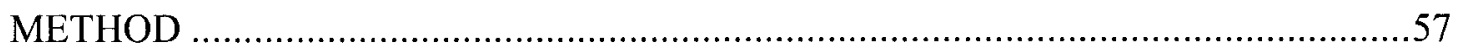

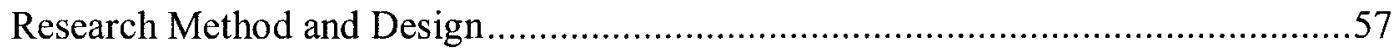

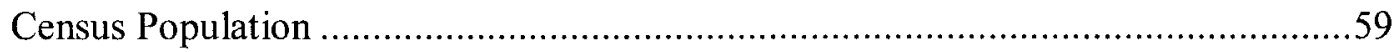

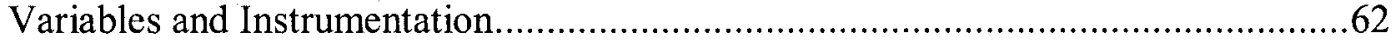

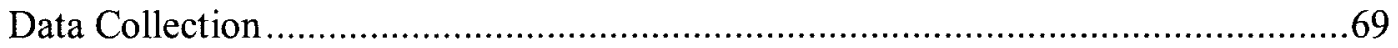

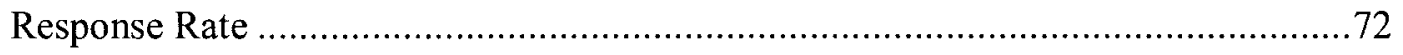

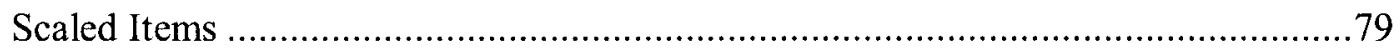

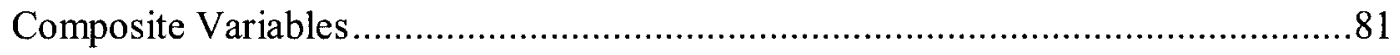

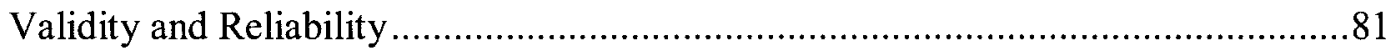

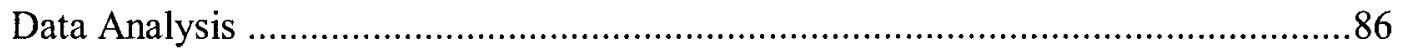

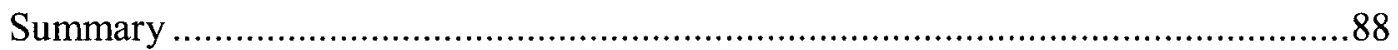

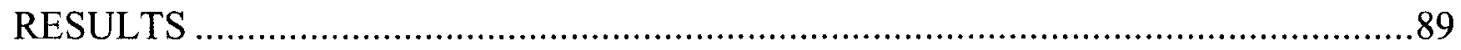

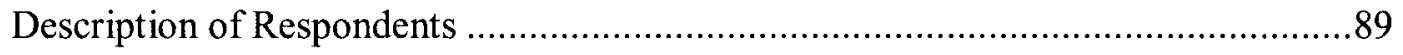

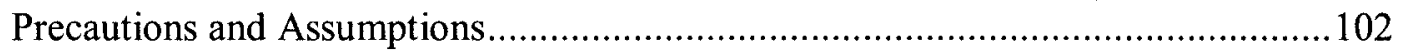

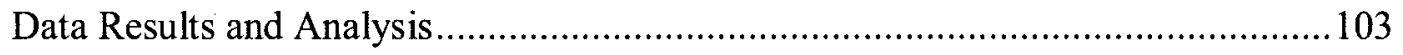

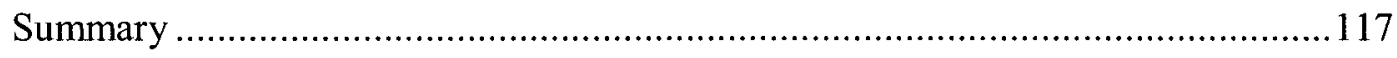

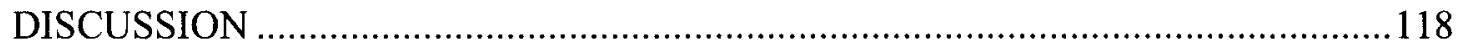

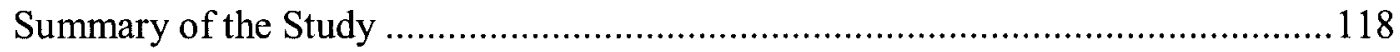

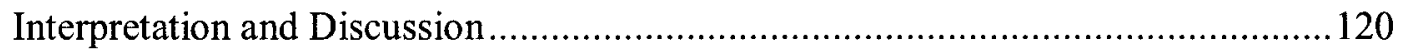

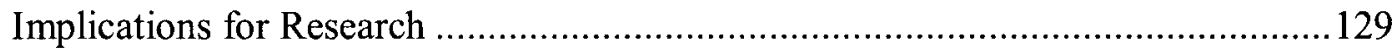

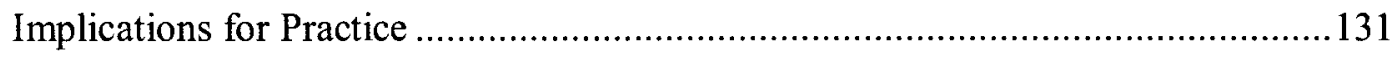


Recommendation for Future Research............................................................... 135

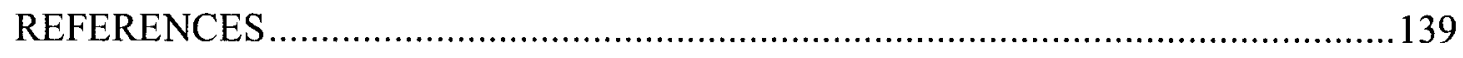

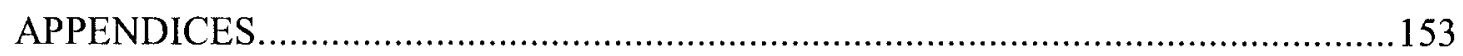

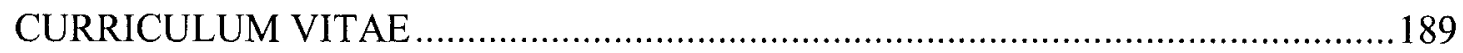




\section{LIST OF TABLES}

TABLE

PAGE

1.1. Retention of Agricultural Extension Agents for Five States Over 5 Years 5

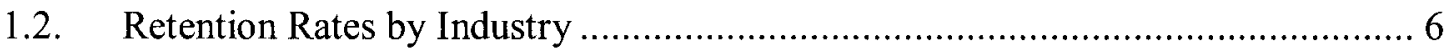

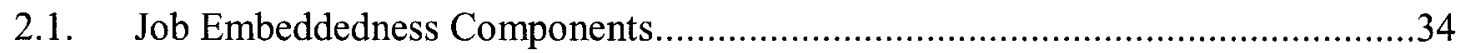

3.1. Population Description (Column Percentages) ..........................................62

3.2. Scales and Corresponding Item Numbers .............................................63

3.3. Survey schedule: Based on Dillman et al. (2009).................................... 71

3.4. Summary of Respondents by State and Week ............................................ 73

3.5. Nonresponse Bias Analysis, by Gender, Race, Education, Age, and State ..........80

3.6. Job Embeddedness Factor Analysis Composite Scores ...................................84

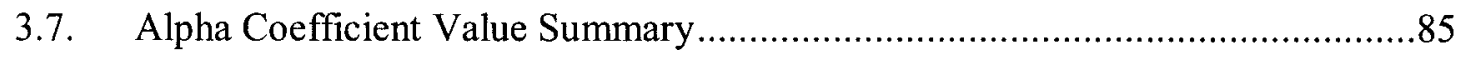

4.1. Cross-Tabulations of Gender and State...................................................90

4.2. Cross-Tabulations of Race and State ................................................91

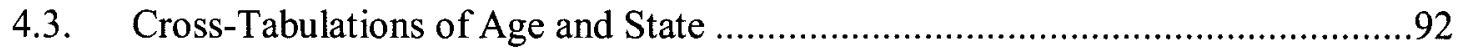

4.4. Cross-Tabulations of Education Level and State.........................................93

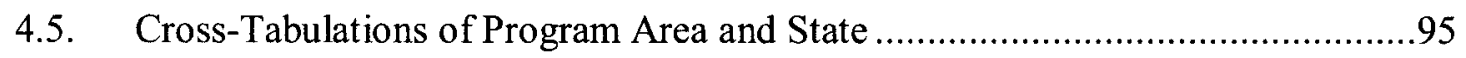

4.6. Cross-Tabulations of Years of Employment and State ...................................96

4.7. Cross-Tabulations of Education Level and State.......................................97

4.8. Cross-Tabulations of Prior Professional Experience Type and State ..................99

4.9. Cross-Tabulations of Agent Performance Review Responsibility and State ......100 
4.10. Cross-Tabulations of County Population and State ........................................101

4.11. ANOVA Summary Table: Job Embeddedness and State ….............................104

4.12. MANOVA Summary Table: Job Embeddedness Components and State ..........106

4.13. Correlations between Job Embeddedness, Intent to Stay and Discretionary

Effort.....

4.14. Job Embeddedness (Six Components), Intent to Stay, and Discretionary Effort Descriptive Statistics.

4.15. Regression Analysis of Employee Engagement, Organization Commitment, Job Satisfaction, Sacrifice Community, Sacrifice Organization, Fit Community, Fit Organization, Links Organization, and Links Community on Intent to Stay.

4.16. Beta Coefficients From the Regression Analysis of Dummy Coded

Variables 


\section{CHAPTER I \\ INTRODUCTION}

This study examined employee retention among Extension agents in Kansas and Kentucky. Specifically, this study focused on the relationships between job embeddedness theory and employees' intent to stay, discretionary effort, employee engagement, job satisfaction, organization commitment, and background information.

The view of one's job has changed for the average American over the past century. The strong philosophy of independence and pride in one's work that existed into the early 1900 s has been replaced by a reluctant dependence on employers and a culture lacking in commitment and loyalty between the employer and employee, both of which ultimately contribute to employee separation (Ciulla, 2000). The beginnings of this trend can be traced to the early Industrial Revolution, with its focus on specialization of work. In more recent decades, work culture has been further fractured by large-scale downsizing in the name of productivity (Luthans \& Sommers, 1999).

The problem of low retention is not new. It has been and will continue to be a challenge for employers. Prior to the Industrial Revolution, employers in the United States were relatively small and labor was readily available. Usually, these small businesses were owned by experienced craftsmen. Young workers would gain knowledge and experience in the apprentice relationship (Ciulla, 2000). Working conditions for apprentices were generally poor and most were forced to enter into contractual 
relationships with their employer. One well-known example of the apprentice relationship involves Benjamin Franklin. At age 12, Franklin became a "bound" apprentice to his older brother James, the printer of the New England Courant. The relationship ended prematurely when Franklin ran away because of ill treatment by his older brother. Franklin ultimately arrived in Philadelphia, where he used his acquired knowledge and skills to publish his own paper The Pennsylvania Gazette (Franklin, 1793/1909).

As demands for products and services increased in the late $1800 \mathrm{~s}$, the size of the urban workforce grew. The remnants of the apprentice system were still in place, with new workers learning from more experienced ones for extended amounts of time. It is also during this time that organized labor in the United States began. The U.S. Iron Rollers, employees of the Columbus Iron Works, are an example of workers who organized themselves to negotiate work quantities, time lines, and fees (Leab, 1985).

As demand for mass-produced products increased, so did tensions between workers and management. This struggle was perpetuated because the knowledge and skills related to various manufacturing trades was still controlled by the workers. This created a sense of independence and defiance of the organization management. It is this conflict that led Fredrick Taylor to study ways to design work so almost any person, could do any job with maximum efficiency (Taylor, 1911). Taylor's theory of scientific management regarding work specialization spread during the early 1900 s, but not without resistance on the part of workers and their unions. While efficiency was increasing, worker commitment and loyalty hit new lows. Turnover rates during this period regularly hit $100 \%$ or higher for many large manufacturers. The Ford Motor Company, for 
example, was forced to hire 54,000 workers just to maintain their real workforce of 13,000, from October 1912 to October 1913 (Clothier, 1916).

In an effort to reduce the costs associated with rampant turnover and absenteeism and to address increasingly influential trade unions, early industrialists began looking for alternatives to the adversarial roles between labor and management. Addressing worker wants and needs has been and continues to be one method that Human Resource Development (HRD) professionals use to increase trust and commitment and to reduce turnover (Jacoby, 1997). But, do these attempts improve retention? The answer depends on each worker and organization (Maling, 2010).

\section{Retention of Extension Agents}

Recent studies have shown that " $86 \%$ of employers experience difficulty attracting new employees and 58\% experience difficulty retaining their employees" (Ramlall, 2003, p. 63). There are two primary perspectives of research regarding this topic. Many have chosen to examine the reasons people leave; that is, the focus is on turnover. This is fundamentally an employer perspective. The work on employee turnover is exhaustive and will continue to be a highly researched topic. The other perspective is to examine why people stay; that is, the focus is on retention. This is mainly employee perspective. Both perspectives are valuable and help answer important questions about the organization and work itself.

According to the United States Department of Agriculture, National Institute of Food and Agriculture (2010), there are approximately 8,000 Extension agents employed in the U.S. Extension System, which includes the 50 states, Washington DC, and the territories of Northern Marianas, Guam, Federal States of Micronesia, American Samoa, 
Puerto Rico, and the Virgin Islands. The retention of these employees is important because low retention represents a potentially large, yet controllable, organizational expense. Although no national retention statistics for the Extension System are known, the fiscal benefits of increasing retention are substantial. For instance, a 1-percentagepoint increase in the overall retention rate of Extension agents nationwide (800 agents $\mathrm{x}$ $\$ 80,000$ ) could reduce organizational expenses by $\$ 6.4$ million dollars annually (Kutilek, 2000).

\section{Retention Rates in Kansas and Kentucky}

An informal survey of Extension agents was conducted by Martha Thompson, University of Kentucky (UK), Extension Employment Specialist. For the survey she contacted colleagues in Midwestern and Southern states regarding the voluntary retention rates within their Extension Services. Four states responded to her request for retention rates. These rates, in addition to the Kentucky retention rate, are summarized in Table 1.1 (M. Thompson, personal communication, November 5, 2010). The rates were used to identify states whose retention rates were lower than Kentucky's retention rate. Louisiana State University was contacted first; however, because the university was in the process of a major reorganization, the administration declined to participate. Kansas State University (KSU) was contacted next, and the KSU Director of Extension responded positively to an invitation from Kentucky's Director of Extension.

\section{Extension Agents' Retention Rates Compared to Other Sectors}

Retention among Extension agents has historically been high compared to most other employee groups. Table 1.1 shows that Extension agent retention rates have ranged between $95.12 \%-97.23 \%$. For instance, the Extension Service's high retention rates are 
Table 1.1

Retention of Agricultural Extension Agents for Five States Over 5 Years

\begin{tabular}{lcccccc}
\hline State & $\begin{array}{c}2005-06 \\
(\%)\end{array}$ & $\begin{array}{c}2006-07 \\
(\%)\end{array}$ & $\begin{array}{c}2007-08 \\
(\%)\end{array}$ & $\begin{array}{c}2008-09 \\
(\%)\end{array}$ & $\begin{array}{c}2009-10 \\
(\%)\end{array}$ & $\begin{array}{c}\text { Means } \\
(\%)\end{array}$ \\
\hline KY & 96.40 & 96.20 & 95.10 & 96.70 & 97.30 & 96.34 \\
TN & 93.81 & 94.10 & 95.67 & 98.13 & 95.88 & 95.12 \\
KS & 98.00 & 92.00 & 94.00 & 95.00 & 98.00 & 95.40 \\
LSU & 96.87 & 94.69 & 95.24 & 94.99 & 92.54 & 94.87 \\
MO & & 96.00 & 98.00 & 97.70 & & 97.23 \\
\hline
\end{tabular}

Note. Retention data provided by respective state's HR departments at the request of Martha Thompson, UK Employment Specialist.

a stark contrast to the rates of $43.6 \%$ in the food-service sector, $47.8 \%$ in the leisure and hospitality sector, and $66.3 \%$ in the retail sector. Even higher retention sectors, such as wholesale trade $84.5 \%$, manufacturing $83.3 \%$, and mining $83 \%$, have rates that are substantially lower than those of Extension Services. The retention rates in Extension Services are also high when compared to government sector employees $91.8 \%$ and elementary and secondary teachers $83 \%$ ("Retention Management and Metrics," 2006). A complete listing of retention rates by industry can be seen in Table 1.2.

Although the high retention rates within the Extension Service are encouraging, they are also somewhat surprising given some of the difficulties that Extension agents list in balancing work-life issues. These issues are similar to the following concerns listed by family members of Extension agents: time, work spillover to home life, family needs, physical needs, and financial needs (Kutilek, Conklin, \& Gunderson, 2002, p. 17).

Given the historically high retention rates of the Extension Services in Kentucky and other states, the focus of future HRD employment studies should not be concerned 
Table 1.2

Retention Rates by Industry

\begin{tabular}{lc}
\hline \multicolumn{1}{c}{ Industry } & $\begin{array}{c}\text { Retention } \\
\text { rate (\%) }\end{array}$ \\
\hline Total U.S. & 76.6 \\
Government & 91.8 \\
Education and health service & 81.4 \\
Health care and social assistance & 80.4 \\
Construction & 71.3 \\
Retail trade & 65.3 \\
Leisure and hospitality & 47.8 \\
Food service & 43.6 \\
\hline
\end{tabular}

Note. Reproduced from "Retention Management and Metrics," 2006. Retrieved from http://www.nobscot.com/survey/index.cfm

with the reasons people leave, but with why they stay. In this study we will use the intent to stay scale as our measure of retention.

Clearly, factors exist that encourage or embed employees within the organization. This study extends the use of job embeddedness theory and the understanding of retention among Extension agents in Kansas and Kentucky. An underlying questions could be "what HRD policies and organizational cultures help promote these high retention rates". In this study, identifying what specifically embeds Extension agents in Kentucky and Kansas could provide HRD professionals with powerful knowledge that can be applied to Extension agents in other states, other Extension Services employee groups that have much higher turnover rates (e.g., support staff and paraprofessionals), and other public employment sectors (Kutilek, 2000). 


\section{Problem Statement}

Although, the HRD literature points to possible reasons for high Extension agent retention (Kroth \& Petuz, 2010), to date no research has been conducted examining the issue through the lens of job embeddedness theory, which focuses on factors that might encourage employees to stay in their organization and community (Mitchell et al., 2001).

An organization's retention rate can lead to substantial negative consequences for all organizations. These costs include lower quality products and services; higher financial expenses in the areas of recruiting, hiring, and retaining employees; and losses in productivity during the time a position is vacant. Low retention also interrupts the flow of products and services, costing organizations thousands of dollars each year (Kutilek, 2000).

Understanding the relationships between job embeddedness and retention within the population of Extension agents will assist HRD professional in formalizing policies and procedures that embed employees to organizations and communities. I hope that the results of this study will be useful in addressing retention among all Extension Service employee groups (Kutilek, 2000). However, a direct analysis of the latter point is beyond the scope of this study and should be the topic of further research.

\section{Purpose}

The purpose of this study was to understand retention among Extension agents in the states of Kansas and Kentucky through the lens of job embeddedness. The study also addresses a void in the literature by examining the relationships between job embeddedness, intent to stay, discretionary effort, job satisfaction, organization commitment, employee engagement and background information. 
This study contributes empirical data to discussions on the impact of job embeddedness on employee retention. The study was exploratory in nature and extended the research of Mitchell et al. (2001) into the public employee sector, of which the Cooperative Extension system is a small subset. Because each state is unique, the results of this study should not be generalized to other state's Extension agents.

\section{Research Questions}

The four major research questions in this study focused on differences in the embeddedness of UK and KSU Extension Service employees and the ability of job embeddedness to predict intent to stay.

Research Question 1: Does job embeddedness differ between KSU and UK Extension agents?

To examine this question, I used ANOVA and MANOVA tests, which are useful when comparing means. In examining Research Question 1, the quantitative dependent variables were the overall and composite scales of job embeddedness and the independent variable was the geographic state of employment (Kansas or Kentucky; hereafter referred to simply as state).

Research Question 2: What are the relationships between job embeddedness, intent to stay and discretionary effort?

To test this question, correlation coefficients were used to examine relationships between variables. Correlation coefficients are useful in testing for levels of significance, direction of effect (positive or negative), and strength of relationship between the variables, which in this case were job embeddedness, intent to stay, and discretionary 
effort? A correlational analysis examines the relationships among the variables (Gravetter \& Wallnau, 1985).

Research Question 3: Can job embeddedness predict unique variance in the outcome variables intent to stay and/or discretionary effort, after controlling for job satisfaction, organization commitment, and employee engagement?

To examine this question, linear regressions were utilized. The quantitative dependent variables were intent to stay and discretionary effort, and the independent variables were the overall job embeddedness mean and the six subcomponent means.

To examine the ability of job embeddedness to predict intent to stay or discretionary effort, a linear regression analysis was performed. A linear regression analysis is "used to explain or predict the values of a dependent variable based on the values of one or more independent variables" (Johnson \& Christensen, 2007). Because other mediating independent variables could have affected the dependent variables, it was necessary to control for job satisfaction, organization commitment, and engagement. This will allow the "unique variance" of job embeddedness to be viewed. Finally, I utilized a step wise regression examining the influence of all variables mentioned above on intent to stay. One of the most significant outputs of the linear regression tests are beta coefficients. Beta coefficients give the relative strength of the predictive ability of each independent variable.

Research Question 4: Are background variables significantly related to and able to predict job embeddedness?

I analyzed the relationships between job embeddedness (total and six components) and all levels of the background variable (gender, race, education-level, age, 
program area, years in organization, years of prior work experience, type of prior work experience, county population, and state). Dummy variables were created from these categorical variables. This allows for linear regression tests to be used in addressing this question.

\section{Significance of Job Embeddedness}

Turnover costs are difficult to determine. Research estimates range from $\$ 80,000$ per employee (Kutilek, 2000) to $150 \%$ of position salary (Friedman, Galinsky, \& Plowden, 1992). The obvious implication is that as retention rates decrease, the associated costs negatively affect an organization's bottom line.

Two primary areas of research have addressed the topics of attracting and retaining employees: the reasons people leave their job (i.e., employee turnover) and the reasons people stay (i.e., retention). Turnover has received more attention in the literature; however, both perspectives are valuable and help answer important questions about an organization's human capital. This study occasionally refers to studies on turnover but will focus largely on retention specifically to test whether job embeddedness theory helps explain the retention of Extension agents in Kansas and Kentucky.

Job embeddedness refers to a relatively new construct that examines an individual's (a) links to other people, teams, and groups; (b) perceptions of their fit with the job, organization, and community; and (c) beliefs about what they would have to sacrifice if they left their jobs (Mitchell et al., 2001).

Links are defined as connections between people and institutions. Highly embedded individuals have many links to the workplace, community, or both. Examples 
of links include age, marital status, number of children and their ages, years of service, hobbies, church-related activities, and membership in community organizations.

Fit can be seen as perceived comfort with an organization and community. The closer that one's personal views, values, and goals are to the organizational culture of the employer, the better the fit and the "higher the likelihood that an employee will feel professionally and personally tied to the organization" (Mitchell et al., 2001, p. 9). Examples of community fit could include weather preferences, access to outdoor activities, entertainment, and political and religious climates.

The final component of the job-embeddedness construct is sacrifice. In this study, sacrifice refers to the material and psychological benefits that could be lost if an employee leaves the organization. These sacrifices might include the corner office, health and retirement benefits, sports tickets, length of time in residence, distance to work location, safety, and leadership in the community.

The significant and unique aspect of job embeddedness is its ability to gauge the impact of community factors on an employee's decision to leave or remain in the current work situation. As indicated earlier, I found no studies on the ability of job embeddedness to impact the retention of Extension agents. The present study of Kansas and Kentucky Extension agents represents the initial work with this population.

\section{Delimitations}

Delimitations are factors affecting the study that are controllable by the author (Mauch \& Birch, 1993). Several delimitations were present in this study. The first delimitation involved the timing of the study. In order to enhance response rate, I followed Dillman's (2009) recommendation to administer the surveys so that they arrive 
on Mondays, prior to the start of the work day. A second delimitation was the location and population of the study. Only persons employed as Extension agents with the KSU and UK were surveyed. The third delimitation was the limitations in the list of independent variables considered in this study. Additional background data not collected could include local employment opportunities, work performance, local employment rates, and employment of family members in Extension Services. The final delimitation was the decision to utilize an online census survey to collect data. A census survey ideal because it seeks to gather data from all members of the population and allows for the collecting of the maximum number of responses and gather large amounts of data at an economical price.

\section{Limitations}

Limitations are weaknesses or problems within a study that are beyond the control of those conducting the study (Roberts, 2004). Study weaknesses often relate to "inadequate measures of variables, loss or lack of respondents, small sample sizes, errors in measurement, and other factors typically related to data collection and analysis" (Creswell, 2005, p. 198). The following limitations are enumerated in the hope of benefiting future research.

1. Financial considerations and time limited this study to only 2 of the 50 states, Washington D.C, and U.S. territories, which have Extension programs.

2. The work in examining job embeddedness within Cooperative Extension is one of very few know efforts outside the private sector in the United States. The lack of such studies in the public, educational, and nonprofit arenas 
should be considered a limitation but also evidence of the timeliness of this study.

3. The recession in the U.S. economy might have limited this study. Because fewer job opportunities were available during the data-collection period, Extension agents were less likely to leave and aspiring Extension agents were more likely to be underemployed.

4. Finally, the very small differences between the two state's retention rates could be a limitation.

\section{Definitions of Key Terms}

In the literature review that follows, I examined turnover, job embeddedness, retention, job satisfaction, organization commitment, intent to stay, discretionary effort, employee engagement, land-grant universities, the Cooperative Extension Service, and Extension agents.

The Cooperative Extension Service was formalized in 1914, when Congress enacted the Smith-Lever Act. The legislation provides for a comprehensive education program in each state. The language of the original act called for the Extension Service to "aid in diffusing among the people of the United States useful and practical information on subjects related to agriculture and home economics, and to encourage the application of the same" (Smith Lever Act, 1914, p.1).

Discretionary effort "is the difference in the level of effort one is capable of bring to an activity or a task, and the effort required only to get by or make do" (Lloyd, 2003, p. 72). 
Dysfunctional turnover can be defined as a level, somewhat unique to each organization, that "produces a divergence between the organization's optimal balance of costs associated with turnover and the costs associated with retaining employees" (Abelson \& Baysinger, 1984, p. 331). In simpler terms, dysfunctional turnover occurs when high-performing employees choose to leave (Park, Ofori-Dankwa, \& Bishop, 1994).

Employee engagement is generally defined as a "positive, fulfilling state of mind, most commonly characterized by vigor, dedication, and absorption" (Halbesleben and Wheeler, 2008, p. 242).

Employee retention policies are those policies and procedures put in place by employers to entice employees to remain in the organization (Nair, 2009)

Extension agents, also referred to as county agents, are individuals employed by their state's land-grant universities to aid in the dissemination of research-based information, at the county level, to the citizens of the state (Smith Lever Act, 1914).

Functional turnover can be thought of as turnover that is beneficial to the organization. This could be the case with low or underperforming employees, whose "desires to leave are not disrupted or hindered by the organization" (Dalton, Krackhardt, \& Porter, 1981, p. 716).

Intent to stay refers to the likelihood that an individual employee will remain in the organization (Tett \&Meyer, 1993).

Involuntary turnover involves an employee being forced to leave an organization. Involuntary turnover can happen for various reasons but usually involves "economic conditions and their effect on the organizational budget, changes in career or retirement" 
(Thomas, 2009, p. 1). This paper considered both voluntary and involuntary turnover, less retirement.

Job embeddedness as defined by Mitchell et al. (2001) refers to the on-the-job and off-the-job factors associated with individual links, fit, and sacrifice.

Job satisfaction can be defined as an "individual's attitude about work roles and the relationship to worker motivation" (Scott, Swortzel, \& Taylor, 2005, p. 89). The general thought process is that if employees are satisfied, they will be less likely to leave the organization.

Land-grant universities were created by the passage of the Morrill Act of 1862 the Morrill Act of 1890, and The Equity in Education Land-Grant Status Act of 1994. These land-grant universities were based on the idea that U.S. higher education should be doing more than producing doctors, lawyers, teachers, and ministers. Instead, land-grant universities would be open to everyone and would focus on "promoting teaching, research and public service" (Iverson, 2008, p. 1). Several land-grant universities have developed into some of the nation's leading institutions of public learning and research.

Organization commitment has been defined as the "relative strength of an individual's identification with and involvement in an organization" (Mowday, Porter, \& Steers, 1982, p. 43). Together, job satisfaction and organization commitment are two of the most historically mature theories predating job embeddedness.

Retention refers to the ability of management to retain employees. Retention policies are those put in place by employers to entice employees to remain in the organization (Nair, 2009) 
Turnover is generally discussed in the contexts of voluntary turnover, involuntary turnover, functional turnover, and dysfunctional turnover.

The underemployment rate refers to "workers who are working part time (less than 35 hours a week) but who both want and are available for full time work" (Sum \& Khatiwada, 2010, p. 10). Sum and Khatiwada (2010) noted that the underemployment rate rose $112 \%$ between 2007 and 2009 .

The unemployment rate describes the portion of the population that is without a job, is actively looking for a job, and is available to work. Also included in the unemployment rate are those who are temporarily laid off and waiting to return to their jobs. For most of the last decade, this rate has held relatively steady at 4 to $6 \%$. However, beginning in March 2008, the rate soared to its peak of 10.1\%. Throughout 2011 the national unemployment rate has held at around 9\%. Appendix A lists unemployment rates for the past 10 years (U.S. Bureau of Labor Statistics, 2011).

Voluntary turnover is defined by Maertz and Campion (1998) as "instances wherein management agrees that the employee had the physical opportunity to continue employment with the company, at the time of termination" (p. 50). Mowbray (2001) built on this definition, adding that "voluntary attrition assumes that the employee did not leave because of internal transfer, promotion or moved to another position within the organization" (p.2).

\section{Organization}

The remaining four chapters of this dissertation are organized as follows. The second chapter contains a review of the literature pertaining to job embeddedness, job satisfaction, organization commitment, engagement, discretionary effort, intent to stay, 
and background variables and how they relate to employee retention. The third chapter acquaints the reader with the dissertation model, research questions, hypotheses, research design, and methodology. In addition, detailed discussions of the survey instrument, datacollection procedures, and study population are included. Chapter 4 contains an analysis of the data and its implications. Chapter 5 includes contributions, limitations, practical implications, and directions for future research. The study concludes with a reference section and appendices.

\section{Summary}

Job embeddedness, as described in the current dissertation, makes new and creative contributions to the literature regarding retention by expanding the study of job embeddedness into the public sector, comparing job embeddedness between Extension agents in Kansas and Kentucky, and tests the ability of job embeddedness to predict intent to stay and discretionary effort. Given that the 2010 retention rates for both states averaged $95.79 \%$ (Table 1.1 ) and that the starting salary in 2012 for Extension agents was approximately $\$ 33,000$, the average annual turnover costs to both states would be $\$ 957,000$ per year (Ramlall, 2003). Even though Extension Service retention rates are substantially higher than the retention rates in other employment sectors of the economy, they still represent a significant cost to the organizational budget. An alternative lens could be to identify factors contributing to the high retention rates in Kansas and Kentucky Extension Services so that other organizations can try to duplicate them. 


\section{CHAPTER II}

\section{LITERATURE REVIEW}

\section{The Land-Grant University System and Cooperative Extensions}

In the mid-1800s, a group of forward thinking Congressmen led by Representative Justin Smith Morrill of Vermont proposed the College Land Bill to develop a different type of college, one devoted to educating the people whose lives would not be spent in the professions of teaching, religion, or the law. The Morrill Act was initially passed by Congress in 1859 , but was vetoed by President James Buchanan. Rep. Morrill resubmitted his legislation in 1861 , with provisions to support military education in addition to engineering and agriculture. President Abraham Lincoln signed The Morrill Act of 1862 into law on July 2, 1862. The Act also allocated land to states based on their representation in Congress (The Morrill Act of 1862). The institutions created by this legislation are known as 1862 land-grant institutions, and both KSU and UK are among them.

As land-grant colleges grew, they gradually realized that teaching "scientific agriculture" required a strong research program. As the need and potential value of the experiment station was recognized, federal support grew. In 1887, passage of the Hatch Act created agricultural-experiment stations to conduct research, investigations, and experiments to establish and maintain the agricultural industry of the United States. These agricultural-experiment stations were patterned after the successful European 
model of agricultural research, which had been thriving for over 50 years prior to 1887 (The Hatch Act of 1887).

In 1890, Morrill was successful in the passing and signing the second Morrill Act into law. The act provided for additional funding to benefit agriculture and the mechanic arts. Additionally, the Morrill Act of 1890 included a provision that led to the creation of 17 predominantly Black land-grant colleges in the southern states. In effect, the Morrill Act of 1890 accomplished for Black citizens of the South what the first act of 1862 had accomplished for White citizens (The Morrill Act of 1890).

Kentucky State University was created in response to the 1890 legislation. Kentucky State University provides teaching, research, and Extension functions to the people of Kentucky and works in concert with the 1862 land-grant institution, UK. Kansas did not create an institution in response to the 1890 legislation.

In 1914, Congress passed the Smith-Lever Act, providing for a comprehensive Extension-education program in each state. The language of the original act called for Extension programs to "aid in diffusing among the people of the United States useful and practical information on subjects related to agriculture and home economics, and to encourage the application of the same" (Smith Lever Act, 1914, p. 1). Smith-Lever funding (also referred to as formula funding) is based on the state's population size. This Extension model for disseminating research-based knowledge to the general public has been replicated in many countries around the world (Ludwig, 1995; Lundy, Place, Irani, \& Telg, 2005). 


\section{History of Retention Problems}

Hale (1998) showed that attracting and retaining the best employees represented a serious problem for organizations. According to Hale's study, $86 \%$ of employers found it difficult to attract new employees, and $58 \%$ found it difficult to retain employees. Two primary lines of research have addressed this topic. Much research has gone into the examination of the reasons people leave their jobs. The other perspective is to examine why people stay. Both perspectives are valuable and help answer important questions about an organization's human capital.

\section{Industrial Revolution}

The work on employee retention is extensive and will continue to be a highly researched topic. Welfare capitalism and its many facets developed into one way to improve retention in the early industrialized workforces (Jacoby, 1997). Introduced during the Industrial Revolution, welfare capitalism emphasized better pay, better treatment of workers, and better public relations, largely to improve retention. Some of the early examples of welfare capitalism include profit sharing at AT\&T, Proctor and Gamble and Sears Roebuck, pension plans at International Harvester (Ciulla, 2000), health insurance at Baylor Hospital (Hague, 2010), and the model-town concept implemented by Pennsylvania iron and steel industrialist George McMurtry (Mosher, 1995).

McCurtry, the son of poor Scottish farmers, immigrated to the U.S. in the late 1850 's, beginning his career in the steel industry as a clerk, and later became a business partner in numerous small to large companies. His model town was named Vandergrift and was located near Pittsburgh (Mosher, 1995). According to Mosher, residents of 
Vandergrift were so loyal to McMurtry that he "successfully used them in 1901 in breaking one of the first strikes waged against the entire system of mills owned by United States Steel Corporation" (Mosher, 1995, p. 84).

\section{Depression Era}

The use of welfare capitalism to address the retention issues lost momentum during the 1930s. The Great Depression brought lower profits to companies and the passing of the Wagner Act in 1935, led to the demise of company-sponsored unions and worker councils (Grant, 1998, p. 71). However, the conflict between organized labor and management raged on in spite of improved working conditions, an increasing variety of benefits, and a general decrease in union membership. The image of paternalistic employers who provided for the needs of their employees was perpetuated, with workers commonly staying with one employer their entire working lives (Gitelman, 1992).

\section{Modern Era}

There have been many examples of corporate downsizing throughout the last century. Some of the nation's largest and more respected companies have instituted huge layoffs in blue-collar and white-collar positions. The scope of the layoffs witnessed in the 1990s shocked the American work force and had chilling effects on the levels of commitment and trust between employees and employers (Luthans \& Sommers, 1999).

Herein lays a great irony and challenge for HRD professionals. How can HRD positively affect retention levels of employees, by building trust and commitment in an environment where employers are either unwilling or are unable to do the same (Ciulla, 2000). Many companies continue down the corporate-welfare path, adding more and more creative benefits to draw the best and brightest to their organizations. Fortune 
Magazine conducts an annual study of the 100 best companies to work for. These companies are listed by "big pay" and "best perks." Companies that spare no expense to entice and pamper their employees include well-known names, such as Google and Microsoft, and lesser known names, such as SAS and Zappos.com ("100 Best Companies," 2009). What all these companies have in common is the belief that employee loyalty and commitment can be purchased at the right price. They may be right. A review of the human resources pages of these " 100 Best Companies" reveals vast lists of employee benefits. Some of the more creative include personal trainers, 24-hour gyms, in-house doctors, dry cleaners, message services, swimming pools and spas, free gourmet meals (breakfast, lunch, and dinner), and free shuttle transportation to and from work. Employee stock-ownership plans, certainly not a new idea, are still being promoted as a means of encouraging retention in private organizations (Marens, Wicks, \& Huber, 1999).What this has done, according to Peter Cappelli (2007), is create a culture where the employer provides for the wants and needs of every employee and where employees willingly spend more and more time at work.

Public organizations are not exempt to using employee benefits as a means to entice and retain the best employees. The foundation of the benefits programs at KSU and UK includes health, dental, eye, life, and accident insurances and flexible-spending accounts. From there the list of employee benefits grows to include vacations, holidays, retirement plans, and discount programs. Both KSU and UK have employee-education programs. In addition, UK offers employees a family-education program and the possibility of paid study leave after a predetermined number of years of service. Worklife policies that were once reserved for private organizations are now found in many 
public organizations. Work-life policies include but are not limited to flexible work scheduling, child-care assistance, and family-leave policies (Roehling, Roehling, \& Moen, 2001).

But, do these modern attempts at welfare capitalism by organizations actually improve employee trust and commitment? The answer depends on individual workers and their personal lists of wants and needs. What is certain is that administrators want and need to recruit and retain the best qualified workers and creative benefits are one way to accomplish this goal (Maling, 2010).

In his book Human Resource Champions, Ulrich (1997) encouraged HRD leaders to be active in the work lives of their employees. He labels this function "management of employee contribution" and uses the metaphor of "employee champion" to describe the role (Ulrich, 1997, p. 28). The practices of open communication, quality circles, and focus groups between management and employees are being used by some organizations to improve retention without breaking the bank. Similarly, retention building through trust, commitment, and open communication can be a foundational competency, as outlined in the competency model by the American Society of Training and Development. This model has been widely accepted throughout the HRD field (Davis, Naughton \& Rothwell, 2004).

Ramlall (2003) identified factors influencing employee retention, including compensation, lack of challenging work, and lack of career-advancement opportunities. These factors also coincide with Mitchell et al.'s (2001) on-the-job components of embeddedness theory. 
Plash (2006) examined the issues that impacted the attrition and retention of special-education teachers in a southeastern Alabama county. Eleven factors were listed as "major" contributors to special-education teacher attrition. The two most important factors were judged to be "excessive paperwork" and "stress created by demands of the job." The findings of this study were limited to a subpopulation of special-education teachers and should not be generalized to other sectors, but the findings do provide a consideration for future research.

Kroth and Peutz (2010) examined workplace issues related to attracting, motivating, and retaining agents of the Cooperative Extension Service. The perceived difficulty involving organizational change ranked first among many concerns, followed by compensation and lack of adequate resources.

Although the issue of compensation has been difficult to address during the current economic environment, retention can be encouraged in other ways. Work-life policies have been shown to have a positive correlation to retention and the perceived flexibility and supportive work-life policies significantly increased the likelihood of expected retention (Richman, Civian, Shannon, Hill, \& Brennan, 2008).

Another area of concern involves the retention of older workers. One study found that training and development for older managers and professionals positively impacted their perceptions of organizational support, whereas job plateauing negatively impacted their perceptions of organizational support (Armstrong-Stassen and Ursel, 2009). In that study, training and job plateauing were both related to a stronger intent to stay. 


\section{Wanted Versus Unwanted Turnover}

When considering turnover within the Cooperative Extension Service or in any other organization, it is important to distinguish between wanted and unwanted turnover. As the previous terms imply, some turnover is desirable (i.e., wanted turnover). For instance, the leaving costs of employees who perform to low or less-than-expected levels are limited to replacement costs, which can be estimated to be $\$ 80,000$ per employee (Kutilek, 2000) to $150 \%$ of position salary (Friedman et al., 1992).

A related conceptualization categorizes turnover as either "dysfunctional" or "functional" (Dalton et al., 1981). Dysfunctional turnover involves situations in which the employee wishes to leave, but the employer would prefer them stay. Others have defined dysfunctional turnover as "the level that produces a divergence between the organization's optimal balance of costs associated with turnover and the costs associated with retaining employees" (Abelson \& Baysinger, 1984, p. 331). Alternatively, functional turnover occurs in situations when the employee wishes to leave and the employer, having a negative view of the employee, is "unconcerned" (Dalton et al., p. 716). The concept of turnover is further defined by Williams (2000), who divided turnover into four categories: "poor performing leavers, good-performing leavers, poor-performing stayers and good performing stayers" (p. 549). Park et al. (1994) found that functional turnover was associated with levels of pay, unemployment, and individual-incentive programs, whereas group-incentive programs and union presence were associated with dysfunctional turnover.

Though the exact costs related to turnover are difficult to estimate, empirical estimates range from $\$ 80,000$ per employee (Kutilek, 2000 ) to $150 \%$ of the position's 
salary (Friedman et al., 1992). The obvious implication is that as turnover rates rise, the associated costs negatively affect an organization's bottom line. Unwanted turnover is much more expansive and includes "development costs, value of knowledge and experience lost, and lost productivity" (Hauenstein, 1999, p. 3). Others (e.g., Tziner \& Birati, 1996) have divided unwanted turnover expense into the following categories.

- Separation costs

- exit interviews

- administrative

- $\quad$ severance pay

- Replacement costs

- advertising for position

- application processing

- screening and interviewing

- Training costs

- Core training

\section{Antecedents to Job Embeddedness}

Job satisfaction, organization commitment, discretionary effort, intent to stay, and job engagement are all theoretical models used by HRD researchers to explain and predict retention and can be considered antecedents of job embeddedness theory.

\section{Job Satisfaction}

Job satisfaction is one of the most researched antecedents used to explain voluntary employee turnover (Rust \& Stewart, 1995). Early work on job satisfaction can be traced to Roethlisberger and Dickson (1939) and their research on job satisfaction and 
dissatisfaction among employees of the Western Electric company. The authors postulated that employee attitudes can be compared to the relationship between an organism and its physical environment (pp. 261-262). In turn, Rosen and Rosen (1955) viewed "job satisfaction as a consequence of the discrepancy between percepts and value standards." Locke (1969, p. 316) defined job satisfaction as "the pleasurable emotional state resulting from the appraisal of one's job as achieving or facilitating the achievement of one's job values." Locke further notes that "job satisfaction and dissatisfaction are a function of the perceived relationship between what one wants from one's job and what on perceives it as offering or entailing."(p. 316). These findings are supported by the work of Rust and Stewart (1995) who determined that intention to remain employed was strongly influenced by the level of job satisfaction.

Scott et al. (2005) noted that "job satisfaction can be defined as an individual's attitude about work roles and the relationship to worker motivation" (p. 89). The general thought process is that if employees are satisfied they will be less likely to leave the organization. The authors examined Extension agents' perceptions of fundamental job characteristics and their level of job satisfaction. Overall, Extension agents indicated that they were satisfied with their jobs. Extension agents were most satisfied with the opportunities that they had for personal learning and growth at work. These findings are consistent with the findings from Barnett and Louderback's (1971) study, which suggested that, in the context of organizational change, administrators should identify opportunities for personal growth. Scott et al.'s study used a very small sample from one state and the authors recommended that it be replicated in other states. 
In another study involving Extension agents, Long and Swortzel (2007) identified age as a significant contributing factor to the variance (7\%) in job satisfaction. Generally, as Extension agents grow older, they became more satisfied.

Vlosky and Dunn (2009) examined a diverse population of Cooperative Extension Services workers in southeastern states and noted a statistically significant difference in job satisfaction between White and non-White employees. Based on the findings of their study, the authors emphasized that administrators and policy makers need to understand the role that race plays in the satisfaction of Extension Services workers.

In a related article, Vlosky and Aguilar (2009) found that autonomy and influence, challenge, performance, feedback, instrumentality, stability and security, and satisfaction were all "highly significant in positively influencing" job satisfaction among Extension Services employees (p. 9). The study showed no differences between genders in regard to these variables.

Most job-satisfaction research follows similar lines of thinking as those discussed previously, with more limited work regarding the effects of the employee's life outside of work on their intent to stay (retention). This aspect of an employee's life can be examined using job embeddedness theory, which will be discussed fully later in this chapter.

\section{Organization Commitment}

Various definitions of organization commitment have been advanced in the field. Wiener (1982) defined commitment "as the totality of internalized normative pressures to act in a way that meets organizational interests" (p. 418). Wiener's definition was based on the notion that individuals were responsible (to some degree) to the organization. Similarly, Mowday et al. (1982) defined organization commitment as the "relative 
strength of an individual's identification with and involvement in an organization" (p. 43). Smith, McCracken, and Suandl (1983) researched the concept of organization commitment with Extension agents in Ohio $(N=108)$, and found that the variables "selfimage reinforcement, personal importance, group attitudes and job autonomy" are significantly related to organization commitment (p. 24).

Allen and Meyer (1990) argued that "the most prevalent approach to organization commitment in the literature is one in which commitment is considered an affective or emotional attachment to the organization such that the strongly committed individual identifies with, is involved in, and enjoys membership in, the organization" (p. 2). In Allen and Meyer's sample, institutionalized tactics were related to custodial orientation and individualized tactics. Each socialization tactic was significantly correlated with commitment. Institutional tactics also tended to be associated with higher levels of commitment.

In an earlier examination of the roles of ambiguity and commitment, Morris and Sherman (1981) found a negative correlation between the two, although the relationship seemed to disappear within 1 year of employment. The findings suggested that, to foster both innovativeness and commitment, one should use investiture tactics, but also that the influences of seasoned workers could have negative impacts on the organization commitment of newer workers. This can be a difficult challenge because long-term employees are generally good mentors but may not be open to innovative work methods.

Allen and Meyer (1990) examined 256 employees in clerical, supervisory, and managerial positions and found that institutionalized tactics correlated with organization commitment, thus impacting intent to leave. Lee, Ashford, Walsh, and Mowday (1992) 
examined commitment propensity, organization commitment, and voluntary turnover within a population of cadets at the United States Air Force Academy from 1982 to 1986 and found that voluntary turnover may be predicted by measuring initial commitment. High levels of organization socialization were shown to be significantly and negatively correlated with turnover (Higgins, 2008).

Like job satisfaction, organization commitment predates job embeddedness and ignores the potential effect of nonwork factors on an employee's intent to stay (retention).

\section{Discretionary Effort}

The intellectual concept of discretionary effort originated with the work of Yankelovich and Immerwahr (1984). The authors describe discretionary effort as being voluntary and beyond what is normally expected by the employer. It is this extra effort on the part of the employee that helps some organizations "outperform" others (Lloyd, 2003). Lloyd (2008) built on her earlier work, which focused on intensity and perseverance, and on work by Campbell, McCloy, Oppler, and Sager (1993), which focused on effort, and created a 7-item discretionary effort scale. Because this scale was found to be behavioral and measurable, it fulfills the definition of a performance measure and was used in the present study.

Work on the topic of discretionary effort has taken many turns. Sleebos, Ellemers, and Gilder (2010) examined employees with different levels of peer respect and found that "the efforts of respected people were primarily motivated by affective commitment to the group" and "the behavior of the disrespected people was driven by anxiety about their acceptance into the group" (p. 244). 
One of the advantages of evaluating discretionary effort in employee behavior research is that it is "not job specific," "may have positive impact on organizational commitment," and "tends to increase productivity and ability to adapt to environmental changes" (Lloyd, 2008, p. 31). The limitations of the discretionary-effort construct are that such behaviors tend to easily overlooked by supervisors, influenced by tenure and impressions of work early in one's career (Lloyd, 2008). The current study helps address these limitations.

\section{Intent to Stay}

Intent to stay refers to the likelihood that an individual employee will remain in the organization (Tett \& Meyer, 1993). Black and Stevens (1989) found a significant negative relationship between intent to stay and turnover.

A study of private sector nurses $(N=303)$ found that job stress (higher levels tended to decrease intent to stay), gender (females had higher stress levels than males), and age (older workers had lower intent to stay) were the highest influences on nurses' intent to stay (Letvak \& Buck, 2008). In a U.S. Army Reserve retention study of nurses, it was found that those who reported at least one mentoring experience had significantly higher levels of job satisfaction and intent to stay (Prevosto, 1998). The impact of mentors (organizational socialization) on intent to stay was corroborated in a study by Gosser (2011), who examined hourly fast-food employees $(N=935)$.

The studies on intent to stay and other employee behaviors have two main limitations: very few include analyses of public-sector employees or the impacts of factors from employees' nonwork lives. This could be because retention rates tend to be higher in the public sector and are not viewed as a critical issue. 


\section{Employee Engagement}

The original concept of employee engagement was developed by Kahn (1990). He defined engagement as "task behaviors that promote connections to work and to others" (Kahn, 2010, p. 293). Kahn also noted that engagement has emotional, cognitive, and physical components. Emotional engagement can be thought of as "meaningful connections to others" (Kahn, 2010, p. 294). Cognitive engagement refers to an employee's awareness of his or her "mission and role" in the organization" (Kahn, 2010, p. 294). Physical engagement refers to the employee's "daily task performances" (Luthans \& Peterson, 2001, p. 378).

The appeal of the direct impact on organizational profit has led to the promotion of employee engagement by HR consulting firms, which rely heavily on anecdotal knowledge to support their claims. In recent years, a greater appreciation of the concept of engagement has come from practitioners, who widely hold that an engaged workforce leads to "competitive advantage," "ability to solve organizational problems," "decrease turnover", "/increase retention" and "increased productivity" (Shuck, 2010, p. 20).

In an engagement study of Extension agents in Midwestern states, Weyhrauch, Culbertson, Mills, and Fullagar (2010) found that those who were the most highly engaged also reported high levels of "work-family facilitation, positive affectivity and psychological capital" (p. 1). The authors also examined engagement by program area (Agriculture, Family, \& Consumer Sciences and 4-H Youth Development) and determined that family and consumer science agents were more highly engaged in their work. Furthermore, they found that workers who were highly engaged tended to have a positive influence on workers who were less engaged. Mentoring programs and 
collaborations were mentioned as tools available to influence engagement levels (Weyhrauch et al., 2010).

However, as a unique research construct, some gaps still remain in the engagement literature (Macey \& Schneider, 2008). This situation has produced an alltoo-common conflict between researchers, who focus on scholarly research, and practitioners, who are most concerned with concepts such as "usability," "retention," "commitment," and "productivity" (Wefald \& Downey, 2009).

Additional research is needed on the subject of employee engagement to validate practitioner claims. Research should focus on generating a consistent definition and measure of employee engagement (Macey \& Schneider, 2008). This study helps build the empirical research base on employee engagement.

\section{Job Embeddedness}

In 2001, Mitchell et al. (2001) introduced a new conceptual framework called job embeddedness. Derived from Lewin's field theory, job embeddedness "represents a broad constellation of influences" (Mitchell et al., 2001, p. 7) on an employee's intent to stay and can be thought of as "a net or a web in which one can become stuck" (Mitchell et al., 2001, p. 7).

Mitchell et al. (2001) clarified that "job embeddedness does not cause one to go out and get married, buy a house, or increase linkages with the organization," but "those activities cause a person to become embedded" (p. 25). They further proposed that job embeddedness represented a unique factor in understanding why people stay at their jobs and discussed ways in which employers can influence employees' embeddedness and propensity to stay. They recommended examining three components-links, fit, and 
sacrifice--each in an organizational and community context. It is this examination of both the organization and community that makes job embeddedness unique in helping explain employee retention.

In Mitchell et al.'s (2001) original job embeddedness study, the authors used chi square and correlational statistics and found that job embeddedness improved the prediction of turnover over and above that provided by job satisfaction, organization commitment, and intent to stay (Mitchell et al., 2001, p. 30). The authors concluded that the job-satisfaction and organization-commitment frameworks insufficiently explain why people stay in an organization, because they ignore the effects of an employee's nonwork life. As described in Table 2.1, these community components are used to equally address the important factors in an employee's community life. It is from this perspective that the concept of job embeddedness has evolved (Mitchell et al., 2001).

\section{Job Embeddedness Defined}

Examined below are the six components of job embeddedness and their ability to assist HRD professionals' efforts to manage retention, which is essential to highperforming organizations. Table 2.1 visualizes the six components of job embeddedness.

Table 2.1

Job Embeddedness Components

\begin{tabular}{lccc}
\hline & Links & Fit & Sacrifice \\
\hline Organization & $\begin{array}{c}\text { Links } \\
\text { organization }\end{array}$ & Fit organization & $\begin{array}{c}\text { Sacrifice } \\
\text { organization }\end{array}$ \\
Community & $\begin{array}{c}\text { Links } \\
\text { community }\end{array}$ & Fit community & $\begin{array}{c}\text { Sacrifice } \\
\text { community }\end{array}$ \\
\hline
\end{tabular}




\section{Links}

Links are defined as "discernible connections between people and institutions" (Mitchell et al., 2001, p. 8). The more links to the workplace or community, the more highly embedded individuals will become. Links can be social, psychological, or financial and include age, marital status, number of children and their ages, years of service, hobbies, church-related activities, and membership in community organizations. The authors acknowledge that the relative importance of each of the previously mentioned factors could differ by population and that there are inherent pressures to stay at one's present work. These pressures can come from family members, team members at work, or other people at work (Maertz, Stevens, Campion, \& Fernandex, 1996). Alternatively, the lack of marital or parental responsibilities or the failure to develop meaningful work relationships could indicate that employees are less likely to stay with their present work situation.

Organization. HRD professionals have a more direct influence on policies that promote organizational links than community links. At the base level, organizational links would include relationships with coworkers, members of work groups, and others. These work relationships can influence personal embeddedness and intention to leave both positively and negatively.

The links-organization component focuses on relationships between individuals that evolve over time and that increase an employee's intention to stay in an organization. Mitchell uses the links-organization component to explore questions about the "number of coworkers, teams and committees" that the respondents may be involved with (Mitchell et al., 2001, p. 17). The links-organization component is somewhat similar to 
the "constituency commitment theory" as developed by Reichers (1985), which measures attachment to specific people or groups in the organization.

Other organizational links include age, membership in professional organizations, and tenure. Additional links that HRD professionals may champion include broader benefits packages, employee education assistance, on-site child care, and paid professional-development opportunities.

Community. Community links can be just as important to retention as organizational links. The principal behind links-community is that activities, relationships, and environmental factors can influence an individual's intent to stay and are independent of one's work environment. This line of thinking is supported by the work of Cohen (1995), who found that church-related activities and hobbies impacted workers' commitment to their jobs.

Examples of community links would be hobbies, church-related activities, involvement in the children's school, or involvement in community activities. Some organizations have creative policies that tend to support community linkages. Examples include home-buying assistance, discounts on various goods and services, and paid community-service days.

Fit

Fit can be seen "as employee's perceived compatibility or comfort with an organization and with his/her environment" (Mitchell et at., p. 9). As mentioned previously, the closer that one's personal views, values, and goals are with those of the organization and community cultures, the "higher the likelihood that an employee will feel professionally and personally embedded" (Mitchell et al., 2001, p. 9). 
Organization. The fit-organization component examines how well an individual views themselves as sharing compatible goals, values, and characteristics with the potential employer and other employees within the organization. The better the fit, the greater the likelihood the employee will stay.

At least two studies support the fit-organization principle. O'Reilly, Chatman, and Caldwell (1991) found that misfits left organizations at a faster rate than fits. Cable and Parsons (1999) reported that people gravitate toward jobs that they view as sharing some or all of the personal goals and values.

Examples of organizational fit include individual "job knowledge, skills and abilities" (Mitchell et al., 2001, p. 9). According to Allen (2006), organizationalsocialization tactics have a positive impact on job embeddedness and reduced turnover. HRD professionals can help influence organizational fit by instituting formal employee socialization processes, mentoring programs, and new-employee orientations. Policies that encourage employees to join professional organizations and attend related professional conferences can also play a role in promoting organizational fit.

Community. Mitchell, et al., (2001) proposed a fit-community concept to address nonwork factors that can help increase workers' intention to stay at their jobs. Fitcommunity factors could include, weather, available and convenient access to outdoor activities and entertainment, community culture, and individuals (neighbors and nonwork friends) who share similar political and religious views. It is important to note that fitcommunity factors can be inversely related to organizational fit. For example, an individual may love Louisville, but hate working for XYZ company in the same city. HRD efforts may be limited in their influence on factors related to fit community, 
however fringe benefits such as county club membership, sports tickets, and access to the local arts and humanities all help strengthen the fit-community component.

\section{Sacrifice}

Sacrifice is the final component of the job embeddedness construct. Here sacrifice refers to the "material" and "psychological" benefits that an employee would lose at any given time if he or she choose to leave the organization. The greater the sacrifice, the more difficult the decision to leave will be (Shaw, Delery, Jenkins, \& Gupta, 1998). As with links and fit, sacrifice also has organization and community components.

Organization. Organizational sacrifices can take many forms. It may be possible for an individual to locate a job with a similar salary and benefits. However, there are many less obvious organizational sacrifices that employees should consider. There may be new retirement and benefit restrictions or some benefits that may actually be nonportable.

Job-related sacrifices might also include the loss of health and retirement benefits, sports tickets, coworker relationships, educational benefits, advancement opportunities, convenience and proximity to the work location, and perhaps even a loss of security. HRD professionals should work to promote competitive, broad-based benefits packages for employees, thereby making the decision to leave a costly one.

Another HR strategy is to provide accrued advantages to workers who choose to stay. The advantages might include the ability to pick one's own office or take sabbatical leave. These benefits are lost permanently to those who leave (Mitchell et al., 2001, p. $10)$. 
Community. Community sacrifices usually are an issue only if relocation is required with a new position. In many cases, an individual's loss of community can represent too great a sacrifice. The length of time and improvements in one's home,

convenience and proximity to the local amenities, community safety, and leadership positions in the community often represent losses that workers are unwilling to bare, even though links to the organization might be minimal. The HRD professional's ability to influence the community-sacrifice component of embeddedness is often limited. On-site child care, company vehicles, preferred parking or holding events that allow professionals to network with other people in the community, such as an awards ceremony for organizations that partner with the company are a few of the tools that HRD professionals could utilize.

\section{Prior Research on Job Embeddedness}

Ramlall (2003) noted that people stay at an organization because of the location, the compensation, and the work itself. In Ramlall's study, the reasons employees chose to leave were low compensation, lack of challenging work, and lack of opportunities for career advancement. These results coincided with the links, fit, and sacrifice components of job embeddedness outlined by Mitchell et al. (2001). In Ramlall's study, all of these factors showed that, as overall embeddedness scores increased, the employee's intention to leave decreased.

The initial study of job embeddedness conducted by Mitchell et al. (2001) consisted of 700 grocery-store and 500 hospital employees who were randomly sampled to participate. Both groups of employees were experiencing a tight labor market with unemployment rates under $5 \%$. The respondents were given a test instrument twice: once 
during employment and once after separation from the organization. The hard-copy surveys were mailed to managers who distributed to employees. The survey packets included a stamped, self-addressed envelope for the convenience of respondents. Weekly follow-up letters were sent to encourage participation.

The useable response rate for hospital employees was $46.4 \%$, and the usable response rate for grocery-store employees was $33.1 \%$. Some respondents failed to identify themselves and were counted as nonrespondents. To test for nonresponse bias, the authors used chi-square test to compare basic information collected prior to the survey, between respondents and nonrespondents. No statistically significant differences were detected in regard to age, tenure with the organization, or job level. However, the two groups did differ in terms of gender, with females responding at a higher rate than males. The authors concluded that the respondents appeared fairly representative of the population.

The results of Mitchell's (2001) study supported the hypothesis that embeddedness would be associated with reduced intent to leave and reduced actual leaving. These findings were affirmed by Lee, Mitchell, Sablynski, Burton, and Holtom (2004); specifically, they examined a sample of 835 financial-service employees and found that community embeddedness had a significant negative correlation with voluntary turnover, but organizational embeddedness was not significantly correlated with voluntary turnover. Lee et al. (2004) did note some limitations to this study.

- This study took a long period of time to complete.

- The construct for measuring the concept of job embeddedness was in a very early stage of development when the article was published and much more 
testing is needed of the construct and it's components.

- The analysis did not test against all alternative theories.

Still, the study suggested some new and intriguing ways to think about employee retention. The results indicated that being embedded in an organization and a community was associated with reduced intention to leave and reduced actual leaving. These findings appear to support the current emphasis in the academic and popular press on the need for organizations to be concerned with employees' lives both on and off the job. The findings also suggest that a focus on money and job satisfaction as the primary factors for retention may be too limited.

\section{Mentors}

Mentoring of newly hired by veteran employees has been found to be critical to the employee-socialization process (Schlichte, Yssel, \& Merbler, 2005). In that study, mentoring helped negate feelings of isolation and helped novice workers through teaching, sponsoring, encouraging, counseling, and befriending. These results closely match the links-organization component developed by Mitchell et al. (2001).

Allen (2006) examined the effects of socialization tactics (links organization) on newcomer turnover by embedding newcomers more extensively into the organization. Utilizing a purposeful sample of 222 financial-services employees, Allen found that all six socialization tactics (collective-individual, formal-informal, sequential-random, fixed-variable, serial-disjunctive, and investiture-divestiture) as classified by Van Maanen and Schein (1979) were significantly and positively correlated with organizational embeddedness, whereas none were significantly correlated with 
community embeddedness. Additionally, organization embeddedness was significantly and negatively correlated with turnover, whereas community embeddedness was not.

These six socialization tactics make practical implications rather straightforward. Turnover among new employees is a critical issue for many organizations. Involving experienced organization insiders in the socialization process as role models, mentors, or trainers should directly reduce newcomer turnover. Organizations should not neglect the importance of the social context of socialization. However, a potential limitation of Allen's (2006) study was a lack of internal consistency in Jones's (1986) Socialization Tactics Scale (Ashforth \& Saks, 1996), indicating that new studies may need to consider revising this scale.

Wheeler, Harris, and Harvey (2010) examined the relationships between human resource management, job embeddedness, turnover intention, and impact of memberleader exchange in a population of 2000 alumni of a private Midwestern university. The authors reported that as organizational job embeddedness increased, turnover intention decreased (Wheeler et al., 2010). The authors acknowledged that the low response rate for this study could be a limiting factor. In addition, the authors failed to collect data on the influence of community job embeddedness. They recommend that future studies use a full job embeddedness survey instrument.

\section{Negative Shocks}

Holtom et al. (2005) defined and examined the impact of significant organizational or community events (shocks) as causes of staff turnover in organizations. The authors looked at this new explanation rather than employee satisfaction, commitment, and other older theories to significantly explain turnover. One benefit of 
shock theory is its ability to help distinguish between functional and dysfunctional turnover (Maertz \& Campion, 1998). The results of the Holtom et al.'s study identified four paths that leavers take:

1. In Path 1, shocks triggered a preexisting plan. Little thought was given to employee attachment to the organization. Further analysis revealed that leavers experienced shocks that were primarily personal, positive, and expected.

2. Path 2 leavers reconsidered organization attachment after experiencing shocks that were organizational and negative, without conducting a job search. No preexisting plan was developed.

3. Path 3 leavers tended to experience mostly unexpected, positive shocks (e.g., job offers). In this path, employees decided to leave after considering alternatives.

4. In Path 4, employees generally decided to leave because of low job satisfaction levels; some conducted a job search and others did not.

Holtom et al. (2005) stated that they did not intend for shock theory to replace any other existing turnover theories, only that it should be utilized in conjunction with other theories. In light of the significant impact of this theory, the authors suggest that organizations incorporate the effect of shocks into retention plans.

Burton et al. (2010) examined the role that work enhancement played in creating job embeddedness reactions. Specifically, the authors discovered that on-the-job embeddedness helped reduce the impact of negative shocks on organizational citizenship and overall job performance. The results indicated that high levels of job embeddedness 
appeared to buffer the effect of thoughts of leaving associated with negative events. For example, when someone experienced a negative event and thought about leaving, but was highly embedded, they performed slightly better and engaged more. One potential limitation of this study was the lag between the time of leaving and survey completion. This time lag could have resulted in recall bias in that the leavers may not have recalled all details accurately.

\section{Coworker Embeddedness}

Felps et al. (2009) examined a model of turnover in which the decision to stay at or leave a job is influenced by coworkers' job embeddedness and job-search behaviors. The study found that coworker's job embeddedness explained variance in voluntary turnover. In addition, as coworkers' job-search activity increased, an individual's likelihood of turnover increased. The authors listed some specific interventions that organizations might use to increase job embeddedness and retention: (a) providing common learning experiences for new workers, (b) utilizing a careful selection process, (c) improving perceived supervisor and organizational support, (d) being creative with work scheduling, (e) offering creative benefits packages, (f) offering a variety of work site food choices, (g) hiring locally, (h) supporting community service, (i) encouraging involvement in professional organizations, and (j) providing home-buying assistance (Felps et al. 2009, pp. 557-558). This study was limited in that the list of variables examined was not exhaustive. The authors recommended that future studies include variables such as "organizational support, leadership quality and compensation policies" (Felps et al. 2009, p. 557). 


\section{Generational Differences}

Giosan (2003) sought to identify predictors of job embeddedness and its six dimensions. The author hypothesized that age, time, strength of attachment, number of children, personality traits, perceptions about work, and perceptions about mating opportunities would account for significant variance in embeddedness. To test these hypotheses, Giosan utilized two samples of full-time workers from the same organization, each of which were asked to complete an antecedents questionnaire and an embeddedness survey. The first sample consisted of 172 respondents who completed the survey instruments at different points in time. The second sample consisted of 129 respondents who completed survey instruments at a single point in time.

The author found that the links-community factors were predicted by age and number of children and that links-organization factors were predicted by age (Giosam, 2003, p. 52). According to the authors, after initial employment, possible methods to increase embeddedness could be increasing organizational and supervisor support, training workers to become highly specialized, and selecting employees who perceive that they lack job alternatives (Giosam, 2003).

\section{Performance and Participation}

Lee et al. (2004) extended theory and research on job embeddedness by demonstrating how the concept's major components differentially predicted the decisions to perform and to participate. In the study, Lee et al. surveyed 1,650 employees of a regional operations center of a large financial institution. In total, 829 usable responses were collected, with a response rate of $50 \%$. Next, the authors surveyed the employees' 
immediate supervisor, and 636 supervisors completed their part in the study for a response rate of $76.7 \%$.

The study also established conceptual and empirical mechanisms through which certain components of embeddedness might influence the decisions to perform and to participate. In particular, both organization and community embeddedness were significantly correlated with turnover intention, citizenship behavior, performance, satisfaction, and commitment. Community embeddedness (but not organizational embeddedness) was correlated with the number of volitional absences.

\section{Cultural Differences}

Mallol, Holtom, and Lee (2007) assessed whether differences between Hispanics and Caucasians existed with respect to job embeddedness and intention to leave. They found that Hispanics demonstrated higher levels of fit-community and sacrificecommunity than did Caucasians. In an interesting yet seemingly contradictory finding, higher levels of job satisfaction did not predict lower intent to leave.

Because the demographic makeup of the Mallol et al. (2007) population was predominately female, the results could be biased. Another possible limitation had to do with the average educational background of the Southeastern Florida Hispanic population, which, according to U.S. Census information, is above the national mean in terms of education and income. Because of this, the study should not be generalized to Hispanics in other parts of the U.S.

\section{Research Gaps}

Differences in gender, race, age, work location, and locus of control have not been widely studied through the lens of job embeddedness. These topics represent gaps in 
the existing job embeddedness research base and are addressed in the current study by surveying background variables of Extension agents and their impact on job embeddedness. Related research involving antecedent variables will be highlighted in this section.

\section{Gender Differences}

Due to its relative newness, several gaps in Mitchell et al.'s (2001) job embeddedness theory are evident. The first of these gaps is gender. Although I was unable to locate any specific studies involving gender and embeddedness, other studies involving gender and turnover were discovered. In a large, nationally representative quantitative study, Royalty (1998) examined gender, education level, and turnover. The results indicated that women with a high-school education did not differ significantly from either less educated or more educated men in their turnover likelihood. Royalty further stated that educated women were more likely to stay on the job than women with less than a high school education and men with any level of education.

Vlosky and Aguilar (2009) developed a model of employee satisfaction that was tested with both male and female Extension Services employees. The results of the "study showed that control/autonomy/influence, challenge, performance measures, feedback, instrumentality, and stability/security" were "highly significant in positively influencing" employee satisfaction among Extension Services employees and that no differences were found between genders (Vlosky \& Aguilar, 2009, p. 1). One limiting factor in relation to the current study was that only organizational influences were examined. 


\section{Racial Differences}

Another gap in the job-embeddedness literature involves race. Vlosky and Dunn (2009) examined racial differences in Extension Services employees' perceptions of job satisfaction. The independent variables were (a) control over one's job, (b) challenge of the job, (c) feedback received on job performance, (d) relevance of the job to society, and (e) security and stability received from the job. The authors ran descriptive statistics on race, gender, age, income, and community size. Likert-type scales (1 equaling strongly disagree and 5 equaling strongly agree) and open-ended questions were used. The findings suggested a statistically significant difference in job satisfaction between White and non-White cooperative Extension Services employees. One implications of this study was the need for administrators and policy makers to understand the driving factors of satisfaction for both White and non-White employees.

A study of the differences in attrition between African American and Caucasian nurses showed that African American nurses were less likely to be unemployed (9.2\% vs. $18.1 \%)$ and more likely to be employed in the nursing profession ( $69.6 \%$ vs. $57.3 \%)$. Other observations showed that African American nurses preferred educational institutions compared to Caucasian nurses. Finally, African American nurses comprised a higher percentage of "non-USA born individuals" (Smith, Crowe, \& Hartman, 2007). The results of this study furthered the discussion of work preferences by race and culture, and the study is one of a growing number of efforts on the retention problem in the nursing field. 


\section{Generational Differences}

Research examining the relationships between age and job embeddedness is limited to Giosan (2003), who sought to identify predictors of six dimensions of job embeddedness. However, a different study's examination of age and turnover has been more widely documented. A study of 2-year college faculty found that older faculty members were less likely than younger members to leave their present employer. In addition, as years in a position increased, intention to leave decreased (Rosser \& Townsend, 2006).

A similar study at an urban community college found that older faculty reported lower levels of attrition intention than younger faculty (Dee, 2004). Furthermore, the same study showed that faculty who perceived high levels of support for innovation, communication, openness, and autonomy reported lower levels of attrition intention.

Long and Swortzel (2007) examined the relationship between personality type, demographic characteristics, and job satisfaction of Extension agents in Mississippi. The results indicated that age was the best predictor of job satisfaction. Specifically, Extension agents between the ages of 31 and 35 were most satisfied with their jobs. Job dissatisfaction was almost nonexistent for Extension agents who had been employed for more than 20 years. The results also suggested that companies should implement annual performance reviews and that follow-up studies were needed to identify individual demographic characteristics and other variables that might relate to job satisfaction. The limitation to this study was that it only sampled Extension agents in Mississippi and therefore should not be generalized to Extension agents in other states. 
Armstrong-Stassen and Ursel (2009) examined the relationships between organizational and career factors and older workers' intentions to remain with their organization. According to the authors, relatively little research has focused on why workers remain in an organization. The main finding from this study was that respondents who felt that their organizations provided older managerial and professional employees with opportunities to advance their existing skills and acquire new skills perceived their organizations as more supportive. This result has several implications for employers. First, organizations that engage in training and development practices targeting older managerial and professional employees may be more successful in retaining these employees than organizations that do not engaging in these practices. The investment in training and development opportunities signals to these employees that their organization values their contribution, cares about their well-being, and is committed to them. However, an organization's provision of flexible work options may have little impact on older managerial and professional employees' perceptions of organizational support and decisions about remaining in the organization (ArmstrongStassen \& Ursel, 2009).

\section{Differences in Work Location}

Ramlall (2003) found that the location of the company, compensation, and the work itself were the most significant factors in employees' decisions to stay. In Ramlall's study, low pay, lack of challenge and opportunity, and lack of career advancement were identified as possible reasons for leaving.

The organizational costs of low employee retention have been noted above and include a loss of knowledge and efficiency within the organization. To minimize the costs 
associated with voluntary turnover, Ramlall (2003) suggested that employers should try to understand both organizational and community employee needs. I will address this issue in the current study by surveying the population of Extension agent's work locations.

\section{Stress and Compensation}

Plash (2006) conducted a study to assess the issues that impact attrition and retention of special-education teachers in a southeastern Alabama county. The author concluded that the two most important factors were "excessive paperwork" and "stress created by demands of the job" (p. 127). Ramlall (2003) cited salary, lack of challenge and opportunity, and lack of career advancement as possible reasons for leaving an organization. Kutilek et al. (2002) identified heavy workload, evening and weekend work commitments, and lack of job autonomy as factors influencing the turnover of Extension agents. Kroth and Peutz (2010) examined workplace issues related to attracting, motivating, and retaining agents of the Cooperative Extension Service. The perceived difficulty involving organizational change ranked first among many concerns, followed by compensation and lack of adequate resources.

Although issues of compensation are difficult to address during the current, deep recession, organizations can address retention in other ways. Richman et al. (2008) found that policies that support work-life balance had a positive correlation with retention and that perceived flexibility significantly increased the likelihood of expected retention.

Public verses private. There are few studies that focus on job embeddedness and public-sector employees, Van Emmerik and Sanders (2004) examined how different relationships in academic settings (i.e., tenured versus nontenured appointments) were 
associated with different types of job-performance efforts. The results showed that tenured faculty members' embeddedness was significantly related to compliance and contextual performance, whereas the embeddedness of nontenured faculty members was not related to efforts to perform well.

Van Emmerik and Sanders (2004) concluded that their results suggest that different types of embeddedness could be a powerful instrument to encouraging both compliance and contextual performance, such as facilitation of network development by junior staff. Also, strategies to enhance the self-esteem and feelings of professionalism may be a good choice to stimulate experienced prestige and thereby inclining compliance and contextual performance at the individual level. For professional groups, and especially for the faculty members, it holds that embeddedness is paramount for efforts to perform well (p. 52). Because this study was conducted in a small university in the Netherlands, the results should not be generalized to other higher education settings.

In a study of United State Air Force maintenance workers, it was found that job embeddedness accounted for significant variance in their intent to leave. More specifically, community job embeddedness was found to account for the total predictive ability of job embeddedness to predict turnover intention (Fletcher, 2005).

Another line of research in the comparison of public and private-sector employees has been in the area of values and motives. Public-sector managers tend to value "public service, development of public policy, self-sacrifice, responsibility and integrity" to a greater extent than private-sector managers (Rainey \& Bozeman, 2000, p. 460).

The results of the two previously discussed studies involving public-sector employees are consistent with the results of job embeddedness studies involving private- 
sector employees. Although very limited and not generalizable to larger populations, the initial results indicate that public employees can be similarly embedded in their work. More research in this specific area of job embeddedness is recommended.

Empirical research on job satisfaction in public versus private employees has shown some conflicting results. Most studies have found lower job satisfaction among public employees (Rainey \& Bozeman, 2000). However, some studies have shown the opposite (Steel \& Warner, 1990). At least part of the explanation can be found in the nature of the survey questions used in each study. When asked in general terms, "Do you like your job?" public-sector employees show job-satisfaction levels comparable to private-sector employees. When asked about specific aspects of their jobs (promotion prospects, autonomy in the job, pay levels) public employees (especially management) tend to express lower levels of job satisfaction.

\section{General Economic Conditions}

It would be naive to ignore the impact that the current economic recession has had on employees' retention decisions. As mentioned previously, retention rates are affected by intent to stay in additional to an employer's decision to hire and maintain their workforce. These employer decisions are affected by a number of different reasons, mostly centered around performance and economic conditions. During recessionary periods with high unemployment rates, there are more job seekers than available jobs (Hall, 2005).

One interesting dichotomy in regard to the retention rates of Extension agents is that, regardless of the economy's condition, retention is consistently higher than other 
employment sectors, including similar sectors such as teaching. This relationship is an intriguing topic for future study.

\section{Study Model}

Dominant research on the topics of retention and turnover has previously focused on job satisfaction and organization commitment. The focus of this study was to enhance the field by included an examination and analysis of the impact that job embeddedness could have on intent to stay, while controlling for the effects of discretionary effort, engagement, organization commitment, and job satisfaction. The effect of background variables on job embeddedness and its six components were also examined. The study model is shown in Figure 2.1.

\section{Summary}

This study analyzed job embeddedness to creatively address a gap in the literature on retention and turnover. The job embeddedness construct developed by Mitchell et al. 2001) has been shown to account for additional influences, beyond the effects of job satisfaction and organization commitment, on a person's decision to stay or leave (Fletcher, 2005). The construct achieves this because it measures the organizational and community forces that may keep a person on the job (Fletcher, 2005).

Mitchell et al. (2001) points to the fact that employers should be concerned about employees' lives on and off the job. It is because job embeddedness can be used to examine both work and nonwork aspects of employees' lives that it was chosen for this study.

Several gaps in the job embeddedness research have been identified, some of which this study was able to address. These include gaps in the research on gender, race, 
employment longevity, and work sector (public vs. private). An analysis of these variables within this study's population of public-sector Extension agents in Kansas and Kentucky helps expand the research base of the job embeddedness construct. 

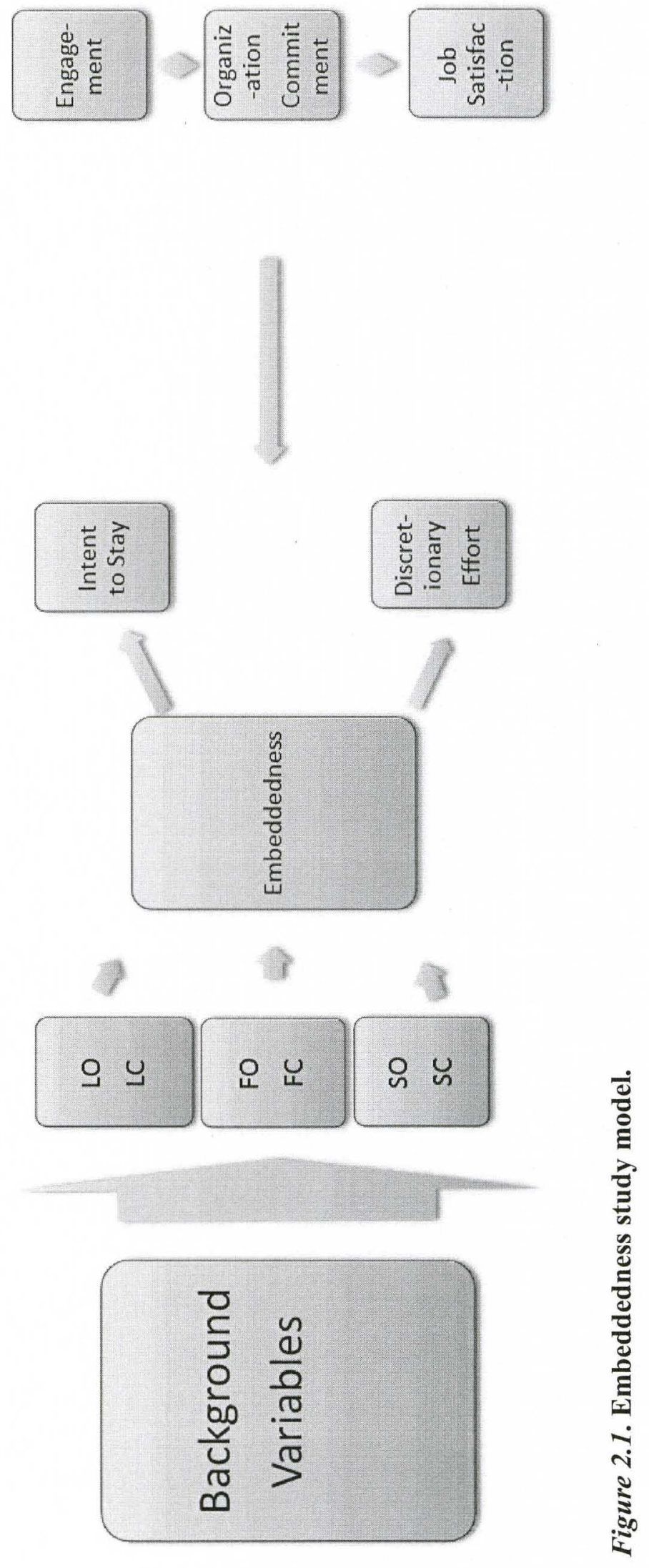


\section{CHAPTER III}

\section{METHOD}

\section{Research Method and Design}

The method to be used in this study was quantitative. Quantitative research has been described as "a means for testing objective theories by examining the relationship among variables" (Creswell, 2008, p. 5). Quantitative research assumes that human nature is regular and predictable under controlled conditions, generally has a narrow focus, and provides results that are generalizable and objective (Johnson \& Christensen, 2008). In general, quantitative designs have several advantages (Rozina, 2002).

- The research problem can be narrowly defined.

- Dependent and independent variables are clearly specified.

- Conclusions are objective and maybe generalizable.

- Higher levels of reliability may be more easily achieved due to controlling the observations and experiments.

- Quantitative designs can be used longitudinally.

Additional determinations of method type can be made by answering two simple questions: Is random assignment being used? and Is there a control group or multiple measures? (Trochim, 2006). If the answer to both questions is no, then the method is further classified as quantitative, nonexperimental. Because the current study does not utilize random sampling or control groups, it is nonexperimental. 
This study used a census design. Baffour \& Paolo (2008) proposed six dimensions that should be examined to evaluate the quality of a census study: (a) the census data should be relevant to the needs of the population; (b) the census should be accurate and reliable; (c) census studies should be timely and conducted in a reasonable period; (d) the results or data should be readily available to the population; (e) results of a census study should be easy to interpret and understand; and ( $f$ ) the census data should be easily integrated with other sources of information (p. 4).

The primary advantage of census research is that the entire population is studied, rather than choosing a sample. Census studies tend to be "exhaustive" in nature (Baffour $\&$ Paolo, 2008, p. 11) and the main advantage is greater accuracy. With the nearuniversal availability of the internet some organization are "eliminating sampling and simply conducting censuses" (Fricker \& Rand, 2002, p. 359). Census research often results in much larger numbers of respondents and allows conclusions to be drawn about the population without the use of random sampling and inferential statistical analyses (Creswell, 2005). The benefits of census research should be balanced by the potential for bias which is addressed later in this chapter.

I was able to gain access to the complete population of Extension agents in Kansas and Kentucky, which allowed for a census study. An online survey was utilized to gather data.

The best known census studies are those created by the U.S. Census Bureau every 10 years from data gathered about the country's population characteristics. The results of these studies are used in many ways. Some of the more important ramifications include the reapportioning of the U.S. House of Representatives, the redistricting of state 
legislative boundaries, and the allocation of over $\$ 400$ billion dollars of local, state, and national aid. The average response rate for the previous three U.S. census surveys has been $68 \%$ (U.S. Department of Commerce, 2010). Because the data in the current study was collected during a specific time period, it can also be described as a cross-sectional study (Johnson \& Christensen, 2010).

\section{Census Population}

The population on which this study focuses includes KSU and UK Extension agents. The choice of these two states was due in part to high retention rates in pre-study data and in part because the directors of both organizations agreed to participate in this research.

Retention rates were gathered from the respective human resource specialists of both KSU and UK Extension. A 5-year summary of retention rates of the two states is shown in Table 1.1. The retention rates were consistently high over the 5 study years (2006 to 2010). Retention rates dropped slightly from 2006 to 2008 , but even at their low point they were higher than all other employment sectors (see Table 1.2). These decreases in retention rates could be the result of periods of past economic strength, with greater available job alternatives for Extension agents. An in-depth examination of this point is beyond the scope of this study but should be addressed in future research. 


\section{Population Description}

A profile of the "typical" Extension agent was developed by a team of Extension Services researchers from Ohio State University in 2002. Their employee profile concluded that the typical Extension agent was Caucasian, married, between 39 to 52 years of age, and a parent of two children; had a job tenure of 15 years; had completed a Master's degree; and no longer lived at home (Kutilek et al., 2002, p. 10). As Table 3.1 shows, this description is very similar to the population of Extension agents in the current study.

The total population for the current study comprised 631 county Extension agents. A substantial majority of the population of Extension agents were female (61.8\%), and the gender distribution was consistent between states. The population was overwhelmingly White (96.3\%) with Black individuals representing the largest group of minority employees $(3.1 \%)$, followed by individuals who identified their race as "other" $(<1 \%)$ KSU employs a smaller percentage of minorities than does Kentucky. The average age of the total population was 43.9 years. On average, UK Extension agents were 1.9 years younger than $\mathrm{KSU}$ Extension agents.

Overall, the education levels of the population were approximately split between those with bachelor's degrees (46.4\%) and master's degrees (52.9\%). Further examination showed that the educational levels of KSU and UK Extension agents were somewhat different; specifically, 37\% of UK Extension agents held a bachelor's degree, $62.2 \%$ had attained a master's degree, and less than $1 \%$ had a doctorate degree, whereas $62.8 \%$ of KSU Extension agents held a bachelor's degree, $36.8 \%$ had attained a master's degree, and less than $1 \%$ had a doctorate degree. 
Extension agents were overwhelmingly employed full-time. Kentucky does employ a small number $(<1 \%)$ of part-time Extension agents, as does Kansas $(<1 \%)$. Extension agents are generally employed to work in 1 of 4 program areas: agriculture and natural resources, family and consumer sciences, 4-H youth development, and horticulture. The minimum educational requirement for county Extension agents is a bachelor's of arts or science degree in a field directly related to their area of work. In addition, Kentucky agents are required to complete 12 credit hours in an approved graduate program within 5 years of the start of employment ("Employment Requirements," 2011). The University of Kentucky offers an employee-education plan that covers the cost of up to 6 credit hours per semester at any publicly funded university in the state ("Educational Benefits," 2011). KSU does not require agents to begin a graduate program at any time. KSU does offer an employee tuition waiver of 3 credit hours per semester ("Division of Human Resources," 2011).

The typical Extension Service county-staffing model for the study population consisted of three agents (one each in agriculture and natural resources, family and consumer sciences, and 4-H youth development). However, other staffing models do exist and range from two agents who share 4-H youth development responsibilities to 12 agents in larger urban centers.

A census of all county Extension agents, in both states, was utilized to help ensure adequate statistical power and full representation of each state. In most studies, when the population and response rate are large, statistical power is not an issue (Stevens, 2009). 
Table 3.1

Population Description (Column Percentages)

\begin{tabular}{|c|c|c|c|c|c|c|}
\hline & $\begin{array}{c}\text { Kansas } \\
(\%)\end{array}$ & $\begin{array}{c}\text { Kansas } \\
(n)\end{array}$ & $\begin{array}{c}\text { Kentucky } \\
(\%)\end{array}$ & $\begin{array}{c}\text { Kentucky } \\
(n)\end{array}$ & $\begin{array}{c}\text { Total } \\
(\%)\end{array}$ & $\begin{array}{c}\text { Total } \\
(n)\end{array}$ \\
\hline \multicolumn{7}{|l|}{ Gender } \\
\hline Male & 36.4 & 84 & 39.2 & 157 & 38.2 & 241 \\
\hline Female & 63.6 & 147 & 60.8 & 243 & 61.8 & 390 \\
\hline \multicolumn{7}{|l|}{ Education } \\
\hline Bachelor's & 62.8 & 145 & 37.0 & 148 & 46.4 & 293 \\
\hline Master's & 36.8 & 85 & 62.2 & 249 & 52.9 & 334 \\
\hline Ph.D. & $<0.1$ & 1 & $<0.1$ & 1 & $<0.1$ & 4 \\
\hline \multicolumn{7}{|l|}{ Race } \\
\hline Asian & 0 & & $<0.1$ & 2 & $<0.1$ & 2 \\
\hline Black & $<0.1$ & 2 & 4.2 & 17 & 3.1 & 19 \\
\hline Hispanic & $<0.1$ & 1 & $<0.1$ & 1 & $<0.1$ & 2 \\
\hline White & 98.7 & 228 & 95.0 & 380 & 96.3 & 608 \\
\hline $\begin{array}{l}\text { Average age } \\
\text { (years) }\end{array}$ & 44.9 & & 43.0 & & 43.9 & \\
\hline
\end{tabular}

Note. Kansas $N=231$; Kentucky $N=400$.

\section{Criteria for Inclusion}

For this study, the total survey population consisted of current agents of KSU's and UK's Extension Services programs. These agents worked in one or more of the following program areas: agriculture and natural resources, horticulture, family and consumer sciences, 4-H youth development, or other areas.

\section{Variables and Instrumentation}

Data were collected via a 100 -item electronic survey sent to all KSU and UK Extension agents. As part of the University of Louisville Institutional Review Board approval process and to encourage participation, a preamble was included with the survey 
that addressed issues related to risks, benefits, and confidentiality. Finally, respondents were informed about who to contact if they had questions or concerns related to the study.

The instrument used in this study was composed of six different scales that related to the study's research questions. The questionnaires were selected because of their previous use and reliability and are listed in Table 3.2.

Table 3.2

Scales and Corresponding Item Numbers

\begin{tabular}{lcc}
\hline \multicolumn{1}{c}{ Variable } & $\begin{array}{c}\text { Number of } \\
\text { questions }\end{array}$ & $\begin{array}{c}\text { Question } \\
\text { numbers }\end{array}$ \\
\hline Job embeddedness & & \\
Links organization & 5 & $29-33$ \\
Links community & 7 & $34-40$ \\
Fit organization & 9 & $20-28$ \\
Fit community & 5 & $15-19$ \\
Sacrifice organization & 10 & $41-50$ \\
Sacrifice community & 5 & $1-5$ \\
Subtotal & 41 & \\
Dependent variables & & \\
Job satisfaction & 3 & $6-8$ \\
Affective (organization) commitment & 6 & $9-14$ \\
Discretionary effort & 7 & $51-57$ \\
Employee engagement & 17 & $58-74$ \\
Intent to stay & 15 & $75-89$ \\
Background variables & 11 & $90-100$ \\
Total & 100 & \\
\hline
\end{tabular}

Scales that made up the survey instrument included the

- Job Embeddedness Scale (Mitchell et al., 2001),

- Intent to Stay Scale (Hoisch, 2001),

- Discretionary Effort Scale (Lloyd, 2008), 
- Job Satisfaction Scale (Luthans, Avilio, Avey, \& Norman, 2007),

- Affective Commitment Scale (Allen \& Meyer, 1990), and

- Job Engagement Scale (Rich, Lepine, \& Crawford, 2010).

The six instruments and the demographic background items were incorporated into one online instrument. Table 3.2 shows item numbers related to each scale. A copy of the final survey instrument can be found in Appendix C.

Background variables are important to help understand the survey population. Oftentimes, background variables can have a significant effect on the dependent variables. In this study I examined the following background variables in relation to job embeddedness: gender, race, highest education level achieved, age, program area, years in organization, years of prior work experience, type of prior work experience, and state.

Since 2001 , the embeddedness scale has been utilized in 12 studies, which are included in the References section of this study. Most job embeddedness items were measured using a Likert-type scale with the following range: $1=$ strongly disagree, $2=$ disagree, $3=$ neither agree nor disagree, $4=$ agree, and 5= strongly agree. This scale was also used in the current study to collect responses for intent to stay, discretionary effort, job satisfaction, affective commitment, and employee engagement. The only exceptions were for the links-community items 35 to 40 and background items 90 to 100 , which were in multiple-choice format.

Given that the individual Likert-scale items "presume the existence of an underlying continuous variable whose value characterizes the respondents' attitudes and opinion" (Clason \& Dormody, 1994, p. 31), I treated the subscales as interval-level variables. 


\section{Job Embeddedness}

In 2001, Mitchell et al. introduced a new conceptual framework called job embeddedness and proposed that this concept represented a unique factor in understanding why people stay at their jobs. In their study, Mitchell et al. discussed three influences on employees' embeddedness and propensity to stay at or leave a job: links, fit, and sacrifice. Mitchell et al. recommended that each of these factors be considered within organizational and community contexts. In the present study, the number of items for each dimension ranged from 5 to 10 , totaling 41 items overall.

Fit community. This sub-dimension consisted of five items developed by Mitchell et al. (2001). Fit community can be seen as perceived comfort within the community. Fit-community was measured by Survey Items $15,16,17,18$, and 19 and included items such as "This community (where I live) is a good match for me" and "The area where I live offers the leisure activities that I like (sports, outdoors, cultural, arts)."

Fit organization. This sub-dimension consisted of nine items developed by Mitchell et al. (2001). Examples of organizational fit included individual "job knowledge, skills and abilities" (Mitchell et al., 2001,p. 9). HRD professionals can help influence organizational fit by instituting formal employee socialization processes, mentoring programs, and new-employee orientations. Fit organization was measured by Survey Items 20, 21, 22, 23, 24, 25, 26, 27, and 28 and included items such as "My values are compatible with Extension's values" and "I feel good about my professional growth and development."

Links community. This sub-dimension consisted of seven items developed by Mitchell et al. (2001). Examples of community links are hobby based groups, church- 
related activities, involvement in children's school or involvement in community activities. The measure was comprised of Survey Items $34,35,36,37,38,39$, and 40 including items such as "My family roots are in this community" and "I own the home I live in (mortgaged or outright)."

Links organization. This sub-dimension is comprised of five items developed by Mitchell et al. (2001). HRD professionals, among others, have a more direct influence on policies that promote organizational links than on policies that promote community links. At the base level, organizational links would include formal and informal relationships with coworkers and others. These work relationships can influence personal embeddedness and intention to stay both positively and negatively. Typically, Senior HRD professionals may influence benefits packages, employeeeducation assistance, on-site child care, and paid professional-development opportunities. Links organization was measured by Survey Items $29,30,31,32$, and 33 , including items such as "How many years have you been in your present position?" and "How many coworkers (at county or district office) are highly dependent on you?"

Sacrifice community. This sub-dimension consisted of five items developed by Mitchell et al. (2001). The length of time and improvements in one's home, convenience of and proximity to the local amenities, safety and positions of leadership in the community often represent losses that workers are unwilling to bare, even though links to the organization might be minimal. The HRD professional's ability to influence the sacrifice-community component of embeddedness is limited. This construct was measured by Survey Items $1,2,3,4$, and 5 and included items such as "Leaving my 
community would be very hard" and "If I were to leave the community, I would miss my neighborhood."

Sacrifice organization. This sub-dimension consisted of 10 items developed by Mitchell et al. (2001). Examples of sacrifice organization include the loss of the "corner office," health and retirement benefits, sports tickets, coworker relationships, educational benefits, advancement opportunities, convenience of and proximity to the work location, and perhaps security within the community. Human resource professionals should work to promote competitive, broad-based benefits packages for employees, thereby making the decision to leave a costly one. The sacrificeorganization construct was measured by Survey Items 41, 42, 43, 44, 45, 46, 47, 48, 49, and 50 and included items such as "I would sacrifice a lot if I left this job" and "I believe the prospects for continuing employment with this organization are excellent."

Job satisfaction. Locke (1969, p. 316) defined job satisfaction as "the pleasurable emotional state resulting from the appraisal of one's job as achieving or facilitating the achievement of one's job values." Scott et al. (2005, p. 89) noted that "job satisfaction can be defined as an individual's attitude about work roles and the relationship to worker motivation." The measure was comprised of Survey Items 6, 7, and 8 and included the following three items from Luthans et al. (2007): "Generally speaking, I am very satisfied with my job;" "I am generally satisfied with the feeling of worthwhile accomplishment I get from doing my job;" and "I am generally satisfied with the kind of work I do in my job." All items were measured on a 5-point Likert Scale.

Affective (organization) commitment. This scale consisted of six items. Allen and Meyer (1990) argued that "the most prevalent approach to organization commitment 
in the literature is one in which commitment is considered an affective or emotional attachment to the organization such that the strongly committed individual identifies with, is involved in, and enjoys membership in, the organization" (p. 2). In this study, affective commitment was measured by Survey Items 9, 10, 11, 12, 13, and 14 and included items such as "I feel a strong sense of belonging to Extension;" "I feel personally attached to Extension" and "I am proud to tell others I work at Extension." Discretionary effort. This scale consisted of seven items developed by Lloyd (2008). The authors describe discretionary effort as being voluntary and beyond what is normally expected by the employer. It is this extra effort on the part of employee that helps some organizations outperform others (Lloyd, 2003). Discretionary effort was measured by Survey Items $51,52,53,54,55,56$, and 57 and included items such as "When I work, I really exert myself to the fullest, beyond that what is expected" and "I finish a job even if it means sacrificing breaks or lunches."

Employee engagement. This scale consisted of seventeen items developed by Rich et al. (2010). The original concept of employee engagement was developed by Kahn (1990). He defined engagement as "task behaviors that promote connections to work and to others" (Kahn, 1990). Employee engagement was measured by Survey Items 58, 59, $60,61,62,63,64,65,66,67,68,69,70,71,72,73$, and 74 and included items such as "I exert my full effort to my job" and "I devote a lot of energy to my job."

Intent to stay. This scale consisted of 15 items developed by Hoisch, (2001). Intent to stay refers to the likelihood that an individual employee will remain in the organization (Tett \& Meyer, 1993). The construct was measured by Survey Items 75, 76, $77,78,79,80,81,82,83,84,85,86,87,87,88$, and 89 and included items such as "In 
the past, it would have been easy to find a job good enough to consider leaving the Cooperative Extension Service" and "It would be easy to find a job now that is good enough to consider leaving Cooperative Extension Service."

\section{Data Collection}

A census survey of KSU and UK Extension agents was used. Census research is utilized to describe occasions in which all elements of a population are studied. Census research can also be useful in discovering the desired descriptive characteristics of a population (Johnson \& Christensen, 2008).

For a study to be successful, a high response rate is crucial. Rosenthal and Rosnow (1975) conducted a meta-analysis that assessed nonvolunteers and developed a list of characteristics "that may reliably differentiate willing and unwilling subjects (p. 195). They argued that there can be high confidence of voluntary participation for subjects who are of a higher social class and who possess higher levels of education, higher social class, higher need for social approval, and sociability.

An examination of Census data from 2008 reveals that the general populations of Kansas and Kentucky had bachelor's degree attainment rates of $29.6 \%$ and $19.7 \%$, respectively (U.S. Census, 2008). The bachelor's degree attainment rate is always 100\% for both states because a bachelor's degree is the minimum education requirement for the position of Extension agent. Agents also tend to hold high profile positions within their local communities. This prominence could be interpreted as higher "social class" and "sociability" (Rosenthal \& Rosnow, 1975).

For the present study, surveys were conducted with all Extension agents in both states. The Qualtrics ${ }^{\circledR}$ on-line survey management software was used to administer and 
distribute the census survey instrument. Qualtrics ${ }^{\circledR}$ allows for unique identifiers to be easily assigned and follow-up e-mails to be sent only to nonrespondents. Qualtrics also enables the comparison late respondents with those who responded earlier in the survey (Dillman, 2009).

The survey instrument was reviewed by a panel of experts consisting of Extension professionals with KSU and UK. The panel reviewed all items to ensure that the content was appropriate, that the items would not infringe upon the respondents' confidentiality, and that the instrument would not place an undue burden on respondents.

The directors of the KSU Extension Service and UK Extension Service were contacted to participate in the study. Each Director sent messages to their respective Extension agents acknowledging their support for the study and the potential benefits it had for their respective organizations (Dillman, Smyth, \& Christian, 2009). The data collection process began the following week. The use of this type of online survey makes replication in additional states relatively simple.

During the months of October and November of 2011, an e-mail message was sent to Extension agents in Kansas and Kentucky outlining the voluntary nature of the study, its objectives, confidentiality, and a link to the questionnaire, which included the consent preamble. The first reminder message was sent 1 week later to those who had not yet responded. A second reminder message was sent 14 days later, and a final reminder message was sent 21 days after the initial message. All reminder messages contained a link to the questionnaire (Dillman et al., 2009). Copies of all correspondence can be found in Appendices D to $M$. 
The response rates were calculated for Extension agents at both universities.

Table 3.3 displays the survey schedule utilized for this study, which was based on Dillman et al. (2009).

Table 3.3

Survey schedule: Based on Dillman et al. (2009)

\begin{tabular}{ll}
\hline \multicolumn{1}{c}{ Time } & \multicolumn{1}{c}{ Action } \\
\hline October 27, 2011 & Extension Director support e-mail \\
October 30, 2011 & Initial survey invitation \\
November 6, 2011 & First reminder e-mail sent to nonrespondents \\
November 13, 2011 & Second reminder e-mail sent to nonrespondents \\
November 20, 2011 & Final reminder e-mail sent to nonrespondents \\
November 27, 2011 & Survey closed. Thank-you e-mail sent to all respondents \\
\hline
\end{tabular}

As surveys were completed, the data were collected and stored in the Qualtrics $®$ online database. After 4 complete weeks, the survey was closed and the database was downloaded into the Statistical Package for Social Sciences (SPSS, version 19.0).

\section{Ethical Considerations}

Being aware of the ethical responsibilities inherent in human-research studies is essential. As part of the dissertation-approval process, this study was reviewed and approved by the University of Louisville Institutional Review Board. Appendix B contains verification of this approval. All guidelines for research involving human subjects were adhered to in order to protect the rights and welfare of the study respondents. The preamble of the survey instrument discussed any known risks, 
discomforts, and benefits of the study, as well as the issues of confidentiality, compensation, and the voluntary nature of the study. A complete example of the survey instrument can be found in Appendix C.

\section{Appropriateness of Internet Surveys}

The use of Internet surveys began in the 1990s and has increased steadily over the years. Some advantages include (a) ease and speed of access to demographically and culturally diverse participant populations; (b) ability to bring the experiment to the participant, rather than the participant to the experiment; (c) high statistical power by enabling access to large samples; and (d) cost savings of laboratory space, person hours, equipment, and administration (Reips, 2000). The disadvantages include issues "such as (a) multiple submissions, (b) self-selection, and (c) dropout" (Reips, 2000, p. 89). In the end though, the advantages of an Internet survey outweigh the disadvantages (Reips, 2000).

All survey items in this study were in the format of forced response (i.e., required an answer to advance to the next question), with only one answer allowed for each question. After successfully answering all questions, the respondents were able to submit their information to the database for compilation.

\section{Response Rate}

In sum, 454 respondents responded to the survey instrument representing a $71.95 \%$ response rate, which is an acceptable level of response (Miller \& Smith, 1983; Babbie, 2007). Table 3.4 provides a detailed breakdown of the response rates by state and by week. 
Table 3.4

Summary of Respondents by State and Week

\begin{tabular}{lcccccc}
\hline Respondents & Week 1 & Week 2 & Week 3 & Week 4 & Respondents & $\begin{array}{c}\text { Non- } \\
\text { respondents } \\
\text { State }\end{array}$ \\
$N(\%)$ & $N(\%)$ & $N(\%)$ & $N(\%)$ & $N(\%)$ & $N(\%)$ \\
\hline KSU & 107 & 22 & 6 & 6 & 141 & 90 \\
& $(16.9)$ & $(3.5)$ & $(1.0)$ & $(1.0)$ & $(22.3)$ & $(14.3)$ \\
UK & 193 & 74 & 14 & 32 & 313 & 77 \\
& $(30.6)$ & $(11.7)$ & $(2.2)$ & $(5.1)$ & $(49.6)$ & $(12.2)$ \\
Total & 300 & 96 & 20 & 38 & 454 & 167 \\
& $(47.5)$ & $(15.2)$ & $(3.2)$ & $(6.1)$ & $(71.9)$ & $(26.5)$ \\
\hline
\end{tabular}

Note. Response percentages were calculated as a proportion to the total population (631).

\section{Nonresponse Analysis}

Although the response rate of almost $72 \%$ for the present study was acceptable (Babbie, 2007; Miller \& Smith, 1983), it remains important to further examine the accuracy of all responses to guard against nonresponse bias. Nonresponse bias can occur when the sample size is too small or when missed responses affect the conclusions of the study (Yu \& Cooper, 1983). The most common method to solve nonresponse bias is to maximize response rate (Groves, 2006). The current response rates were the result of a carefully laid-out plan involving the introduction and distribution of the survey instrument (Dillman et al. 2009). The following strategies were used to ensure the high response rate of $72 \%$.

- Personalized e-mail messages to participate were sent from the Extension Service Director of each state. 
- Personalized e-mail invitations to participate were delivered to Extension agents on Monday mornings.

- Multiple reminder messages were sent. However, whereas up to six reminders have been found to yield productive results in previous studies, this study only utilized four reminder messages.

- The potential benefits of the study were included in all messages. (Miller \& Smith, 1983).

Miller and Smith (1983) recommended that background variables should be compared between the population and study respondents. If the data for the respondents are "similar to the population, the assumption could be made that the respondents are a subpopulation of the total population" (Miller \& Smith, 1983, p. 47).

Miller and Smith also recommended that respondents and nonrespondents should be compared on a comprehensive set of socio-demographic-background characteristics. If there are no statistically significant differences, the results can be generalizable to the total population. Research has shown that late respondents tend to be similar to nonrespondents (Miller \& Smith, 1983). Therefore, responses received after November 6, 2012, were categorized as nonrespondents.

Nonresponse tests will be between (a) population verses respondents, and (b) respondents verses nonrespondents. I employed a chi-square test (also called Pearson's chi-square test) to examine statistical differences between the groups. Two general assumptions must be met to employ chi square. The first is that all observations must be independent. The second is that less than " $20 \%$ of the expected counts must be less than five and all counts must be greater than one" (Yates, Moore, \& McCabe, 1999, p. 734). 
Before actual numbers can be counted, the null hypothesis for the nonresponse test must be stated. In the tests below, the nonresponse null hypothesis was that there would be no differences between the groups. This analysis compared the total state population with the respondents and the respondents with the nonrespondents.

Prior to collection of the main study data, I was able to gather data on the gender, race, education level, age, and state of residence of the general state populations for Kansas and Kentucky from the respective employment specialists of each state. Details of each analysis appear in the following subsections.

\section{Gender}

The gender distribution for the population of Extension agents (Kansas and Kentucky) was $36.75 \%$ male (231) and $60.75 \%$ female (390). When compared to the total population to the number of respondents, the results showed that a slightly larger proportion of males $41.9 \%$ (190) and a slightly smaller proportion of females $58.1 \%$ (264) participated in the survey.

A calculation of the Pearson chi-square test of the variable gender between total population and respondents yielded a chi-square statistic of 2.38 , which did not exceed the critical value of 3.841 (.05 probability level). Therefore, it could be concluded that the respondents group shared the same characteristics as the general population when analyzed by gender.

A Pearson chi-square test was also used to test for gender between respondents and nonrespondents. This test yielded a value of .86 , which was not statistically significant at alpha level .05 . Therefore, it could be concluded that the respondents group 
shared the same characteristics as the nonrespondents when analyzed by gender (Creswell, 2005).

Race

Overall, $95.6 \%$ of respondents described themselves as White, $2.2 \%$ as Black, $0.4 \%$ as American Indian, and $1.5 \%$ as other. Among UK Extension agents, $95 \%$ described themselves as White, $4.25 \%$ as Black, $0.5 \%$ as Hispanic, and $0.25 \%$ as Asian. Most KSU Extension agents (99.7\%) were also White, with less than $1 \%$ self-identifying as a racial minority. There was a slight discrepancy between race data provided by the universities and the survey race data. Our university data indicated that one Hispanic and two Asian individuals were included in the population; however, there were no data in those survey categories. A possible explanation for this is that these three individuals chose not to participate in the study.

Two respondents self-identified as American Indian and seven identified as "other." None of these individuals were included in the original data provided by the universities. A possible explanation of this situation is that between April 2011 (time of university race data collection) and November 2011 (date census was conducted), the actual population of minorities changed through attrition and staff changes.

A chi-square test of the variable race, between total population and respondents yielded a coefficient of 0.61 . This value did exceed the critical probability level of .05 (3.841). Again, this indicated no statistically significant difference between the total population and the respondents when compared by race.

A Pearson chi-square test was also used to test for differences in race between respondents and nonrespondents. The test yielded a value of 8.38 , which was statistically 
significant at alpha level .05. Therefore, it could be concluded that the respondents group differed from nonrespondents when analyzed by race (Creswell, 2005).

Although the chi-square statistic can give a measure of statistical significance, it is often beneficial to examine practical significance. Eta square is one measure of practical significance that can be utilized to gain perspective when comparing two groups. An examination of the eta square statistic for the respondents and nonrespondents yielded a value of .01, which is considered a small effect size (Cohen, 1988). In summary, although statistically significant, the respondents and nonrespondents did not show a practical difference in terms of race.

\section{Education Level}

For the total population of Extension agents in both states, $46.9 \%$ held a bachelor's degree, $52.4 \%$ held a master's degree, and less than $1 \%$ held a doctoral degree. In a comparison of Extension agents with a bachelor's degree, Kansas $(N=148)$ and Kentucky $(N=144)$ agents had a similar frequency; however, the percentage of Kansas Extension agents with a bachelor's degree was higher than the percentage in Kentucky. An examination of agents with master's and doctorate degrees showed that approximately 3 times as many Kentucky agents $(N=244)$ as Kansas agents $(N=86)$ held a master's or doctorate degree.

The chi-square test of differences in education level between the total population and respondents yielded a chi-square statistic of 4.70 ; this did exceed the critical probability value of $.05(3.841)$. This indicated that statistically significant differences did exist between groups. This difference was partially explained by comparing the actual education level percentages for the two groups. The difference between the total 
population with a bachelor's degree and respondents with a bachelor's degree $(46.9 \%$ $39.9 \%$ ) was $+7 \%$. The difference between the total population and respondents with a master's degree or higher $(52.4 \%-59.2)$ was $-6.8 \%$. These two differences essentially negate each other, mainly because of the overall higher number of Kentucky Extension agents (313) in the study as compared to Kansas Extension agents (141) and because the differences in education levels between states were statistically significant $\left(X^{2}=36.6\right)$ and practically significant (Eta square $=.08$, small effect size). In summary, although statistically significant, the differences in education level were partially explained by differences between states and by the larger frequency of respondents from Kentucky.

A Pearson chi-square test was also used to check for differences in education level between respondents and nonrespondents. The test yielded a value of 1.43 , which was not statistically significant at the .05 level. Therefore, the respondents group showed no statistically significant difference from nonrespondents when analyzed by education level (Creswell, 2005).

\section{Age}

The average age of the population of Extension agents was 43.95 years. A comparison with the average age of the respondents yielded a chi-square statistic of 1.42. This value did not exceed the critical probability value of .05 (3.841). Therefore, it could be concluded that the population showed no statistically significant difference from respondents when analyzed by age (Creswell, 2005).

A chi-square test was also run to check for differences in age between respondents and nonrespondents; the test yielded a value of .17 at alpha level .05 , which was not statistically significant. Again it could be concluded that the respondents showed 
no statistically significant difference from nonrespondents when analyzed by age (Creswell, 2005).

\section{Summary}

To summarize, in establishing a cohort of Kansas and Kentucky Extension agents, response bias was assessed by comparing respondents with the total population and respondents with nonrespondents with regard to gender, education level, race, and age. Respondents were not different from the total population in terms of gender, race, and age. However, respondents did appear to differ from the total population in terms of education level. Two possible explanations for this finding are that there were more Kentucky respondents than Kansas respondents and more of the Kentucky respondents with a graduate degree.

Comparisons of respondents and nonrespondents showed no differences in gender, education level, and age. Respondents did differ from nonrespondents in terms of race, but further analysis with an Eta squared test indicated no practical significance.

In conclusion, study respondents appeared to be reasonably similar to both the total population and to nonrespondents. Thus, responses were unlikely to be affected by major bias (Groves, 2006). See Table 3.5 for further details.

\section{Scaled Items}

The developers of the original job embeddedness scale (Mitchell et al., 2001) created items to specifically measure each of its six dimensions (links organization, link community, fit organization, fit community, sacrifice organization and sacrifice community). However, they did not adequately describe how the links-organization items should be scaled. Data for these particular items were not assessed using a 5-point Likert 
Table 3.5

Nonresponse Bias Analysis, by Gender, Race, Education, Age, and State

\begin{tabular}{llccc}
\hline Descriptor & \multicolumn{1}{c}{ Group of analysis } & Statistic & $p$ value & $\begin{array}{c}\text { Exceeds } \\
\text { critical value }\end{array}$ \\
\hline Gender & Population/respondents & Chi-square & 2.4 & No \\
Race & Population/respondents & Chi-square & 0.6 & No \\
Education & Population/respondents & Chi-square & 4.7 & Yes* \\
Age & Population/respondents & Chi-square & 1.4 & No \\
& & & & \\
Gender & Respondents/nonrespondents & Chi-square & .03 & $>.05$ \\
Race & Respondents/nonrespondents & Chi-square & 8.4 & $<.05^{* *}$ \\
Education & Respondents/nonrespondents & Chi-square & 1.43 & $>.05$ \\
Age & Respondents/nonrespondents & Chi-square & 10.3 & $>.05$ \\
\hline
\end{tabular}

* Indicates statistically significant difference

** Indicates statistical but not practical significance

scale (as was the case in the original scale items). Instead, to accurately scale items for the links-organization items in a way that would maintain the original intent of the participants' responses, in this study I assigned a Likert value of 1 to the lowest value (strongly disagree), 2 to the next highest value (disagree), 4 to the next highest value (agree), and 5 to the highest value (strongly agree). This scale was used for the linksorganization items only.

For example, Item 36 asks, "How many coworkers do you interact with on a weekly basis?' Respondents had four options to choose from: $0-5,6-10,11-15$, and $15+$. The SPSS default was to assign the values 1 to 4 , respectively. The $0-5$ choice retained its original default value of 1 . The $6-10$ choice retaining its original value of 2 . The $11-$ 15 choice was reassigned a value of 4 . The $15+$ choice (the highest possible level of links-organization) was reassigned a value of 5 . 


\section{Composite Variables}

For this study the following new composite variables were created: links organization, links community, links total, fit organization, fit community, total fit, sacrifice organization, sacrifice community, total sacrifice, total job embeddedness, job satisfaction, organization commitment, discretionary effort scale, employee engagement, intent to stay, and respondents and nonrespondents. These means of means were used in Mitchell et al.'s (2001) study and allowed me to gain further insight into the components that impacted variance.

\section{Validity and Reliability}

Validity has been defined by many authors. Shavelson, defined validity as "the extent to which the interpretation of the results of the study follows from the study itself and the extent to which the results may be generalized to other situations with other people" (Shavelson, 1988, p. 21). Shadish, Cook, and Campbell (2002) added that validity involves the strength of the study results or the best available approximation of the truth. In other words, does the study gather the data that are desired and relevant to the study as described? The discussion that follows explores the validity and reliability of all six instruments.

Four different types of validity are generally examined in research studies: statistical conclusion validity, internal validity, external validity, and construct validity (Shadish et al., 2002). In every study, including the present study, there are threats one or more of these types of validity. 


\section{Statistical Conclusion Validity}

Statistical-conclusion validity has been defined as the "validity of inferences about the correlation (co-variation) between treatment and outcome" (Shadish et al., 2002). The strengths of this study related to statistical-conclusion validity include the potential for high power resulting from a high response rate and the documented reliability of the embeddedness scale.

Some threats to this type of validity would be low power because of a poor response from the study population. To address this threat, Dillman's (2009) suggested methods for conducting survey research were followed. These methods included but were not limited to personalizing emails, clearly stating the benefits to the individual and organization, and the offer to provide an executive summary when study is completed. Another potential threat to statistical-conclusion validity involves heterogeneity of units. This study involved the population of Extension agents at UK and KSU, all of which had similar job duties and expectations.

\section{Internal Validity}

Internal validity refers to the "validity of inferences about whether observed covariation between $\mathrm{A}$ (the presumed treatment) and $\mathrm{B}$ (the presumed outcome) reflects a causal relationship from A to B as those variables were manipulated or measured" (Shadish et al., 2002, p. 53). A large population sample size strengthens internal validity. A threat involves nonresponses and incomplete responses of population members. This has been a problem in previous embeddedness studies (Mitchell et al. 2001). To account for this problem, the survey design outline by Dillman (2009) was followed strictly. To reduce incomplete surveys, all questions were in a forced-response format. This means 
that each question must be answered before the participant is allowed to advance to the next one.

\section{External Validity}

External validity involves "inferences about whether the cause-effect relationship holds over variation in persons, settings, treatment variables, and measurement variables" (Shadish et al., 2002. p. 38). Teddlie and Tashakkori list five threats to research involving external validity:

- interaction of the causal relationship with units,

- interaction of the causal relationship over treatment variations,

- interaction of the causal relationship with outcomes,

- interaction of the causal relationship with settings, and

- context-dependent mediation.

To address the concerns of external validity I compared the population and respondents and respondents and nonrespondents for response bias. The analyses indicated that respondents were reasonably representative of the total population.

\section{Construct Validity}

Construct validity has been defined as "validity of inferences about the higher order constructs that represent sampling particulars" (Shadish et al., 2002. p. 38). The construct validity of this study is strengthened by its past replication. An additional method of validating this study is the ease with which it can be replicated. The replication of research findings is another way to account for bias (Rosnow \& Rosenthal, 1975). 


\section{Additional Types of Validity}

A factor analysis can be used to analyze the relationship among the survey items to determine whether they all measure the construct job embeddedness. Alpha coefficients can be used to validate the survey instruments. A coefficient alpha of less than .70 indicates that some items could be measuring the wrong constructs (Johnson \& Christensen, 2008).

Mitchell et al. (2001) conducted an exploratory factor analysis on each item on job-embeddedness for each of the two study populations. A summary of these factoranalysis scores is shown in Table 3.6. The first population sampled grocery-store employees, and the second sampled hospital employees. In addition, Mitchell et al. listed composite alpha coefficients for each job embeddedness dimension. Mitchell et al. concluded that the "data from these two samples indicated evidence of convergent and discriminate validity for job embeddedness" (p. 27).

Table 3.6

Job Embeddedness Factor Analysis Composite Scores

\begin{tabular}{lcc}
\hline & \multicolumn{2}{c}{ Factor-analysis } \\
\multicolumn{1}{c}{$\begin{array}{c}\text { Job embeddedness } \\
\text { dimensions }\end{array}$} & \multicolumn{2}{c}{ composite scores } \\
Fit: Community & .78 & .79 \\
Fit: Organization & .75 & .86 \\
Links: Community & .77 & .50 \\
Links: Organization & .65 & .62 \\
Sacrifice: Community & .61 & .59 \\
Sacrifice: Organization & .82 & .82 \\
\hline
\end{tabular}




\section{Internal Consistency Reliability}

Generally, instrument testing is not necessary if an established instrument is used (Sproull, 2004). To fortify previously demonstrated reliability, I calculated Cronback's Alpha for each of the scales used in this study. Cronbach's Alpha is used to measure internal consistency and yields an alpha coefficient (Cronbach, 1984). In general, an alpha coefficient of .70 or higher is considered acceptable for most social science research. Other scholars have proposed more specific guidelines for interpreting alpha coefficients. Guadagnoli and Velicer (1988) recommended that component saturation and absolute sample size be used to determine a scale's reliability be examined. According to Stevens (2009),

components with four or more loadings above .60 are reliable, regardless of sample size. . . Components with about 10 or more low $(.40)$ loading are reliable as long as sample size is greater than about $150 \ldots$ Components with only a few low loadings should not be interpreted unless sample size is at least 300 (p.137).

Using the guidelines provided by Cronbach (1984) and Guadagnoli and Velicer (1988), all of the scales utilized in this research were deemed reliable (based on alphacoefficient values for each scale). These scales are summarized in Table 3.7.

Table 3.7

Alpha Coefficient Value Summary

\begin{tabular}{lcc}
\hline \multicolumn{1}{c}{ Scale } & $\begin{array}{c}\text { Cronbach's } \\
\text { alpha }\end{array}$ & $N$ of Items \\
\hline Job embeddedness & .893 & 40 \\
Job satisfaction & .825 & 3 \\
Organization commitment & .905 & 6 \\
Discretionary effort & .906 & 7 \\
Engagement & .947 & 17 \\
Intent to stay & .828 & 15 \\
\hline
\end{tabular}




\section{Data Analysis}

I used SPSS analytical software to conduct separate data analyses to address the research questions for the present study. These tests include descriptive statistics (including means, medians, modes, standard deviations, chi squares, and correlations), analyses of variance (ANOVAs), multiple analyses of variance (MANOVA), and linear regression analyses needed to address the research questions and hypotheses. An alpha level of .05 was used to test all hypothesis testing. Descriptions of each research question and the data analyses are addressed next.

The four major research questions in this study focused on differences in the embeddedness of UK and KSU Extension Service employees and the ability of job embeddedness to predict intent to stay.

Research Question 1: Does Job embeddedness differ between KSU and UK

\section{Extension agents?}

To examine this question, I used ANOVA and MANOVA tests, which are useful when comparing means. First, ANOVA was used to examine the job embeddedness means of each state for differences. Next, I used MANOVA to test for differences in the six job embeddedness component variables. In examining Research Question 1 , the quantitative dependent variables were the overall and composite scales of job embeddedness and the independent variable was the geographic state of employment (Kansas or Kentucky; hereafter referred to simply as state).

Research Question 2: What are the relationships between job embeddedness, intent to stay, and discretionary effort? 
To test this question, correlation coefficients were used to examine relationships between variables. Correlation coefficients are useful in testing for levels of significance, direction of effect (positive or negative), and strength of relationship between the variables, which in this case were job embeddedness, intent to stay, and discretionary effort? A correlational analysis examines the relationships among the variables (Gravetter \& Wallnau, 1985).

Research Question 3: Can job embeddedness predict unique variance in the outcome variables intent to stay and/or discretionary effort, after controlling for job satisfaction, organization commitment, and employee engagement?

To examine this question, linear regressions were utilized. The quantitative dependent variables were intent to stay and discretionary effort, and the independent variables were the overall job embeddedness mean and the six subcomponent means.

To examine the ability of job embeddedness to predict intent to stay or discretionary effort, a linear regression analysis was performed. A linear regression analysis is "used to explain or predict the values of a dependent variable based on the values of one or more independent variables" (Johnson \& Christensen, 2007). Because other mediating independent variables could have affected the dependent variables, it was necessary to control for job satisfaction, organization commitment, and engagement. This will allow the "unique variance" of job embeddedness to be viewed. Finally, I utilized a step wise regression examining the influence of all variables mentioned above on intent to stay. One of the most significant outputs of the linear regression tests are beta coefficients. Beta coefficients give the relative strength of the predictive ability of each independent variable. 
Research Question 4: Are background variables significantly related to and able to predict job embeddedness?

To examine Research Question 4, I analyzed the influence that and all levels of the background variable (gender, race, education-level, age, program area, years in organization, years of prior work experience, type of prior work experience, county population) had on job embeddedness. Dummy variables were created from these categorical variables, which allowed for linear regression tests to be used in addressing this question.

\section{Summary}

Chapter 3 discussed the methodology used to conduct this study. This chapter also included a discussion of the research design, sampling, population, instrumentation, datacollection procedures, data analysis, and limitations of the research. Chapter 4 presents detailed findings, and chapter 5 includes an analysis of the results and implications for theory, research, and practice. 


\section{CHAPTER IV}

\section{RESULTS}

This study was designed to understand retention among Extension agents in Kansas and Kentucky. This chapter contains the results obtained through quantitative analyses of the survey instrument.

The instruments examined in the study were job embeddedness, job satisfaction, organization commitment, job engagement, intent to stay, discretionary effort, and background variables. Descriptive statistics (frequencies, means, medians, modes, and standard deviations), chi squares, correlations, ANOVAs, MANOVA, and linear regression analyses were performed by SPSS and used to examine the relationships and predictive influence between variables.

\section{Description of Respondents}

The following sections provide a detailed description of the respondents. In addition, each background variable was examined for differences between states using a chi-square test. These data are provided to give a clear picture of the respondent population. The effect of each background variable on job embeddedness components is examined thoroughly in Research Question 4.

\section{Gender}

Of the 454 Extension agents who chose to participate in this study, 141 resided in Kansas and 313 resided in Kentucky. The total number of males was 190 and the total 
number of females was 264 . As shown in Table 4.1, a larger frequency (58.1\%) of the total population of Extension agents who participated was female. A chi-square test showed that the percentage of respondents by gender did not significantly differ by state, $X^{2}(1, N=454)=.00, p=.99$. Cramer's V strength of association statistic was .00 out of a maximum of 1 . This indicates a zero association $(p=.99)$ between gender and state (Fields, 2005). Therefore, I did not reject the null hypothesis, which was that no statistically significant differences in gender of the respondents existed between states (Creswell, 2005).

Table 4.1

Cross-Tabulations of Gender and State

\begin{tabular}{lccc}
\hline & \multicolumn{3}{c}{ State } \\
\multicolumn{1}{c}{ Gender } & Kansas & Kentucky & Total \\
Male & 59 & $N(\%)$ & $N(\%)$ \\
& $(13.0)$ & $(28.9)$ & $(41.9)$ \\
Female & 82 & 182 & 264 \\
& $(18.1)$ & $(40.0)$ & $(58.1)$ \\
Total & 141 & 313 & 454 \\
& $(31.1)$ & $(68.9)$ & $(100.0)$ \\
\hline
\end{tabular}

Note. Frequencies and Percentages of total responses $(N=454) . X^{2}=.00$. Cramer's V test $=.00$.

\section{Race}

Table 4.2 contains a summary of the race data for all respondents' chi-square tests, which showed that the percentage of respondents by race did not differ significantly by state, $X^{2}(1, N=454)=5.94, p=.12$. Cramer's $V$ strength of association statistic was 
.11 out of a maximum of 1 . This indicated a small but non-significant $(p=.11)$

association between race and state (Fields, 2005). Therefore, I did not reject the null hypothesis, which was that no statistically significant differences in race existed between states (Creswell, 2005).

Table 4.2

Cross-Tabulations of Race and State

\begin{tabular}{|c|c|c|c|}
\hline & \multicolumn{3}{|c|}{ State } \\
\hline Race & $\begin{array}{c}\text { Kansas } \\
N(\%)\end{array}$ & $\begin{array}{c}\text { Kentucky } \\
N(\%)\end{array}$ & $\begin{array}{l}\text { Total } \\
N(\%) \\
\end{array}$ \\
\hline Black & $\begin{array}{c}2 \\
(0.4)\end{array}$ & $\begin{array}{c}8 \\
(1.8)\end{array}$ & $\begin{array}{c}10 \\
(2.2)\end{array}$ \\
\hline Indian & $\begin{array}{c}2 \\
(0.4)\end{array}$ & $\begin{array}{c}0 \\
(0.0)\end{array}$ & $\begin{array}{c}2 \\
(0.4)\end{array}$ \\
\hline White & $\begin{array}{c}136 \\
(30.0)\end{array}$ & $\begin{array}{c}299 \\
(65.9)\end{array}$ & $\begin{array}{c}435 \\
(95.8)\end{array}$ \\
\hline Other & $\begin{array}{c}1 \\
(0.2)\end{array}$ & $\begin{array}{c}6 \\
(1.3)\end{array}$ & $\begin{array}{c}7 \\
(1.5)\end{array}$ \\
\hline Total & $\begin{array}{c}141 \\
(31.1)\end{array}$ & $\begin{array}{c}313 \\
(68.9)\end{array}$ & $\begin{array}{c}454 \\
(100)\end{array}$ \\
\hline
\end{tabular}

Note. Frequencies and percentages of total responses $(N=454) . X^{2}=5.94$. Cramer's V test $=.12$.

Age

The average age of all respondents was 41.45 years. A detailed summary of age is shown in Table 4.3. The number of respondents by age group was somewhat different across the range of possible choices. The average age of Kansas respondents was 43.27 years, and the average age of Kentucky respondents was 40.54 years. 
Of all agents, $245(53.9 \%)$ were over 44 years of age. A chi-square test showed that the percentages of respondents by age did not differ significantly by state, $X^{2}(1, N=$ $454)=9.56, p=.21$. Cramer's V strength of association statistic was .14 out of a maximum of 1 . This indicated a small but nonsignificant association $(p=.22)$ between age and state (Fields, 2005). Again, I did not reject the null hypothesis that no statistically significant differences in age of respondents existed between states (Creswell, 2005).

Table 4.3

Cross-Tabulations of Age and State

\begin{tabular}{cccc}
\hline & \multicolumn{3}{c}{ State } \\
\cline { 2 - 4 } Age group & Kansas & Kentucky & Total \\
\hline $22-37$ & 13 & $N(\%)$ & $N(\%)$ \\
\hline \multirow{2}{*}{$28-32$} & $(2.9)$ & $(7.5)$ & $(10.4)$ \\
& 14 & 33 & 47 \\
$33-38$ & $(3.1)$ & $(7.3)$ & $(2.9)$ \\
& 19 & 46 & 65 \\
$39-43$ & $(4.2)$ & $(10.1)$ & $(14.3)$ \\
& 13 & 37 & 50 \\
$44-49$ & $(2.9)$ & $(8.1)$ & $(11.0)$ \\
& 17 & 53 & 70 \\
$50-55$ & $(3.7)$ & $(11.7)$ & $(15.4)$ \\
& 27 & 49 & 76 \\
$56-61$ & $(5.9)$ & $(10.8)$ & $(16.7)$ \\
& 31 & 39 & 70 \\
$62+$ & $(6.8)$ & $(8.6)$ & $(15.4)$ \\
& 7 & 22 & 29 \\
Total & $(1.5)$ & $(4.8)$ & $(6.4)$ \\
& 141 & 313 & 454 \\
& $(31.1)$ & $(68.9)$ & $(100.0)$ \\
\hline
\end{tabular}

Note. Frequencies and percentages of total responses $(N=454) . X^{2}=9.56$. Cramer's V test $=.14$. 


\section{Education Level}

Table 4.4 shows a detailed summary of the education levels of Extension agents in the two states. A chi-square test showed that the percentage of respondents by education level was significantly different by state, $X^{2}(1, N=454)=36.61, p=.00$.

Cramer's V strength of association statistic was .28 out of a maximum of 1 . This indicated a moderately significant association between education level and state (Fields, 2005). Therefore, I rejected the null hypothesis, which was that no statistically significant differences in education level existed between states (Creswell, 2005). The differences in education level of respondents between states were easily observed and were discovered earlier when testing for response bias. The effect of education level of job embeddedness is examined later in this chapter.

Table 4.4

Cross-Tabulations of Education Level and State

\begin{tabular}{lccc}
\hline & \multicolumn{3}{c}{ State } \\
\cline { 2 - 4 } Degree & Kansas & Kentucky & Total \\
Bachelor's & 86 & $N(\%)$ & $N(\%)$ \\
\hline Master's & $(18.9)$ & $(21.4)$ & $(40.3)$ \\
& 54 & 214 & 268 \\
Ph.D. & $(11.9)$ & $(47.1)$ & $(59.0)$ \\
& 1 & 2 & 3 \\
Total & $(0.2)$ & $(0.4)$ & $(0.7)$ \\
& 141 & 313 & 454 \\
& $(31.1)$ & $(68.9)$ & $(100.0)$ \\
\hline
\end{tabular}

Note. Frequencies and percentages of total responses $(N=454) . X^{2}=36.61$. Cramer's V test $=.28$. 


\section{Program Area}

Table 4.5 shows that Kansas respondents were more likely to be employed as agriculture and natural resources Extension agents, whereas Kentucky respondents were more likely to be employed as 4-H youth development Extension agents. A chi-square test showed that the percentage of respondents by program area were significantly different by state, $X^{2}(1, N=454)=23.54, p=.00$. Cramer's V strength of association statistic was .23 out of a maximum of 1 . This indicated a moderately significant association (sig. $p=.00$ ) between program area and state (Fields, 2005).Therefore, I rejected the null hypothesis, which was that no statistically significant differences in program area would exist between states (Creswell, 2005). The differences in the program areas of respondents between states and the effect of program area on job embeddedness are examined later in this chapter.

\section{Years of Extension Employment}

A frequency analysis of the years of Extension Services employment in Table 4.6 showed a large proportion of Extension agents with fewer than 15 years of Extension Services experience (57\%). The newest group, those with $0-5$ years of experience, represented $19 \%$ (87) of the study respondents. The least experienced group was also the largest subgroup in Kansas, representing $24.1 \%$ of the state's total Extension agents.

Those with 6-10 years of Extension Services experience comprised the largest subgroup in Kentucky, representing $22.4 \%$ of the state's total Extension agents.

A chi-square test showed that the percentage of respondents by years of Extension Services employment were not significantly different by state, $X^{2}(1, N=454)=6.24, p=$ 51. Cramer's V strength of association test statistic was .12 out of a maximum of 1 ( $p=$ 
Table 4.5

Cross-Tabulations of Program Area and State

\begin{tabular}{lccc}
\hline & \multicolumn{3}{c}{ State } \\
\cline { 2 - 4 } \multicolumn{1}{c}{ Program area } & Kansas & Kentucky & Total \\
\hline ANR & $N(\%)$ & $N(\%)$ & $N(\%)$ \\
\hline FCS & 58 & 101 & 159 \\
& $(12.8)$ & $(22.2)$ & $(35.0)$ \\
4-H & 43 & 79 & 122 \\
& $(9.5)$ & $(17.4)$ & $(26.9)$ \\
Horticulture & 23 & 111 & 134 \\
& $(5.1)$ & $(24.4)$ & $(29.5)$ \\
Community economic & 11 & 20 & 31 \\
development & $(2.4)$ & $(4.4)$ & $(6.8)$ \\
Other & $(0.4)$ & $(0.0)$ & $(0.4)$ \\
& & & 2 \\
Total & 4 & 2 & 6 \\
& $(0.9)$ & $(0.4)$ & $(1.3)$ \\
& 141 & 313 & 454 \\
& $(31.1)$ & $(68.9)$ & $(100.0)$ \\
\hline
\end{tabular}

Note. Frequencies and percentages of total responses $(N=454) . X^{2}=23.54$. Cramer's V test $=.23$. 
Table 4.6

Cross-Tabulations of Years of Employment and State

\begin{tabular}{|c|c|c|c|}
\hline \multirow{2}{*}{$\begin{array}{c}\text { Years of } \\
\text { extension } \\
\text { employment }\end{array}$} & \multicolumn{3}{|c|}{ State } \\
\hline & $\begin{array}{c}\text { Kansas } \\
N(\%)\end{array}$ & $\begin{array}{c}\text { Kentucky } \\
N(\%)\end{array}$ & $\begin{array}{l}\text { Total } \\
N(\%) \\
\end{array}$ \\
\hline $0-5$ & $\begin{array}{c}34 \\
(7.5)\end{array}$ & $\begin{array}{c}53 \\
(11.7)\end{array}$ & $\begin{array}{c}87 \\
(19.2)\end{array}$ \\
\hline $6-10$ & $\begin{array}{c}23 \\
(5.1)\end{array}$ & $\begin{array}{c}70 \\
(15.4)\end{array}$ & $\begin{array}{c}93 \\
(20.5)\end{array}$ \\
\hline $11-15$ & $\begin{array}{c}23 \\
(5.1)\end{array}$ & $\begin{array}{c}60 \\
(13.2)\end{array}$ & $\begin{array}{c}83 \\
(18.3)\end{array}$ \\
\hline $16-20$ & $\begin{array}{c}13 \\
(2.9)\end{array}$ & $\begin{array}{c}35 \\
(7.7)\end{array}$ & $\begin{array}{c}48 \\
(10.6)\end{array}$ \\
\hline $21-25$ & $\begin{array}{c}15 \\
(3.3)\end{array}$ & $\begin{array}{c}36 \\
(7.9)\end{array}$ & $\begin{array}{c}51 \\
(11.2)\end{array}$ \\
\hline $26-30$ & $\begin{array}{c}13 \\
(2.9)\end{array}$ & $\begin{array}{c}24 \\
(5.3)\end{array}$ & $\begin{array}{c}37 \\
(8.1)\end{array}$ \\
\hline $31-35$ & $\begin{array}{c}13 \\
(2.9)\end{array}$ & $\begin{array}{c}22 \\
(4.8)\end{array}$ & $\begin{array}{c}35 \\
(7.7)\end{array}$ \\
\hline $35+$ & $\begin{array}{c}7 \\
(1.5)\end{array}$ & $\begin{array}{c}13 \\
(2.9)\end{array}$ & $\begin{array}{c}20 \\
(4.4)\end{array}$ \\
\hline Total & $\begin{array}{c}141 \\
(31.1)\end{array}$ & $\begin{array}{c}313 \\
(68.9)\end{array}$ & $\begin{array}{c}454 \\
(100.0)\end{array}$ \\
\hline
\end{tabular}

Note. Frequencies and percentages of total responses $(N=454) . X^{2}=6 \cdot 24$. Cramer's V test $=.12$. 
.51). This indicated a small, non-significant association between the variable years of work experience and state (Fields, 2005). Therefore, I did not reject the null hypothesis, which was that no statistically significant differences in respondents' Extension Services employment existed between states (Creswell, 2005).

\section{Years of Prior Work Experience}

Table 4.7 shows that the vast majority of respondents indicated that they had 5 years or fewer of professional work experience prior to joining Extension Services $(65 \%)$. This indicated that a large number of the Extension agents in the study were hired immediately after college graduation or shortly afterward.

Table 4.7

Cross-Tabulations of Education Level and State

\begin{tabular}{cccc}
\hline $\begin{array}{c}\text { Years of } \\
\text { prior } \\
\text { professional } \\
\text { experience }\end{array}$ & \begin{tabular}{c} 
Kansas \\
\cline { 2 - 4 }
\end{tabular} & $\begin{array}{c}\text { Kentucky } \\
N(\%)\end{array}$ & $\begin{array}{c}\text { Total } \\
N(\%)\end{array}$ \\
\hline $0-5$ & 88 & 208 & 296 \\
& $(19.4)$ & $(45.8)$ & $(65.2)$ \\
$6-10$ & 19 & 49 & 68 \\
& $(4.2)$ & $(10.8)$ & $(15.0)$ \\
$11+$ & 34 & 56 & 90 \\
& $(7.5)$ & $(12.3)$ & $(19.8)$ \\
Total & 141 & 313 & 454 \\
& $(31.1)$ & $(68.9)$ & $(100.0)$ \\
\hline
\end{tabular}

Note. Frequencies and percentages of total responses $(N=454) . X^{2}=2.45$. Cramer's V Test $=.07$. 
A chi-square test showed that the percentage of respondents did not differ significantly by previous work experience across states, $X^{2}(1, N=454)=2.45, p=.29$. Cramer's V strength of association test statistic was .07 out of a maximum of $1(p=.29)$. This indicated a small, non-significant association between years of prior work experience and state (Fields, 2005). Therefore, I did not to reject the null hypothesis, which was that no statistically significant differences in respondents' years of prior work experience existed between states (Creswell, 2005).

\section{Type of Prior Work Experience}

Of the 454 total study respondents, $420(95.2 \%)$ reported some sort of prior work experience. The majority of respondents $(223$, or $53 \%)$ reported working for another public organization prior to joining Extension Services, $156(37 \%)$ came from the private sector, and $41(10 \%)$ came from a nonprofit organization. Table 4.8 shows that some differences between states were present. The type of prior work experience of Kansas Extension agents was about equally distributed among public and private jobs, whereas a clear majority of Kentucky Extension agents came from the public sector. A chi-square test showed that the percentage of respondents by type of prior work experience type was significantly different by state, $X^{2}(1, N=454)=8.47, p=.014$. Cramer's V strength of association statistic was .14 out of a maximum of 1 . This indicated a small (sig. $p=.01$ ) association between type of prior work experience and state (Fields, 2005). Therefore, I rejected the null hypothesis, which was there would be no differences in type of prior work experience between states (Creswell, 2005). 
Table 4.8

Cross-Tabulations of Prior Professional Experience Type and State

\begin{tabular}{lccc}
\hline \multirow{3}{*}{$\begin{array}{c}\text { Type of } \\
\text { prior work }\end{array}$} & Kansas & Kentucky & Total \\
\cline { 2 - 4 } experience & $N(\%)$ & $N(\%)$ & $N(\%)$ \\
\hline Public & 56 & 167 & 223 \\
& $(13.3)$ & $(38.8)$ & $(53.1)$ \\
Private & 60 & 96 & 156 \\
& $(14.3)$ & $(22.9)$ & $(37.1)$ \\
Nonprofit & 10 & 31 & 41 \\
& $(2.4)$ & $(7.4)$ & $(9.8)$ \\
Total & 126 & 294 & 420 \\
& $(30.0)$ & $(70.0)$ & $(100.0)$ \\
\hline
\end{tabular}

Note. Frequencies and percentages of total responses $(N=454) . X^{2}=8 \cdot 47$. Cramer's V test $=.14$.

\section{County Directors}

Originally, the presence of County Directors (Extension agents who supervise other Extension agents) in Kansas was a topic of concern for this study. This survey question was intended to allow the exclusion of those Kansas Extension agents who responded positively. The question, "Does your job include agent performance review?" was included in order to identify county directors in Kansas. Initially, I planned to exclude those agents from the study; however, Table 4.9 shows that the question was unclear to the respondents. This conclusion was reached by conducting a cross-tabulation analysis between the respondents to the previous question ("Does your job include agent performance review?') and the variable state. Even though no Kentucky Extension agents 
supervise other Extension agents, 96 responded positively to the question. This indicated that the question was confusing and poorly worded.

Table 4.9

Cross-Tabulations of Agent Performance Review Responsibility and State

\begin{tabular}{lccc}
\hline \multirow{2}{*}{$\begin{array}{c}\text { Agent } \\
\text { performance } \\
\text { review }\end{array}$} & Kansas & Kentucky & Total \\
\cline { 2 - 4 } responsibilities & $N(\%)$ & $N(\%)$ & $N(\%)$ \\
\hline Yes & 76 & 96 & 172 \\
& $(16.7)$ & $(21.1)$ & $(37.9)$ \\
No & 65 & 217 & 282 \\
& $(14.3)$ & $(47.8)$ & $(62.1)$ \\
Total & 141 & 313 & 454 \\
& $(31.1)$ & $(68.9)$ & $(100.0)$ \\
\hline
\end{tabular}

Note. Frequencies and percentages of total responses $(N=454) . X^{2}=.06$. Cramer's V test $=.00$.

To test whether the respondent population was homogeneous, Pearson chi-square tests were used. The results showed that the responses did not differ by state, $X^{2}(1, N=$ $454)=.06, p>.05$, and Cramer's V strength of association test value was $.0, p=.81$. This indicated a very small but non-significant association. These results support the decision not to exclude any respondents from the study.

\section{Population of Work County}

Results of the 2010 U.S. Census showed that Kansas had a total population of $2,871,238$ and Kentucky had a total population of $4,369,356$ (2010 Census). In this question respondents were asked to indicate the population of the county in which they worked. Table 4.10 showed the largest number of respondents $(M=164)$ reported 
working in a county with 10,001 to 30,000 residents. A chi-square test showed that the distribution of respondents by county population was significantly different by state, $\mathrm{X}^{2}$ $(1, N=454)=34.15, p=.00$. Cramer's V strength of association test value was .27 out of a maximum of $1(p=.00)$. This indicates a small to moderate association $(p=.01)$ between the variable county population and state (Fields, 2005). Therefore, I rejected the null hypothesis, which was that the populations of respondents work counties were not significantly different between states (Creswell, 2005).

Table 4.10

Cross-Tabulations of County Population and State

\begin{tabular}{cccc}
\hline & \multicolumn{3}{c}{ State } \\
\cline { 2 - 4 } Population of & Kansas & Kentucky & Total \\
work county & $N(\%)$ & $N(\%)$ & $N(\%)$ \\
\hline Under 10,000 & 54 & 57 & 111 \\
& $(11.9)$ & $(12.6)$ & $(24.4)$ \\
$10,001-30,000$ & 31 & 133 & 164 \\
& $(6.8)$ & $(29.3)$ & $(36.1)$ \\
$30,001-60,000$ & 19 & 61 & 80 \\
& $(4.2)$ & $(13.4)$ & $(17.6)$ \\
$60,001-100,000$ & 10 & 27 & 37 \\
& $(2.2)$ & $(5.9)$ & $(8.1)$ \\
Over 100,000 & 27 & 35 & 62 \\
& $(5.9)$ & $(7.7)$ & $(13.7)$ \\
Total & & & \\
& 141 & 313 & 454 \\
\hline
\end{tabular}

Note. Frequencies and percentages of total responses $(N=454) . \mathrm{X}^{2}=34.15$. Cramer's V test $=.27$. 


\section{Precautions and Assumptions}

Several precautions and assumptions were observed to assure accuracy and validity of the statistical tests.

\section{Multicollinearity}

Multicollinearity refers to instances of moderate to high intercorrelations among the predictor variables. Multicollinearity can present three problems when using regression. First, multicollinearity can limit the size of $\mathrm{R}$, because the predictors are influencing the same variance in the dependent variable (Stevens, 2009). Second, the correlations between predictor variables make judging their relative importance difficult (Stevens, 2009). Third, multicollinearity increases the variances of the regression coefficients "resulting in unstable predictor equations" (Field, 2005, p. 175).

As proposed by the study model, I theorized that the background variables will predict the six components of job embeddedness (links organization, links community, fit organization, fit community, sacrifice organization, and sacrifice community). I examined the model's variance inflation factors (VIF). "VIF indicates whether a predictor has a strong linear relationship with other variables" (Field 2005, p. 175). In addition, according to Myers (1990) researchers should pay close attention to VIF's of 10 or above. Since no values higher than 10 were discovered, little interaction among variables was assumed (Stevens, 2009).

A second stage of analysis, based on the study model, examined the research question regarding the ability of job embeddedness to predict intent to stay, while controlling for the effects of job satisfaction, organization commitment, and employee 
engagement. A final examination of variance-inflation values of multicorrelation again showed no values higher than 10 , indicating no cause for concern (Stevens, 2009).

\section{Linearity}

The assumption of linearity (linear relationships between the independent and dependent variables) states that the "mean values of the outcome variable for each increment of the predictor variable lie along straight line" and that "attempting to apply a nonlinear relationship using a linear model limits generalizability of the findings" (Field, 2005, p. 170). The scatterplots for all combinations of independent and dependent variables were examined, and showed linear relations.

\section{Homoscedasticity}

Homoscedasticity is one of the necessary assumptions when conducting a regression analysis. Homoscedasticity "means that the residuals at each level of the predictor(s) should have the same variance" (Field, 2005, p. 170). To test for homoscedasticity, I examined probability plots and found them to be randomly dispersed throughout the plot in a generally oval shape, which indicated that the assumptions of linearity and homoscedasticity were met (Field, 2005, p. 203).

\section{Data Results and Analysis}

The four research questions focused on differences in the job embeddedness of UK and KSU Extension Service employees and the relationships between and the ability of the six components of job embeddedness to predict intent to stay and discretionary effort. Additionally, the predictive ability of background variables was studied. 


\section{Job Embeddedness of KSU and UK Extension Agents}

\section{Research Question 1: Does job embeddedness differ between KSU and UK}

\section{Extension agents?}

Table 4.11 shows the mean participant scores of total job embeddedness and does indicate that Kentucky's Extension agents (3.24 mean) were somewhat more embedded than were Kansas's Extension agents (3.14 mean). An examination of means can show general trends but cannot indicate strength or significance of differences.

Table 4.11

ANOVA Summary Table: Job Embeddedness and State

\begin{tabular}{lccccc}
\hline & $\boldsymbol{N}$ & $\begin{array}{c}\text { Total mean } \\
(\boldsymbol{S D})\end{array}$ & $\begin{array}{c}\text { KSU mean } \\
(\boldsymbol{S D})\end{array}$ & $\begin{array}{c}\text { UK mean } \\
(\boldsymbol{S D})\end{array}$ & $\begin{array}{c}\boldsymbol{F} \\
(\mathrm{sig})\end{array}$ \\
\hline $\begin{array}{l}\text { Total Job } \\
\text { Embeddedness }\end{array}$ & 454 & 3.21 & 3.14 & 3.24 & $6.10^{* *}$ \\
& & $(.41)$ & $(.36)$ & $(.42)$ & $(.014)$ \\
\hline
\end{tabular}

Note. Eta square .014 .

** Significance at .01 alpha level (2-tailed).

To explore if any statistically significant differences existed between the jobembeddedness means of KSU and UK Extension agents, I used ANOVA tests. In this analysis the independent variable was the state and the dependent variable was job embeddedness. An ANOVA is a statistical test used to examine the means of two or more treatment groups (Gravetter \& Wallnau, 1985).

The results of the ANOVA test revealed a statistically significant difference in the level of job embeddedness between the workers in the two states. Because the $F$ value indicated statistical significance (.05 level), it was also important to examine eta squared 
$\left(\eta^{2}\right)$ for practical significance. The observed eta squared value of .014 indicated a small effect size (Cohen. 1988).

These results parallel Kentucky's (96.34\%) and Kansas’s (95.40\%) Extension Services retention rates and support the proposition that higher job embeddedness correspond to higher retention rates.

To provide a deeper understanding of the differences in the job embeddedness component means, I used a multivariate analysis of variance (MANOVA) test to examine the relationship between state and the six components of job embeddedness (links organization, links community, fit organization, fit community, sacrifice organization, and sacrifice community). Table 4.12 illustrates the results of the tests of between-subject effects, which show that states differed significantly on fit community and links organization. Of the two significant components, links organization had the higher $F$ value and observed power.

Sacrifice community, had the highest mean score of the six job-embeddedness components for both states (although no statistically significant differences in sacrifice community between states were indicated by the ANOVA results). These results could support Mitchell's et al. (2001) position that community plays an important role in an individual's intent to stay.

In summary, the ANOVA tests indicated that the job-embeddedness indices for KSU and UK Extension agents were significantly different. Furthermore, MANOVA testing was able to more specifically identify that the statistically significant difference in job embeddedness by state was found in the components links organization and fit 
Table 4.12

MANOVA Summary Table: Job Embeddedness Components and State

\begin{tabular}{|c|c|c|c|c|c|c|c|c|}
\hline \multirow[b]{2}{*}{ Source } & Total & $\mathrm{KSU}$ & UK & \multirow[b]{2}{*}{$d f$} & \multirow[b]{2}{*}{$F$} & \multirow[b]{2}{*}{ Sig. } & \multirow{2}{*}{$\begin{array}{c}\text { Part. Eta } \\
\text { squared }\end{array}$} & \multirow{2}{*}{$\begin{array}{c}\text { Observed } \\
\text { power }\end{array}$} \\
\hline & $M(S D)$ & $M(S D)$ & $M(S D)$ & & & & & \\
\hline \multirow{2}{*}{$\begin{array}{l}\text { Sacrifice } \\
\text { community }\end{array}$} & 4.02 & 4.01 & 4.02 & 1,452 & .04 & .85 & .000 & .054 \\
\hline & $(.62)$ & $(.53)$ & $(.65)$ & & & & & \\
\hline \multirow{2}{*}{$\begin{array}{l}\text { Sacrifice } \\
\text { organization }\end{array}$} & 3.65 & 3.66 & 3.65 & 1,452 & .11 & .74 & .000 & .063 \\
\hline & (.54) & (.54) & $(.54)$ & & & & & \\
\hline Fit community & $\begin{array}{l}3.89 \\
(.72)\end{array}$ & $\begin{array}{l}3.78 \\
(.67)\end{array}$ & $\begin{array}{l}3.94 \\
(.74)\end{array}$ & 1,452 & 4.86 & $.03 * *$ & .011 & .595 \\
\hline Fit organization & $\begin{array}{l}3.93 \\
(.62)\end{array}$ & $\begin{array}{l}3.96 \\
(.61)\end{array}$ & $\begin{array}{l}3.92 \\
(.62)\end{array}$ & 1,452 & .37 & .55 & .001 & .093 \\
\hline Links community & $\begin{array}{l}1.86 \\
(.48)\end{array}$ & $\begin{array}{l}1.80 \\
(.44)\end{array}$ & $\begin{array}{l}1.90 \\
(.50)\end{array}$ & 1,452 & 3.16 & .08 & .007 & .426 \\
\hline Links organization & $\begin{array}{l}1.90 \\
(.76)\end{array}$ & $\begin{array}{l}1.62 \\
(.56)\end{array}$ & $\begin{array}{l}2.02 \\
(.80)\end{array}$ & 1,452 & 28.32 & $.00^{* *}$ & .059 & 1.00 \\
\hline
\end{tabular}

Note. $N=454$.

** significant at .05 alpha level (2-tailed). 
community. Finally, the sacrifice community component showed consistently high means in both states.

\section{Relationship Between Job Embeddedness, Intent to Stay, and Discretionary Effort}

Research Question 2: What are the relationships between job embeddedness, intent to stay and discretionary effort?

This question examined relationships between total job embeddedness, the six components of job embeddedness, intent to stay, and discretionary effort. Table 4.13 summarizes the Pearson correlations and show that job embeddedness was significantly related to intent to stay and discretionary effort. A summary of the correlations between all variables involved in this study can be found in Appendices Q and $R$.

Table 4.13

Correlations between Job Embeddedness, Intent to Stay and Discretionary Effort

\begin{tabular}{lccc}
\hline & Job embeddedness & Intent to stay & Discretionary effort \\
\hline Job embeddedness & - & $.22^{* *}$ & $.33^{* *}$ \\
Intent to stay & - & -.01 \\
Discretionary effort & & & - \\
\hline
\end{tabular}

Descriptive statistics are summarized in Table 4.14. Sacrifice community had the highest mean scores of all job embeddedness components. An examination of the means for job embeddedness total, intent to stay and discretionary effort showed a noticeably higher mean for discretionary effort. 
Table 4.14

Job Embeddedness (Six Components), Intent to Stay, and Discretionary Effort

Descriptive Statistics

\begin{tabular}{|c|c|c|}
\hline & & Total score \\
\hline & $N$ & $\begin{array}{c}\text { Mean } \\
(S D)\end{array}$ \\
\hline Intent to stay & 454 & $\begin{array}{l}3.25 \\
(.38)\end{array}$ \\
\hline $\begin{array}{l}\text { Discretionary } \\
\text { effort }\end{array}$ & 454 & $\begin{array}{l}4.30 \\
(.50)\end{array}$ \\
\hline $\begin{array}{l}\text { Job } \\
\text { embeddedness }\end{array}$ & 454 & $\begin{array}{l}3.21 \\
(.41)\end{array}$ \\
\hline $\begin{array}{l}\text { Sacrifice } \\
\text { organization }\end{array}$ & 454 & $\begin{array}{l}3.65 \\
(.54)\end{array}$ \\
\hline $\begin{array}{l}\text { Sacrifice } \\
\text { community }\end{array}$ & 454 & $\begin{array}{l}4.02 \\
(.62)\end{array}$ \\
\hline $\begin{array}{l}\text { Fit } \\
\text { organization }\end{array}$ & 454 & $\begin{array}{l}3.93 \\
(.62)\end{array}$ \\
\hline Fit community & 454 & $\begin{array}{l}3.89 \\
(.72)\end{array}$ \\
\hline $\begin{array}{l}\text { Links } \\
\text { organization }\end{array}$ & 454 & $\begin{array}{l}1.89 \\
(.76)\end{array}$ \\
\hline $\begin{array}{l}\text { Links } \\
\text { community }\end{array}$ & 454 & $\begin{array}{l}1.86 \\
(.48)\end{array}$ \\
\hline
\end{tabular}

Note. $N=454$. 


\section{Predicting Unique Variance of Intent to Stay and Discretionary Effort}

Research Question 3: Can job embeddedness predict unique variance in the outcome variables intent to stay, after controlling for job satisfaction, organization commitment, and employee engagement?

This question examined the degree to which the six components of job embeddedness predicted unique variance in the outcome variable intent to stay after controlling for job satisfaction, organization commitment, and employee engagement. The following section details the results of each outcome variable separately.

To examine the ability of the six job embeddedness components to predict intent to stay, correlation and linear-regression analyses were performed (Johnson \& Christensen, 2007). First, Pearson correlations between the variables intent to stay, jobembeddedness links (organization and community), job-embeddedness fit (organization and community), job-embeddedness sacrifice (organization and community), job satisfaction, employee engagement, and organization commitment were examined. With respect to multicollinearity, the data showed no values greater than .9; therefore, multicollinearity was not an issue in this model (Field, 2005). Almost all variables were significantly correlated, except that intent to stay was not correlated with links organization and links community. A complete list of the Pearson correlations can be found in Appendices P and Q. Of particular interest are the correlations of sacrifice organization and fit organization with intent to stay. The correlations between the links organization and links community were not significant. 
Next, I conducted a linear regression analysis between the dependent variable intent to stay and the six components of job embeddedness. A step wise entry method was selected. Job satisfaction, employee engagement, and organization commitment were held constant to measure the unique effect of job-embeddedness components on intent to stay. Descriptive statistics and beta coefficient values for each variable are listed in Table 4.15. Beta coefficients indicate the predictive value of each variable.

Table 4.15

Regression Analysis of Employee Engagement, Organization Commitment, Job

Satisfaction, Sacrifice Community, Sacrifice Organization, Fit Community, Fit

Organization, Links Organization, and Links Community on Intent to Stay.

\begin{tabular}{|c|c|c|c|c|c|c|}
\hline Source & Mean & $S D$ & $\beta$ & $R^{2}$ & Adj. $R^{2}$ & $R^{2} \Delta$ \\
\hline \multicolumn{7}{|c|}{ Step 1} \\
\hline $\begin{array}{l}\text { Organization } \\
\text { commitment }\end{array}$ & 4.02 & .71 & $.19^{* *}$ & & & \\
\hline Block & & & & .13 & .13 & .13 \\
\hline \multicolumn{7}{|c|}{ Step 2} \\
\hline Job satisfaction & 4.08 & .64 & $.09 * *$ & & & \\
\hline Employee engagement & 4.23 & .47 & -.02 & & & \\
\hline Block & & & & .14 & .14 & .01 \\
\hline \multicolumn{7}{|c|}{ Step 3} \\
\hline Job embeddedness & & & & & & \\
\hline Sacrifice community & 4.02 & .62 & -.75 & & & \\
\hline Sacrifice organization & 3.65 & .54 & $.16^{* *}$ & & & \\
\hline Fit community & 3.89 & .72 & -.02 & & & \\
\hline Fit organization & 3.93 & .62 & .04 & & & \\
\hline Links organization & 1.89 & .76 & $-.05 * *$ & & & \\
\hline Links community & 1.86 & .48 & -.07 & & & \\
\hline Block & & & & .19 & .18 & .04 \\
\hline
\end{tabular}

Note. The dependent variable was intent to stay.

$* *$ Sig. $<.05$ 
In Step 1 of the regression models, the independent variable organization commitment was found to be a significant predictor of intent to stay. In Step 2, job satisfaction was significant and added to the regression equation however employee engagement was not. These variables were held constant in order to evaluate any unique variance produced by the job-embeddedness components. In Step 3, the six components of job embeddedness were entered in the regression equation. Of the six only sacrifice organization and links organization were shown to significantly predict intent to stay and added to the model summary. Sacrifice organization was the stronger predictor, while links-organization was weaker and has negative predictive value.

The model summary yielded $R^{2}$ and adjusted $R^{2} . R^{2}$ (multiple correlation coefficient) is the proportion of variance in the dependent variable (intent to stay), which can be explained by the independent variables (job satisfaction, organization commitment, employee engagement, sacrifice community, sacrifice organization, fit community, fit organization, links community, and links organization). A summary of the regression statistics revealed that sacrifice organization and links organization explained $4 \%$ of the unique variance in the dependent variable intent to stay (Field, 2005). In total, the independent variables explained $18 \%$ of the variance in intent to stay. The addition of the variable discretionary effort had no significant effect on the regression equation or model summary.

\section{Predicting Job Embeddedness With Background Characteristics}

Research Question 4: Are background variables significantly related to and able to predict job embeddedness? 
In this study I hypothesized that background variables can have an influence on job embeddedness. I began by examining the Pearson correlation values. Correlations between job embeddedness, gender, race, education level, age, program area, years in organization, years of prior work experience, type of prior work experience, county population, and state were examined. I included the variable county population to investigate whether the size of the community had an impact on job embeddedness (retention). A study by Vlosky and Dunn (2009) found that community size was directly correlated with income among White Extension agents and that income was one significant factor in Extension-agent satisfaction. In other words, "the smaller the community, the lower the average income" (Vlosky \& Dunn, 2009, p. 4).

No values greater than .9 were observed, indicating that multicollinearity was not an issue in this test (Field, 2005). All correlations are shown in Appendices P and Q. Age, years of Extension and state, were all moderately correlated with job embeddedness at the .05 alpha level. Job embeddedness was correlated with state, age, and years employed with Extension Services. Age and years of experience had the highest correlation values. The correlation between job embeddedness and state was previously noted during discussion of Research Question 1.

Next, I used linear regressions to test the ability of the background variables to predict total job embeddedness and each of the six components of job embeddedness and examined each level of each background variables (Table 4.16) to discover more specifically where predictive ability lies within that variable. Because our background variables are categorical in nature and not continuous it was necessary to create dummy variables to examine where the predictive power lies within the levels of our predictor 
variables. "Dummy coding is a way of representing groups by using only zeros and ones" (Field, 2005, p.208). In this case we will be creating k-1 dummy variables for each predictor variable (where $\mathrm{k}$ is the number of levels), each of which will be compared to a constant. For example, the predictor variable "program area" has six levels. Therefore, one will be the constant (ANR) and five new variables would be created (FCS, 4-H, Hort., CED and other). The SPSS output yields a beta coefficient, showing the direction $(+,-)$ and statistical significance for each dummy variable. A negative statistically significant beta coefficient is interpreted as having less (-) predictive power than the constant (Stevens, 1999). The constant for each variable is shown on Table 4.16 in parentheses.

After all linear-regression tests were completed, beta coefficients were summarized in Table 4.16. While interesting, the beta coefficients of the background variables are of limited value to HRD professionals because there is little ability to manipulate them.

As shown in Table 4.16, the background variables gender and program area did not significantly predict any job embeddedness scores. In addition, no respondents indicated their race to be either Asian or Hispanic. SPSS excluded these dummy variables for the regression analysis.

Significant beta coefficients for race were found with the components sacrificeorganization and fit-organization components. The results indicate that both AfricanAmerican and American Indian respondents have less predictive influence on sacrificeorganization and fit-organization component scores, than the constant (zero value) 
Table 4.16

Beta Coefficients From the Regression Analysis of Dummy Coded Variables

\begin{tabular}{|c|c|c|c|c|c|c|c|}
\hline \multirow[b]{2}{*}{ Source } & \multicolumn{6}{|c|}{$\beta$ coefficients } & \multirow[b]{2}{*}{$\begin{array}{c}\text { Total job } \\
\text { embeddedness }\end{array}$} \\
\hline & $\begin{array}{c}\text { Sacrifice } \\
\text { community }\end{array}$ & $\begin{array}{c}\text { Sacrifice } \\
\text { organization }\end{array}$ & Fit community & Fit organization & $\begin{array}{c}\text { Links } \\
\text { community }\end{array}$ & $\begin{array}{c}\text { Links } \\
\text { organization } \\
\end{array}$ & \\
\hline \multicolumn{8}{|l|}{ Gender (female) } \\
\hline Male & -.04 & -.01 & .03 & -.017 & .02 & $.12^{*}$ & .02 \\
\hline \multicolumn{8}{|l|}{ Race (white) } \\
\hline African American & .02 & $-.10^{*}$ & .17 & $-.12 *$ & .11 & -.20 & -.06 \\
\hline American Indian & $-.13^{*}$ & $-.21 *$ & $-.11^{*}$ & $-.17^{*}$ & $-.10^{*}$ & -.05 & $-.18^{*}$ \\
\hline \multicolumn{8}{|c|}{ Education level (bachelors) } \\
\hline Masters & .22 & .16 & .31 & -.02 & $.72 *$ & $-.62 *$ & .09 \\
\hline Doctoral & .51 & .41 & .74 & .03 & $.82^{*}$ & $-.74^{*}$ & .26 \\
\hline \multicolumn{8}{|l|}{ Age (22-27 yrs) } \\
\hline Age $28-32$ & -.10 & $-.22 *$ & -.02 & -.08 & -.12 & .06 & -.07 \\
\hline Age $33-38$ & -.05 & $-.28^{*}$ & -.02 & -.05 & -.05 & .03 & -.04 \\
\hline Age $39-43$ & $-.03 *$ & $-.27 *$ & -.02 & -.07 & -.06 & -.02 & -.05 \\
\hline Age $44-49$ & $-.04 *$ & $-.22 *$ & -.01 & -.03 & -.04 & -.03 & -.03 \\
\hline Age 50-55 & -.09 & -.04 & .00 & -.00 & -.02 & -.02 & -.02 \\
\hline Age 56-61 & -.01 & -.03 & .00 & -.02 & -.00 & -.01 & -.01 \\
\hline Age 62up & $-.30^{*}$ & $-.30^{*}$ & -.08 & -.36 & -.34 & .00 & $-.24^{*}$ \\
\hline \multicolumn{8}{|l|}{ Program area (ANR) } \\
\hline FCS & -.17 & .04 & -.08 & .12 & -.10 & -.13 & -.05 \\
\hline $4-\mathrm{H}$ & -.11 & .04 & .01 & .07 & -.07 & -.09 & -.03 \\
\hline Horticulture & -.08 & .05 & -.02 & .08 & -.06 & -.10 & -.02 \\
\hline CED & .07 & .13 & .16 & .18 & .03 & -.12 & .07 \\
\hline Other & -.15 & .07 & .09 & .23 & -.19 & -.42 & -.06 \\
\hline
\end{tabular}




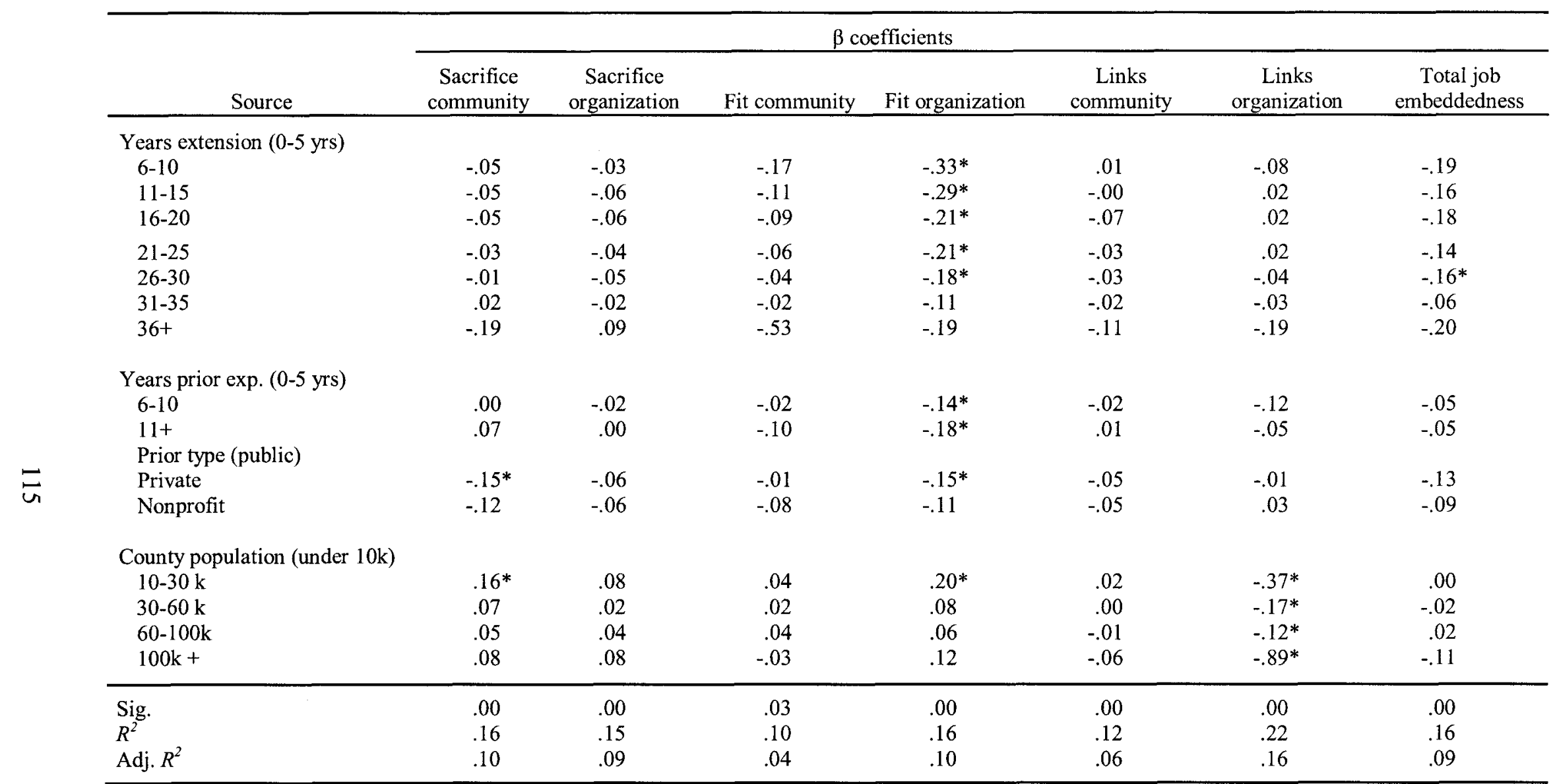

Note. $N=454$. Asian, Hispanic and other race dummy variables were excluded by SPSS because no respondents selected these options. State constant $=$ Kentucky. Gender constant $=$ female. Race constant $=$ white. Education level constant $=$ bachelor's degree. Age constant $=22-27$ years of age. Program area constant $=$ ANR. Years Extension experience constant $=0-5$ years. Years prior experience constant $=0-5$ years. Previous type constant $=$ public. County population constant $=$ under 10,000 .

*Sig. $<.05$ 
variable White. All significant levels of the variable race showed less predictive ability than the race constant, which was white.

Education level showed significant predictive ability for Links-Community and Links-Organization. This means that as employee education levels increase, their links to the community increased, while their links to the organization decreased. Those with Masters and Doctoral degrees showed greater ability to predict Links Community than those with Bachelor's degrees and less ability than those with Bachelor's degrees for Links Organization.

Years of Extension experience was a significant predictor for fit community. This could indicate that as years worked increases, fit-community increases. Analysis of the dummy variables indicated that all levels of this variable showed less predictive ability than the constant $(0-5$ years of experience).

Analysis of the dummy variables for age indicated that all age groups were less likely to predict job embeddedness or its components than the constant (22-27 years of age).

Finally, county population was a moderately significant predictor of links organization. This would indicate that as population increases, links-organization decreases. Put another way Extension agents in smaller counties are more linked to the organization than those working in larger counties. As with the analyses of the previous research questions, an examination of the data plots and residual statistics showed that no linear-regression assumptions were violated. These results confirm that state, age, and education level explained significant amounts of variance and are significant predictors for the variable job embeddedness. 


\section{Summary}

The results from Research Question 1 indicated that the job-embeddedness levels of KSU and UK Extension agents were significantly different. Testing identified a significant main effect of state on the job-embeddedness components links organization and fit community.

Pearson correlations between intent to stay and job embeddedness and between discretionary effort and job embeddedness were significant.

A regression analysis indicated that the model of all variables was significant in predicting a total of $16 \%$ of the variance in intent to stay (job embeddedness components predicted $4 \%$ of the unique variance after controlling for the effects of job satisfaction, organization commitment, and employee engagement; Field, 2005). Finally, the results indicated that the dummy levels of the background variables explained $9 \%$ of the variance in job embeddedness.

Chapter 5 will explore the results in more detail and present conclusions and recommendations based on the findings. 


\section{CHAPTER V}

\section{DISCUSSION}

Low employee retention rates represent a substantial problem for all organizations, costing them thousands of dollars per employee each year (Kutilek, 2000). These costs include lower quality products and services; financial expenses related to recruiting, hiring, and retraining employees; losses in productivity during the time a position is vacant; and interruptions in the flow of products and services (Friedman et al., 1992).

The purpose of this study was to understand the impact of job embeddedness on retention. Specific questions addressed differences in the job embeddedness of Extension agents in Kansas and Kentucky; the relationships between job embeddedness, intent to stay, and discretionary effort; the ability of job embeddedness to predict intent to stay and discretionary effort; and the impact of background variables on workers' levels of job embeddedness.

\section{Summary of the Study}

Job embeddedness refers to a relatively new construct that examines an individual's (a) links to other people, teams, and groups; (b) perceptions of their fit with the job, organization, and community; and (c) beliefs about what they would have to sacrifice if they left their jobs (Mitchell et al., 2001). Job embeddedness has been shown to be positively correlated with performance (Emmerik \& Sanders, 2004) and 
organizational citizenship (Lee et al., 2004). In addition, organizational-socialization tactics have been shown to be positively correlated with organizational embeddedness (Allen, 2006) and negatively correlated with employees' intentions to quit (Crossley et al., 2007). Coworkers' embeddedness has been found to be a valid predictor of voluntary turnover (Felps et al., 2009), and Hispanic employees have been shown to be significantly more embedded in their communities than Caucasian employees (Mallol, Holtom, \& Lee, 2007).

Four major research questions guided this study.

1. Does job embeddedness differ between UK and KSU Extension agents?

2. What were the relationships between job embeddedness, intent to stay and discretionary effort?

3. Can job embeddedness predict intent to stay even after controlling for job satisfaction, organization commitment and engagement?

4. Are background variables significantly related to and able to predict job embeddedness?

I utilized a census research design in the current study, and 454 Extension agents completed the survey instrument. This represented a $72 \%$ response rate. The UK Cooperative Extension Service currently employs 400 county Extension agents, of which $313(78 \%)$ voluntarily participated in this study. This compares to 231 Extension agents at $\mathrm{KSU}$, of which $141(61 \%)$ responded.

An array of scales was utilized to examine the relationships among variables. Scales that made up the survey instrument included a 41 -item embeddedness scale (Mitchell et al., 2001), a 15-item intent-to-stay scale (Hoisch, 2001), a 7-item 
discretionary-effort scale (Lloyd, 2008), a 3-item job-satisfaction scale (Luthans, 2007), a 6-item affective-commitment scale (Allen \& Meyer, 1990), and a 17-item employeeengagement scale (Rich et al., 2010). The six instruments and the demographic questions were incorporated into one online instrument. Table 3.3 shows which items related to each scale. A copy of the final survey instrument can be found in Appendix C.

The prevailing literature was examined and used to frame this research study. The results indicated that statistically significant differences in embeddedness were present between Kansas and Kentucky Extension agents.

\section{Interpretation and Discussion}

The following sections discuss the results of each research question. The analyses of these questions suggest that there were statistically significant relationships among the variables of interest.

\section{Research Question 1: Job Embeddedness of Kansas and Kentucky Extension Agents}

The first research question of the study examined whether job embeddedness differed significantly between KSU and UK Extension agents. An examination of the means of the individual states overall job-embeddedness scale did show some differences, indicating that UK Extension agents $(M=3.24)$ were somewhat more embedded than KSU Extension agents $(M=3.14)$. These results parallel the retention rates for UK (96.34\%) and KSU (95.40\%) Extension Services and seem to support the

proposition that higher job embeddedness will correspond to higher retention rates. These results are supported in the job embeddedness literature by the work of Mitchell, et al. (2001); Lee, et at. (2004); and Allen, (2006). 
ANOVA tests indicated statistically significant differences in job embeddedness scores between Kansas and Kentucky Extension agents. To obtain a more detailed picture of state differences, a MANOVA test examined the effects of state on the six components of job embeddedness (links organization, links community, fit organization, fit community, sacrifice organization, and sacrifice community). The tests of betweensubject effects revealed statistically significant differences in fit community and links organization by state.

The fit-community component of job embeddedness is designed to measure perceived comfort in the community. This is significant because of the unique ability of job embeddedness to identify important aspects of an employee's non-work life that increase the likelihood they will stay with their present employer. In this study UK Extension agents indicated a significantly higher mean score $(M=3.94)$ for fitcommunity than KSU Extension agents $(M=3.78)$. This would further indicate that UK Extension agents see themselves as somewhat more assimilated into their community, than KSU Extension agents. However, the differences in this analysis were small, and further research involving other state's Extension agents is recommended.

The links-organization component was designed to measure formal and informal relationships with coworkers and other connected to the organization. Results showed that UK Extension agents mean score $(M=2.02)$ for links-organization was significantly higher than that of KSU Extension agents $(M=1.62)$. These work relationships are very important as shown in the work of Felps et al. (2009) who found a negative correlation between coworker's job embeddedness and voluntary turnover. Generally, this means that if coworkers are highly embedded, you are less likely to leave and vice versa. 


\section{Research Question 2: Relationships Among Job Embeddedness, Intent to Stay, and Descritionary Effort}

This question examined the relationships between job embeddedness and its six components with intent to stay, and discretionary effort. First, I examined the mean scores of each component variable. The sacrifice-community means from both states $(M$ $=4.02$ ) were the highest among all job-embeddedness components. The sacrificecommunity component was designed to measure the bonds within the community that would be broken if individuals left and initially indicate the relative importance that Extension agents in both states place on community linkages.

Pearson correlations were examined next. The analysis showed significant positive correlations between job embeddedness and intent to stay and job embeddedness and discretionary effort.

Finally, Pearson correlations were also used to test for relationships between discretionary effort and the six previously mentioned job-embeddedness variables, all of which were significantly related. Total job-embeddedness was significantly related to discretionary effort $(r=.34)$. The component variable with the highest Pearson correlation was sacrifice community $(r=.27)$, and the component with the lowest Pearson correlation was links community $(r=.13)$.

Some interesting topics for future research would be to examine job embeddedness and discretionary effort levels over time. It would be interesting to know if discretionary effort levels remain steady or do the levels peak and regress over time. It would also be interesting to know if prolonged high discretionary effort levels are correlated with decreased retention and burnout. 
Importantly, the difference between the intent-to-stay means was not significant, and lower than I expected. This is concerning from an administrative perspective and could indicate that Extension agents are not as embedded to the Extension organization as I would have hoped, emphasizing the need to increase embeddedness levels in both states. This point is supported by research examining the relationships between professional and organizational loyalty and performance. Jauch, Glueck and Osborn (1978) in a study of university professors, found that organizational loyalty was not significantly related to productivity, however those with "strong professional commitment had higher research productivity"(p. 84). Clearly, additional research is needed to clear up this point.

The findings related to Research Question 2 indicate that as job embeddedness increases, both intent to stay and discretionary effort also increase. These findings are consistent with the research between job embeddedness (Mitchell et al., 2001) and intent to leave, which show negative correlations between variables, indicating that as jobembeddedness increases, intent-to-leave decreases (Lee et al., 2004).

\section{Research Question 3: Predicting Intent to Stay and Discretionary Effort}

This question examined the ability of job embeddedness and its six components to predict the outcome variable intent to stay after controlling for job satisfaction, organization commitment, and employee engagement.

A regression analysis was conducted between the dependent variable intent to stay and the predictor variables job satisfaction, organization commitment, employee engagement, sacrifice community, sacrifice organization, fit community, fit organization, links community, and links organization. 
All variables, except links organization and links community, were significantly related to intent to stay. Sacrifice organization had the highest correlation value $(r=.38)$.

Next, I conducted a linear regression between intent to stay, total job embeddedness, and its six components. Linear regression was used to help determine the prediction power of the independent variables. An examination of the beta coefficients showed that sacrifice organization and links organization were significant predictors of intent to stay.

These results could illustrate the value that Extension agents place on the benefits and relationships linking them to their organizations and the difficulty they may perceive in finding similar positions.

The sacrifice-organization beta coefficient had the highest predictive strength $(\beta=$ .16) of intent to stay. As the label implies, the sacrifice-organization items described employee perceptions of what would be lost if they left their organization.

The results showed that sacrifice organization and links organization explained $4 \%$ of the unique variance of the dependent variable intent to stay, after controlling for job satisfaction, organization commitment, and employee engagement. In total, the test explained $18 \%$ of the variance in intent to stay (Field, 2005).

Programs and benefits that might increase the level of sacrifice among Extension agents could include creative benefits packages, professional development, professional freedom, employee education, sabbatical leave, and opportunities to gain respect among peers (Mitchell et al., 2001). Most importantly is the issue of "insufficient pay and the amount of work expected" (Mowbray, 2001, p. 126). Mowbray found that Extension 
agents viewed their salary as "insufficient to live off of" which lead them to seek other job opportunities.

During recessionary periods with high unemployment rates, there are more job seekers than available jobs (Hall, 2005). It is possible that with fewer job alternatives available, Extension agents' perceived sacrifice of leaving or losing their positions would be magnified. However, this hypothesis contrasts with data regarding Extension agent retention rates, which are generally higher than the retention rates in other employment sectors, including similar sectors such as teaching, regardless of the larger economic conditions.

Mentoring of the newly hired by veteran employees is critical to the employeesocialization process. Mentoring helps eliminate feelings of isolation and helps the novice employee understand norms within the organization. Essential functions provided by the mentor include teaching, sponsoring, encouraging, counseling, and befriending (Schlichte et al., 2005). The relationships that are formed during the socialization process could increase the level of sacrifice that Extension agents would experience if they chose to leave their organization (Allen, 2006).

Giosan (2003) suggested that organizations hire individuals who perceive that they lack job alternatives, which could work to increase sacrifice-organization. These relationships would be an intriguing topic for future study.

The links-organization beta coefficient was relatively low and negative $(\beta=-.05)$. The negative value of the links-organization component could have been caused by individuals who were too heavily linked to their organization. Although this might not seem intuitive, very strong links to the organization could lead to conflict in other areas 
of one's life and eventually, lower levels of intent to stay (Mitchell, et al., 2001). In summary, at the .05 level of significance, the results provided sufficient evidence that sacrifice organization was a useful predictor for the dependent variable intent to stay (Fields, 2005).

Although HRD involves much more than implementing successful hiring practices (Swanson \& Holton, 2009), successful hiring is an essential organizational function. Practices that can be implemented by the organization to increase fitorganization begin with clear and consistent recruitment, careful screening, and productive interviews. Comp time, flex time and telecommuting are possible way to address this issue and improve Extension agent's perception of their fit in the organization, while demonstrating the organization's commitment to helping balance one's nonwork life. Finally, providing a structured mentoring experience and positive feedback, grouping structured orientation activities so that new employees can attend together, and providing clear information about the stages of the socialization process should also strengthen fit-organization (Allen, 2006).

\section{Research Question 4: Can Background Variables Help Predict Job Embeddedness?}

This question examined the relationships and predictive ability of background variables and job embeddedness. Only three correlations variables were correlated with job embeddedness, these variables were correlated with state, age, and years employed with Extension Services.

A regression analysis was utilized to examine the ability of the background variables to predict job embeddedness. The model summary included the independent variables age, education level, and state and yielded an adjusted $R^{2}$ value of .074 . This 
means that $7.4 \%$ of the unique variance in the dependent variable job embeddedness was explained by age, education level, and state. The regression output showed that age $(\beta=$ $.04)$, education level $(\beta=-.08)$, and state $(\beta=.14)$ all significantly predicted job embeddedness scores.

The effect of the variable state on job embeddedness has been addressed previously in this chapter. In addition to being able to significantly predict job embeddedness, state also predicted the fit-community, links-community and linksorganization components of job embeddedness. This could be interpreted to mean that Extension agents have strong affinity toward the community in which they live and the Extension organization of their respective states.

Previous research supports the effect of employee age on job embeddedness. A study by Abeslon (1987) found that older workers tended to have more organization-links and community-links and were less likely to leave their current employer. In addition, Giosam (2003) found that links-community and links-organization were predicted by age. These findings are supported by previous research (Fetsch \& Kennington, 1977; March \& Simon, 1958; Mobley et. Al, 1979; Muchinsky \& Tuttle, 1979; Porter \& Steers, 1973; Price, 1977; Rousan, 1995; Scott, Swortzel \& Taylor, 2005; VanTilburg, 1985; and Vlosky \& Dunn, 2009) that showed younger workers more likely to leave their positions than older workers and that years of employment is a significant predictor of job satisfaction (Long \& Swortzel, 2007). Beta coefficients for age dummy variables indicated that all were weaker predictor than the constant (22-27 years old) for sacrifice community. This trend was strongest for the group 62 years and up. This would tend to 
indicate that the negative influence of younger workers on job embeddedness outweighs the positive predictive ability of those 62 and up.

The variable education level significantly predicted links-community and linksorganization components. I was unable to locate studies on the effect of education level on job embeddedness in the United States. However, a large European-workforce study found that higher education increased the likelihood of turnover (Tanova \& Holtom, 2008). Tanova and Holtom (2008) found that higher education levels led to increased career opportunities and a higher likelihood that individuals would be willing to risk change careers. This would help explain the negative beta coefficient for linksorganization, but runs contrary to the purpose of the employee tuition education benefit provided by both universities. It could be that Extension agents take advantage of the opportunity to further their education and then decide to explore other job opportunities, including relocation to other communities, when degrees are completed. The dummy variables for master's degree and doctoral degree levels were stronger predictors of links community, but weaker than bachelor's degree for links organization. So perhaps the time needed to complete advanced degrees serves to link Extension agents to their communities.

These findings in regard to education level are supported in the literature by studies which examined professional verses organizational commitment. An early study by Lee (1970) noted the growing importance of organizational commitment among industrial psychologists and found that among the study population of university scientists, "those with high organizational identification were generally more productive, 
better motived and rewarded, more satisfied and less propensity to leave the organization than those scientists with low organizational identification" (p. 225).

Baugh \& Roberts (1994), in a study of 114 engineers found that the highest performers had high levels of both professional and organizational commitment, while those with the "lowest levels of satisfaction and performance reported low organizational commitment and high professional commitment" (p. 108).

County Population was not a significant predictor on total job embeddedness, however it was shown to significantly predict the links-organization component. In addition, regression analysis of the dummy variables showed that the predictive strength of this variable lies with those who work in the most rural locations whose populations are under 10,000 . This could mean that as population of the community increases the respondents links-organization scores would decrease. It is possible that in spite of greater job opportunities and networking potential, respondents in counties with larger populations fail to develop organizational links as strong as respondents in rural areas.

\section{Implications for Research}

An important implication regarding this study is that it expands job embeddedness research involving public employees. The bulk of past research has been with employees in the private sector. With that said, this study was only able to involve two of the fifty states and U.S. territories that employee Extension agents. The expanded use of the jobembeddedness survey instrument to Extension agents in other states and territories would provide additional data and could further clarify the relationships between job embeddedness and retention rates and understand the variability between states and territories. In addition, the list of pertinent background variables should be expanded 
beyond those examined in this study. Such variables could include data on local employment opportunities, local employment rates, performance ratings, availability of employee and family tuition benefits, membership in professional organizations, and employment of family members in Extension Services.

Longitudinal job-embeddedness research would also be useful in understanding how embeddedness changes over time. A variety of time periods could be selected, including monthly or yearly studies or studies based on particular events. Additionally, the use of structured qualitative exit interviews or case studies could add more depth to the field's understanding of job-embeddedness theory (Holtom et al., 2006).

Experimental studies would also be useful in adding to the depth of knowledge of job embeddedness. For example, an intervention effect related to job embeddedness could be measured and compared against a control group. For example, a control group could be made up of Extension agents with a bachelor's degree. The control group could complete the initial job-embeddedness survey instrument. Then, agents who later complete a more advanced degree (intervention) could complete the survey again. This would allow for comparisons between the two samples based on advanced degree attainment

In addition, a comparison study of professional workers (Extension agents), paraprofessional workers (program assistants), and office support staff would add another layer of understanding to the impact that job embeddedness has on employee retention. 


\section{Implications for Practice}

Thoughtful organizations are looking to decrease unnecessary expenses. In many organizations the expenses related to low employee retention represents an area worthy of attention. Human resource professionals can play an important role in impacting the organization's bottom line by understanding their retention challenges through the lens of job embeddedness. This includes examining employee links, fit, and sacrifice in organization and community contexts.

The results indicated that the largest variation of job embeddedness between Kansas and Kentucky Extension agents occurred in the area of links organization. Links organization considers the formal and informal connections that exist between an employee, other people, or groups within the organization (Mitchell et al., 2001). Along with links community $(M=1.86)$, links organization $(M=1.90)$ had the lowest mean scores out of the six job embeddedness components. For Kentucky Extension agents, the means for both links community $(M=1.89)$ and links organization $(M=2.02)$ were larger than those of Kansas Extension agents ( $M=1.80$ and $M=1.62$, respectively).

Initially, this information seems to suggest that employees do not see themselves as highly linked to either their organization or their communities. However, in the context of community linkages, many Extension agents live and work in very rural areas, where the opportunities for participation in workgroups and committee tend to be limited. This does not necessarily mean that they are less embedded. Still, it seems that high organizational retention rates are masking issues regarding Extension agent's intent to stay. 
One method that human resource professionals could implement to enhance organization links would be to cultivate interaction and teamwork among Extension agents. In a community context, Extension agent involvement and participation in local service organizations, professional groups, and places of worship would tend to increase their links to their community. Clearly, this is an area in need of further research. Dwovedila \& Bredillet (2010) studied 141 project managers and found that the formal job orientation had an important role in reinforcing the employee's decision to join the organization. The authors also found that workers "perceived professionalism helped moderate the strength of their organizational commitment" (p. 12)

The mean scores of sacrifice community $(M=4.02)$ were somewhat higher than the mean scores of sacrifice organization $(M=3.65)$. Sacrifice community is mostly an issue if individuals are forced to relocate. Leaving a community that is attractive, safe, and where one is liked or respected can be difficult. Of course, one can change jobs but stay in the same home. But even then, various conveniences such as an easy commute or flextime may be lost.

Sacrifice organization had the highest predictive ability on the variable intent to stay. Sacrifice-organization captures the perceived cost of material or psychological benefits forfeited by leaving one's job. For example, leaving an organization likely promises personal losses (e.g., giving up colleagues, projects, or perks). The more an employee gives up when leaving, the more difficult it is to sever employment with the organization.

Extension agents indicated that the perceived costs of leaving their community would be greater than the perceived costs of leaving their organization. Given the high 
profile that most Extension agents occupy within their local communities, this observation was not unexpected.

Human-resource professionals should seek to increase the perceived organization sacrifice of Extension agents; however, the scope of options available in public organizations can be more limited than in private organizations, especially in the area of salaries $(M=2.73)$ and promotional opportunities $(M=2.54)$. The mean scores for the two survey questions related to salaries and promotions were the lowest within the jobembeddedness component sacrifice-organization. According to the 2010 USDA Agricultural Research Service, Salary Analysis of Extension Service Positions, the average Extension agent salary in the U.S. and its territories was $\$ 54,442$. This compares to $\$ 51,200$ for Kansas Extension agents and $\$ 46,737$ for Kentucky Extension agents. Appendix P gives a national summary of Extension agent's salaries.

This suggests that Extension Services administrators should emphasize health and retirement benefits $(M=4.23)$, freedom to pursue professional goals $(M=4.04)$, the respect that Extension agents experience $(M=3.89)$, and prospects for continuing employment $(M=3.75)$ in marketing Extension Services to potential employees.

Discretionary effort is voluntary and exceeds the employer's expectations. It is this extra effort on the part of employees that helps some organizations "outperform" others (Lloyd, 2003). To promote discretionary effort in Extension agents, human resource professionals should emphasize the following sacrifice community items: friendships that Extension agents build in their communities $(M=4.05)$, the respect that Extension agents enjoy in their communities $(M=4.19)$, and neighborhood safety $(M=$ 4.24). 
Successful hiring is a key factor in how employees view themselves in an organization. The fit-organization item "I feel like I'm a good match for Extension" ( $M=$ 4.26, $S D .656$ ) yielded an $R^{2}$ change of .12 ; that is, this item explained $12 \%$ of the variance in discretionary effort. Human resource professionals should continue to place extreme importance on matching the right person to the organization.

Mowbray (2001, p. 142) noted the need for Extension administration to address the following issues which were related to the retention of Extension agents:

- Explore ways to share or shift workloads. Suggestions included shared positions, flexible work time and compensatory time.

- Explore new and creative delivery methods to decrease the number of night and weekend activities.

- Starting salaries should be kept competitive with benchmark institutions and similar jobs.

- Administration should do a better job in providing recruits with realistic expectations about the job.

- Administration should develop a formal exit interviewing process.

In summary, this study found that Extension agents "fit" well within the Extension organization and their local community. They also indicated that their "sacrifice" would be high if they chose to leave. The area of alarm for Extension Services HR professionals is the relatively low levels of "links" that Extension agents expressed through the survey instrument. Although retention rates have been both high and stable for Extension agents across various economic states, it is still quite possible that Extension agents will begin to turn over more once the economy improves and more job 
opportunities become available. These events and opportunities are described as shocks and are mediated by higher job embeddedness levels (Holtom et al., 2005). The study results illustrate a gap among respondents between organizational commitment and professional commitment.

\section{Recommendation for Future Research}

Job embeddedness may have organizational benefits other than helping to improve retention. For instance, job embeddedness might be related to reduced absenteeism, better job performance, and stronger organizational citizenship; such factors should be a topic of future research Mitchell et al. (2001).

There is also the possibility that high levels of embeddedness could decrease retention (Mitchell et al., 2001). For example, being highly linked within the organization and community could lead to unexpected job alternatives (Holtom et al., 2005). This is supported by the research of Tanova and Holtom, (2008), who found that higher education increased the likelihood of turnover. The authors reasoned that higher education levels lead to increased career opportunities and possibly make workers with additional education more likely to risk career changes.

Another possibility involves the difficulty that highly embedded employees could have balancing work and family responsibilities. We assume that employees with higher organizational embeddedness spend more of their available time involved in work related activities. Given that time is limited, logically there must reach a point where work life and personal life become unbalanced, leading to conflicts within the family and possibly undesired turnover. 
In a study of work-life issues, Beauregard \& Henry (2009) found that there were some ways that HRD could influence retention. They found that "the presence of supportive managers and organizational climates was important in decreasing (work-life) conflict (p. 30). They also found that work-life balance practices were often related to improved organizational performance and competitive advantage in recruitment, while "promoting employee interest in and obligation to the organization" (p. 30)

The successful response rate achieved in this study was made possible through the use of a well-crafted data collection plan (Dillman, 2009). In addition, support from the directors of the Kansas and Kentucky Extension services greatly helped communicate the purpose and benefits of the study to the study population. Researchers in future studies could use this tactic to improve response rates.

The list of independent variables considered in this study was limited by design. Additional questions not asked could include data on local employment opportunities, local employment rates, performance ratings, availability of employee- or family-tuition benefits, membership in professional organizations, and whether other family members were employed by Extension Services.

Research on the utility of age, tenure, and state of residence in predicting embeddedness is limited and deserves further investigation. Giosan (2003) found that age was a significant predictor of links community and links organization in a small urban organization. In a nationwide study of Extension agents and job satisfaction, Vlosky and Dunn (2009) found that age was correlated with satisfaction and income of Extension agents. In a study of Mississippi Extension agents, Long and Swortzel (2007) discovered that age was the best predictor of job satisfaction. 
Upon review of the results of the study, I would recommend that the original study model be amended as shown in Figure 5.1. The major change involved a stronger focus on intent to stay (our measure of retention) and a more limited use of the discretionary effort scale. This will allow future researchers to more clearly identify the ability of each variable to impact intent to stay.

In conclusion, the results of this study show that job embeddedness was significantly different between Kansas and Kentucky Extension agents. In addition, correlations were found between job embeddedness, intent to stay, and discretionary effort. Job embeddedness was also shown to explain unique variance in intent to stay and discretionary effort. Finally, the background variables state, age, and education level predicted variance in job embeddedness. The results of this study cannot be generalized to other states because of the many unique and valuable differences that exist in Extension Services organizations; however, the findings provide evidence of relationship between job embeddedness and retention indicators and demonstrate the predictive value of the job embeddedness construct. 


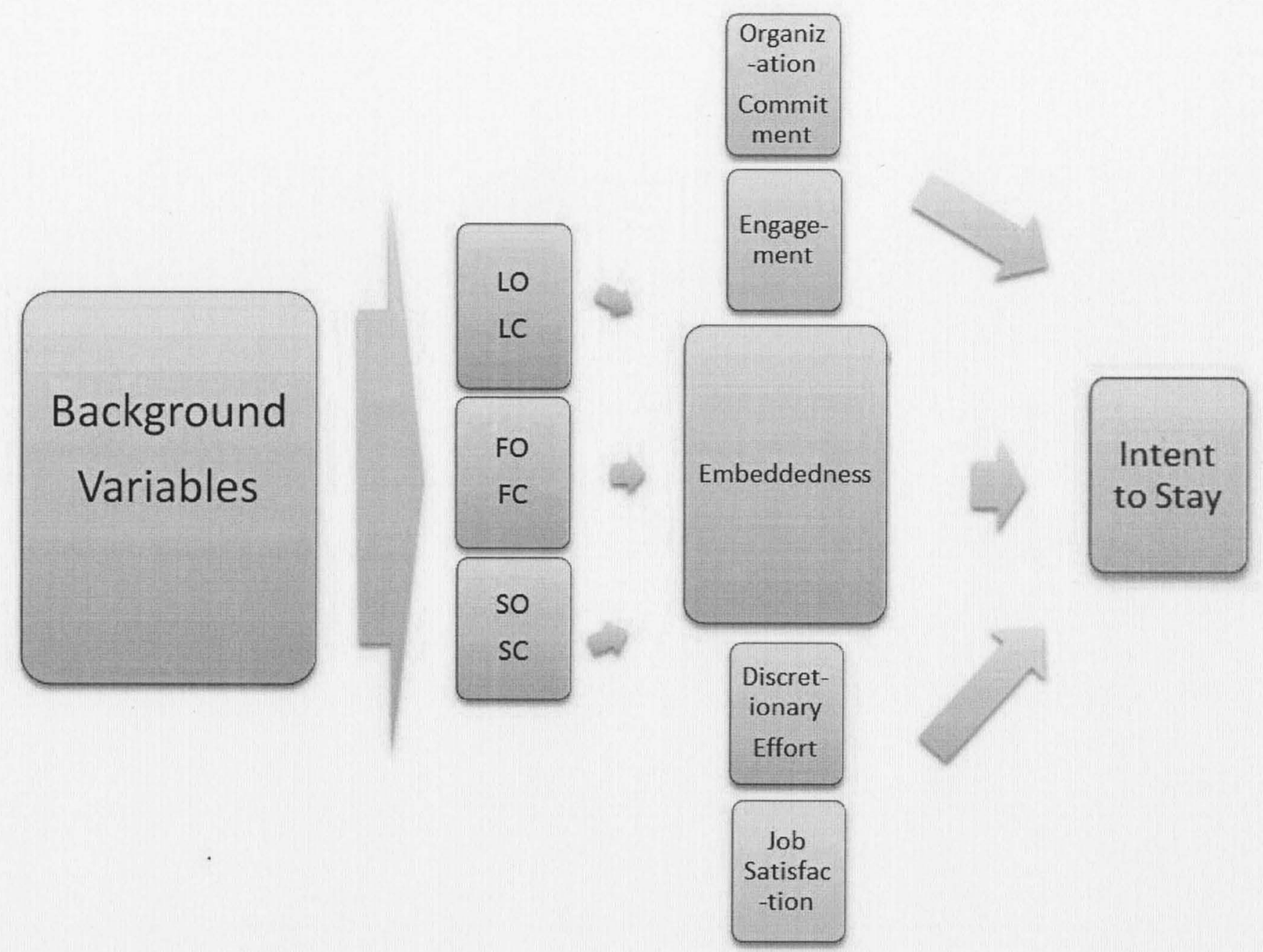

Figure 5.1. Recommended model for future studies. 


\section{REFERENCES}

Abelson, M. A., \& Baysinger, B. D. (1984). Optimal and dysfunctional turnover: Toward an organizational level model. The Academy of Management Review, 9, 331-341.

Abelson, M. A. (1987). Examination of avoidable and unavoidable turnover. Journal of Applied Psychology, 72, 382-386.

Allen, D. G. (2006). Do organization socialization tactics influence newcomer embeddedness and turnover? Journal of Management, 32, 237-256.

Allen, N. J., \& Meyer, J. P. (1990). The measurement and antecedents of affective, continuance and normative commitment to the organization. Journal of Occupational Psychology, 63, 1-18.

Amason, A. C. (1996). Distinguishing the effects of functional and dysfunctional conflict on strategic decision making: Resolving a paradox for top management teams. The Academy of Management Journal, 39, 123-148.

Armstrong-Stassen, M., \& Ursel, N. D. (2009). Perceived organizational support, career satisfaction, and the retention of older workers. Journal of Occupational and Organizational Psychology, 82, 201-220.

Arnold, S., \& Place, N. (2010). What influences agents to pursue a career in Extension? Journal of Extension, 48, 1-6.

Ashforth, B. E., \& Saks, A. M. (1996). Socialization tactics: Longitudinal effects on newcomer adjustment. Academy of Management Journal, 39, 149-178.

Ajzen, I., \& Fishbein, M. (1980). Understanding attitudes and predicting social behavior. Englewood Cliffs, NJ: Prentice Hall.

Babbie, E. (2007). The practice of social research (11th ed.). Belmont, CA: Wadsworth.

Baffour, B., \& Valente, P. (2008). Census quality assurance and evaluation. Geneva, Switzerland. Economic Commission for Europe, Conference of European Statisticians.

Bares, A. (2009, September). Re: 2009 Turnover rates by industry [Web log message]. Retrieved from http://compforce.typepad.com/compensation_force/2009/09/2009turnover-rates-by-industry.html 
Barnett, R., \& Louderback, L. (1971). When organizations change. Journal of Extension, 9, 9-15.

Baugh, S. G., \& Roberts, R. M. (1994). Professional and organizational commitment among engineers: conflicting or complementing? IEEE Transactions on Engineering Management, 41, 108-114.

Beauregard, T. A., \& Henry, L. C. (2009). Making the link between work-life balance practices and organizational performance. Human Resource Management Review, 19, 9-22. doi: http://dx.doi.org/10.1016/j.hrmr.2008.09.001

Black, J. S., \& Stevens, G. K. (1989). The influence of spouse on expatriate adjustment and intent to stay in overseas assignments. International Journal of Human Resource Management, 3, 585-592.

Borr, M. L., \& Young, R. B. (2010). Retirement and attrition trends of Extension professionals in North Dakota. Journal of Extension, 48, 1-8. Retrieved from http://www.joe.org/joe/2010february/rb4.php

Bredillet, C., \& Dwivedula, R. (2010). The relation between organizational and professional commitment in case of project workers: Implications for project management. PMI research conference: Defining the future of project management. Paper presented at the PMI Research Conference, Washington D.C. Retrieved from http://eprints.qut.edu.au/49519/

Burton, J. P., Holtom, B. C., Sablynski, C. J., Mitchell, T. R., \& Lee, T. W. (2010). The buffering effects of job embeddedness on negative shocks. Journal of Vocational Behavior, 76, 42-51.

Campion, M. A. (1991). Meaning and measurement of turnover: Comparison of alternative measures and recommendations for research. Journal of Applied Psychology, 76, 199-212.

Cardy, R. L., \& Lengnick-Hall, M. L. (2011). Will they stay or will then go? Exploring a customer-oriented approach to employee retention. Journal of Business Psychology, 26, 213-217.

Ciulla, J. B. (2000). The working life. New York, NY: Random House.

Clason, D. L., \& Dormody, T. J. (1994). Analyzing data measured by individual Likerttype items. Journal of Agricultural Education, 35, 31-35.

Clothier, R. C. (1916). Personnel and employment problems in industrial management. The American Academy of Political and Social Science, 65, 101. Retrieved from http://books.google.com/books?id=bH8QAAAAYAAJ\&dq=ford $\% 20$ motor $\% 20 \mathrm{c}$ ompany $\% 20$ turnover\&pg=PA101 
Cohen, J. (1988). Statistical power analysis for the behavioral sciences. San Diego, CA: Academic Press.

Colarelli, S. M. (1984). Methods of communication and mediating processes in realistic job previews. Journal of Applied Psychology, 69, 633-642.

Creswell, J. W. (2005). Educational research: Planning conducting and evaluating quantitative and qualitative research. Upper Saddle River, NJ: Merrill Prentice Hall.

Creswell, J. W. (2009). Research design: Qualitative, quantitative, and mixed methods approaches. Thousand Oaks, CA: Sage.

Crossley, C. D., Bennett, R. J., Burnfield, J. L., \& Jex, S. M. (2007). Development of a global measure of job embeddedness and integration into a traditional model of voluntary turnover. Journal of Applied Psychology, 92, 1031-1042.

Dalton, D. R., Krackhardt, D. M., \& Porter, L. W. (1981). Functional turnover: An empirical assessment. Journal of Applied Psychology, 66, 716-721.

Davis, P., Naughton, J., \& Rothwell, W. (2004). New roles and new competencies for the professional. $T D, 58,26-36$.

DeConinck, J. B., \& Johnson, J. T. (2009). The effects of perceived supervisor support, perceived organizational support, and organizational justice on turnover among salespeople. Journal of Personal Selling and Sales Management, 29, 333-350.

Dee, J. R. (2004). Turnover intent in an urban community college: Strategies for faculty retention. Community College Journal of Research and Practice, 28, 593-607.

Dillman, D. A., Smyth, J. D., \& Christian, L, M. (2009). Internet, mail and mixed-mode surveys. Hoboken, NJ: Wiley.

Discretionary effort. (n.d.). in Business Dictionary. Retrieved from http://www.businessdictionary.com/definition/discretionary-effort.html

Division of Human Resources. Retrieved September 22, 2011, from http://www.kstate.edu/hr/benefits/tuition.htm

Educational Benefits. (2011). In Extension Manual. Retrieved from: http://ces.ca.uky.edu/Extensionmanual/node/6?q=node/52

Emmerik, H. V., \& Sanders, K. (2004). Social embeddedness and job performance of tenured and non-tenured professionals. Human Resource Management Journal, $14,40-54$.

Employment Requirements. (2011). In Extension Manual. Retrieved from: http://ces.ca.uky.edu/Extensionmanual/node/3?q=node $/ 21$ 
Equity in Educational Land-Grant Status Act of 1994, 7 U.S.C. $\S 532$ (2006).

Felps, W., Mitchell, T. R., Hekman, D. R., Lee, T. W., Holtom, B. C., \& Harman, W. S. (2009). Turnover contagion: How coworkers' job embeddedness and job search behaviors influence quitting. Academy of Management Journal, 52, 545-561.

Fetsch, R. J., \& Kennington, M. S. (1997). Balancing work and family in cooperative Extension: History, effective programs, and future directions. Journal of Extension, 35(1), article 2.

Fletcher, R. E. A. (2005). Job embeddedness: A construct of organizational and community attachment utilized to assess voluntary turnover. Unpublished manuscript, Department of Systems and Engineering Management, Air Force Institute of Technology, Air University, Wright-Patterson Air Force Base, Ohio.

100 best companies to work for in 2009. (2009). Fortune magazine. Retrieved from http://money.cnn.com/magazines/fortune/bestcompanies/2009/full_list/index.html

Franklin, B. (1793/1909). The autobiography of Benjamin Franklin. New York, NY: Collier.

Fricker, R. D., \& Rand, M. S. (2002). Advantages and disadvantages of internet research surveys: Evidence from the literature. Field Methods, 14, 347-367.

Friedman, D., Galinsky, E., \& Plowden, V. (1992). Parental leave and productivity: Current research. New York, NY: Families and Work Institute.

Gitelman, H. M. (1992). Welfare capitalism reconsidered. Labor History, 33, 5-31.

Giosan, C. (2003). Predictors of job embeddedness (Bulletin no. 1). New York, NY: New School University.

Gravetter, F. J., \& Wallnau, L. B. (1985). Statistics for the behavioral sciences. St. Paul, MN: West.

Griffeth, R. W., Hom, P. W., \& Gaertner, S. (2000). A meta-analysis of antecedents and correlates of employee turnover: Update, moderator tests, and research implications for the next millennium. Journal of Management, 26(3), 463-488.

Groves, R. M. (2006). Nonresponse rates and nonresponse bias in household surveys. Public Opinion Quarterly, 70, 646-675.

Guthrie, J. P. (2000). Alternative pay practices and employee turnover: An organization economics perspective. Group and Organization Management, 45, 419-442.

Hackett, R. D. (1990). Age, tenure, and employee absenteeism. Human Relations, 42, 601-619. 
Halbesleben, J. R. B., \& Wheeler, A. R. (2008). The relative roles of engagement and embeddedness in predicting job performance and intention to leave. Work and Stress, 22, 242-256.

Hale, J. (1998). Strategic rewards: Keeping your best talent from walking out the door. Compensation \& Benefits Management, 14(3), 39-50.

Hall, R. E. (2006). Job loss, job finding and unemployment in the U.S. economy over the past 50 years. National Bureau of Economic Research, 20, 102-166.

Hannay, M., \& Northam, M. (2000). Low-cost strategies for employee retention. Compensation and Benefits Review, 32, 65-72.

Harman, W. S., Lee, T. W., Mitchell, T. R., Felps, W., \& Owens, B. P. (2007). The psychology of voluntary employee turnover. Association for Psychological Science, 16, 51-54.

Hauenstean, P. (1999). Understanding turnover. Advantage Hiring Newsletter Online. Retrieved from http://www.advantagehiring.com/newsletter/n99Q4_1.html

Hoisch, M. (2001), Organizational factors influencing longevity in professional, managerial and administrative employee retention. UMI Dissertation Services, No. 3038765 .

Holtom, B. C., Mitchell, T. R., Lee, T. W., \& Inderrieden, E. J. (2005). Shocks as causes of turnover: what they are and how organizations can manage them. Human Resource Management, 44, 337-352.

Holtom, B. C., Mitchell, T. R., \& Lee, T. W. (2006). Increasing human and social capital by applying job embeddedness theory. Organizational Dynamics, 35, 316-331.

Iglehart, A. P. (1990). Turnover in the social services: turning over to the benefits. Social Service Review, 64, 649-657.

Introduction. (2009). In Extension manual: A reference on policies and procedures for Extension agents. Retrieved from: http://ces.ca.uky.edu/Extensionmanual/

Iverson, S. V. (2008, February 1). Now is the time for change: Reframing diversity planning at land-grant universities. Journal of Extension, 46(1), 1-11.

Jacoby, S. M. (1997). Modern Manors: Welfare Capitalism since the New Deal. Princeton, New Jersey: Princeton University Press.

Jauch, L. R., Glueck, W. F., \& Osborn, R. N. (1978). Organizational loyalty, professional commitment, and academic research productivity. Academy of Management Journal, 21, 84-92. 
Johnson, B., \& Christensen, L. (2007). Educational Research: Quantitative, Qualitative, and Mixed Approaches. Thousand Oaks, California: Sage Publications.

Johnson, B., \& Christensen, L. (2010). Educational Research: Quantitative, Qualitative, and Mixed Approaches. Thousand Oaks, California: Sage Publications.

Judge, T. A., \& Cable Daniel M. (1997). Applicant personality, organizational culture, and organization attraction. Personnel Psychology, 50, 359-394.

Kahn, W. (1990). Psychological conditions of personal engagement and disengagement at work. Academy of Management Journal, 33, 692-724.

Kim, S., Price, J. L., Mueller, C. W., \& Watson, T. W. (1996). The determinants of career intent among physicians at the U.S. Air Force Hospital. Human Relations, 49, 947-976.

Kroth, M., \& Peutz, J. (2010). Workplace issues in Extension. Journal of Extension, 48, $1-9$.

Kutilek, L. M. (2000). Learning from those who leave. Journal of Extension, 38. Retrieved from http:/www.joe.org/joe/2000june/iw2.php

Kutilek, L. M., Conklin, N. L., \& Gunderson, G. (2002). Investing in the future: Addressing work/life issues of employees. Journal of Extension, 40. Retrieved from http://www.joe.org/joe/2002february/a6.php

Letvak, S., \& Buck, R. (2008). Factors influencing work productivity and intent to stay in nursing. Nursing Economics, 26, 159-165.

Lee, S. M. (1971). An empirical analysis of organizational identification. The Academy of Management Journal, 14, 213-223.

Lee, T. W., Mitchell, T. R., Holtom, B. C., McDaniel, L. S., \& Hill, J. W. (1999). The unfolding model of voluntary turnover: A replication and Extension. The Academy of Management Journal, 42, 450-462.

Lee, T. W., Mitchell, T. R., Holtom, B. C., Sablynski, J. P., \& Burton, J. P. (2004). The effects of job embeddedness on organizational citizenship, job performance, volitional absences, and voluntary turnover. Academy of Management Journal, $47,711-722$.

Lee, T. W., \& Mowday, R. T. (1987). Voluntarily Leaving an Organization: An Empirical Investigation of Steers and Mowday's Model of Turnover. The Academy of Management Journal, 30, 721-743.

Lloyd, R. (2003). Discretionary effort in the workplace. Unpublished thesis, Macquarie University, Sydney, Australia. 
Lloyd, R. (2008). Discretionary effort and the performance domain. Unpublished thesis, Macquarie University, Sydney, Australia.

Locke, E. A. (1969). What is job satisfaction? Organizational Behavior and Human Performance, 4, 309-336.

Long, J. L., \& Swortzel, K. A. (2007). Factors influencing job satisfaction of Extension agents in Mississippi state university [Conference proceedings] AAAE Research Conference (Vol. 34, pp. 41-53). Minneapolis, Minnesota: American Associate of Agricultural Education. Retrieved from http://aaae.okstate.edu/proceedings/2007/intro.pdf

Ludwig, B. G. (1995). What characterizes an internationalized U.S. Extension system? Journal of Agricultural and Extension Education, Fall, 28-32.

Lundy, L., Place, N. T., Irani, T., \& Telg, R. (2005, May). What in the world are they thinking? Perceptions of Extension personnel regarding internationalizing agricultural Extension. Association of International Agricultural and Extension Education 2005. Proceedings of the 21st Conference, San Antonio, Texas.

Luthans, B. C., \& Sommers, S. M. (1999). The impact of downsizing on workplace attitudes. Group and Organization Management, 24, 46-70.

Luthans, F., Norman, S. M., Avolio, B. J., \& Avey, J. B. (2008). The mediating role of psychological capital in the supportive organizational climate - employee performance relationship. Journal of Organizational Behavior, 29, 219-238.

Macey, W. H., \& Schneider, B. (2008). The meaning of employee engagement. Industrial and Organizational Psychology, 1, 3-30.

Maertz, C. P., \& Campion, M. A. (1998). 25 years of voluntary turnover research: a review and critique. International Review of Industrial and Organizational Psychology, 13, 49-81.

Mallol, C. M., Holtom, B. C., \& Lee, T. W. (2007). Job embeddedness in a culturally diverse environment. Journal of Business Psychology, 22, 35-44.

Maling, B. (2010). Building company loyalty with unusual benefits. HR World, Features. Retrieved September 28, 2010 from http:/www.hrworld.com/features/buildloyalty-unusual-benefits

March, R., \& Mannari, H. (1977). Organizational commitment and turnover: a predictive study. Administrative Science Quarterly, 22, 57-75.

Marens, R. S., Wicks, A. C., \& Huber, V. L. (1999). Cooperating with the disempowered using ESOP's to forge a stakeholder relationship by anchoring employee trust in workplace participation programs. Business Society, 38, 51-82. 
Maslow, A. (1954). Motivation and personality. New York, NY: Harper.

Mauch, J. E., \& Birch, J. W. (1993). Guide to the successful thesis and dissertation. New York, NY: Marcel Dekker.

Miller, L. E., \& Smith, K. L. (1983). Handling nonresponse issues. Journal of Extension, $21,45-50$.

Mitchell, T. R., Holtom, B. C., \& Lee, T. W. (2001). How to keep your best employees: Developing an effective retention policy. Academy of Management Executive, 15, 95-109.

Mitchell, T. R., Holtom, B. C., Lee, T. W., Sablynski, C. J., \& Erez, M. (2001). Why people stay: Using job embeddedness to predict voluntary turnover. The Academy of Management Journal, 44, 1102-1121.

Mobley, W. H., Griffeth, R. W., Hand, H. H., \& Meglino, B. H. (1979). Review and conceptual analysis of the employee turnover process. Psychological Bulletin, 8 , 493-522.

Morris, J. H., \& Sherman, J. D. (1981). Generalizability of an organizational commitment model. The Academy of Management Journal, 24, 512-526.

Mosher, A. E. (1995). Something better than the best: Industrial restructuring. Annals of the Association of American Geographers, 85, 84-107. Retrieved from http://www.jstor.org/stable/2564280?origin=JSTOR-pdf

Mowbray, J. (2001). Factors affecting turnover of county Extension agents in the University of Kentucky, Cooperative Extension Service (unpublished doctoral dissertation). University of Kentucky, Lexington, Kentucky.

Mowday, R. T., Porter, L. W., \& Steers, R. M. (1982). Employee-organization linkages: the psychology of commitment, absenteeism, and turnover. New York, NY: Academic Press.

Muchinsky, P. M., \& Tuttle, M. L. (1979). Employee turnover: An empirical and methodological assessment. Journal of Vocational Behavior, 14, 37-43.

Mustapha, N., Ahmad, A., Uli, J., \& Idris, K. (2010). Job characteristics as antecedents of intention to stay and mediating effects of work family facilitation and family satisfaction among single mothers in Malaysia. International Journal of Business and Social Science, 3, 59-74.

Myers, R. (1990). Classical and modern regression with applications (2nd ed.). Boston, MA: Duxbury. 
Nair, S. S. (2009, June 26). Employee retention. Articlesbase. Retrieved from http://www.articlesbase.com/human-resources-articles/employee-retention995426.html

Ng, T. W. H., \& Feldman, D. C. (2010). Organizational tenure and job performance. Journal of Management, 36, 12220-1250. DOI: 10.1177/0149206309359809

Nobscot Corporation. (2006). Retention management and metrics. 2006 employee turnover rates by sector. Retrieved November 13, 2010, from Nobscot Corporation: http://www.nobscot.com/survey/index.cfm

Ng, T. W. H., \& Butts, M. B. (2009). Effectiveness of organizational efforts to lower turnover intentions: The moderating role of employee locus of control. Human Resource Management, 48, 289-310.

Park, H. Y., Ofori-Dankwa, J., \& Bishop, D. R. (1994). Organizational and environmental determinants of functional and dysfunctional turnover: Practical and research implications. Human Relations, 47, 353-366.

Perk place: The benefits offered by Google and others may be grand, but they're all business. (2007). Retrieved from http://knowledge.wharton.upenn.edu/article.cfm ?articleid $=1690$

Plash, S., \& Piotrowshi, C. (2006). Retention issues: A study of Alabama special education teachers. Education, 127, 125-128.

Porter, L. W., \& Steers, R. M. (1973). Organizational, work and personal factors in employee turnover and absenteeism. Psychological Bulletin, 80, 151-176.

Price, J. (1977). The study of turnover. Ames, IA: Iowa State Press.

Punch, K. F. (1998). Introduction to social research, quantitative and qualitative approaches. London, England: Sage.

Prevosto, P. E., (1998). The effect of "mentored" relationships on satisfaction and intent to stay of company grade U.S. Army Reserve (USAR) nurses. Carlisle Barracks, PA: U.S. Army War College.

Prugh, C. C. (1998). Managing the career-mobile workforce. Compensation \& Benefits Management, 14, 31-38.

Rainey, H. G., \& Bozeman, B. (2000). Comparing public and private organizations: Empirical research and the power of the a priori. Journal of Public Administration Research and Theory, 10, 447-469.

Ramage, K. (2010). Summary of staffing models for Extension. Unpublished raw data. 
Ramlall, S. (2004). A review of employee motivation theories and their implications for employee retention within organizations. Journal of American Academy of Business, 5, 52-63.

Ramlall, S. (2003). Managing employee retention as a strategy for increasing organizational competitiveness. Applied H.R.M. Research, 8, 63-72.

Reips, U. (2000). The web experiment method: advantages, disadvantages, and solutions. In M.H. Birnbaum (Ed.), Psychology experiments on the Internet. New York: Academic Press.

Rich, B. L., Lepine, J. A., \& Crawford, E. R. (2010). Job engagement: antecedents and effects on job performance. Academy of Management Journal, 53, 617-635.

Richman, A. L., Civian, J. T., Shannon, L. L., Hill, E. J., \& Brennan, R. T. (2008). The relationship of perceived flexibility, supportive work-life policies, and use of formal flexible arrangements and occasional flexibility to employee engagement and expected retention. Community, Work and Family, 11, 183-197.

Roehling, P. V., Roehling, M. V., \& Moen, P. (2001). The relationship between work-life policies and practices and employee loyalty: A life course perspective. Journal of Family and Economic Issues, 22, 141-170.

Roethlisberger, F. J., \& Dickson, W. J. (1939). Management and the worker. Harvard University Press. Oxford, England.

Rousan, L. (1995). Agent turnover in Ohio State University Extension. Unpublished doctoral dissertation, The Ohio State University, Columbus.

Rosen, R. A., \& Rosen, H. (1955). A suggested modification in job satisfaction surveys. Personnel Psychology, 8, 304-314.

Rosenthal, R., \& Rosnow, R. L. (1975). The volunteer subject. New York, NY: Wiley.

Rosnow, R. L., \& Rosenthal, R. (1997). People studying people: artifacts and ethics in behavioral research. New York, NY: Freeman.

Rosser, V. J., \& Townsend, B. K. (2006). Determining public 2-year college faculty's intent to leave: An empirical model. Journal of Higher Education, 77, 125-151.

Royalty, A. B. (1998). Job-to-job and job-to-non-employment turnover by gender and education level. Journal of Labor Economics, 16, 392-433.

Rozina, I. N. (2002). Theory of communication and applied communication. Russian Journal of Communication, 1, 59-67. 
Ruth, R. T., \& Stewart, G. L. (1995). The satisfaction and retention of frontline employees: A customer satisfaction measurement approach. International Journal of Service Industry Management, 7, 62-80.

Safrit, R. D., \& Owen, M. B. (2010). A conceptual model for retaining county Extension program professionals. Journal of Extension, 48, 1-10.

Safrit, R. D., Gleim, R. R., Gleim, J. A., Owen, M., \& Sykes, W. (2009). A qualitative study of retention of North Carolina cooperative Extension county program professionals. American Association for Agricultural Education Research Conference (pp. 198-213). Louisville, Kentucky: American Associate of Agricultural Education.

Saks, A. M. (2006). Antecedents and consequences of employee engagement. Journal of Managerial Psychology, 21, 600-619.

Schlichte, J., Yssel, N., \& Merbler, J. (2005). Pathways to burnout: Case studies in teacher isolation and alienation. Preventing School Failure, 50, 35-41.

Scott, M., Swortzel, K. A., \& Taylor, W. N. (2005). Extension agents' perceptions of fundamental job characteristics and their level of job satisfaction. Journal of Southern Agricultural Education Research, 55, 88-101. Retrieved from http://www.jsaer.org/pdf/Vol55/55-01-088.pdf

Shadish, W. R., Cook, T. D., \& Campbell, D. T. (2002). Experimental and quasiexperimental designs for generalized causal inference. Belmont, CA: Wadsworth.

Shavelson, R. J. (1988). Statistical reasoning for the social sciences. Needham Heights, MA: Simon and Schuster.

Shaw, J. D., Delery, J. E., Jenkins, G. D., \& Gupta, N. (1998). An organization-level analysis of voluntary and involuntary turnover. The Academy of Management Journal, 41, 511-525.

Shuck, M. B. (2010). Employee engagement: an examination of antecedent and outcome variables (Doctoral Dissertation). Retrieved from http://digitalcommons. fiu.edu/etd/235/

Sleebos, E., Ellemers, N., \& Gilder, D. (2006). The carrot and the stick: affective commitment and acceptance anxiety as motives for discretionary group efforts by respected and disrespected group members. Personality and Social Psychology Bulletin, 32, pp. 244-255.

Smith Lever Act of 1914,7 U.S.C. $\S 341$ et seq.

Smith, S. A., Crow, S. M., \& Hartman, S. J. (2007). Attrition in nursing among black and white nurses. Journal of Nursing Management, 15, 357-366. 
Steers, R. M. (1977). Antecedents and outcomes of organizational commitment. Administrative Science Quarterly, 22, 46-56.

Stevens, J. P. (2009). Applied multivariate statistics for the social sciences. New York, NY: Rutledge.

Sum, A., \& Khatiwada, I. (2010). Underemployment in the "Great Recession." Monthly Labor Review, November, 3-15.

Tett, R. P., \& Meyer, J. P. (1993). Job satisfaction, organizational commitment, turnover intention, and turnover: Path analyses based on meta-analytic findings. Personnel Psychology, 46, 259-293.

Tanova, C., \& Holtom, B. C. (2008). Using job embeddedness factors to explain voluntary turnover in four European countries. The International Journal of Human Resource Management, 19, 1553-1568.

Morrill Act of 1862, 7 U.S.C. $\S 301$ (2006).

Morrill Act of 1890, 7 U.S.C. $\S 323$ (2006).

Hatch Act of 1887, 7 U.S.C. $§ 361$ a (2006).

Smith Lever Act of 1914, 7 U.S.C. $§ 342$ (2006).

Trochim, W. M. K. (2011). Types of Design. http://www.lib.wsc.ma.edu/webapa.htm

Tziner, A., \& Birati, A. (1996). Assessing employee turnover costs: A revised approach. Human Resource Management Review, 6, 113-122.

U.S. Census Bureau. (2009). Educational Attainment by state: 2009. Retrieved from: http://www.census.gov/compendia/statab/2011/tables/11s0229.pdf.

U.S. Department of Education Institute of Education Sciences. (2010). Fast facts [Education statistics] (National center for education statistics). Retrieved November 13, 2010, from U.S. Department of Education Institute of education sciences: http://nces.ed.gov/fastfacts/display.asp?id $=28$

U.S. Department of Agriculture, National Institute of Food and Agriculture, Extension. (n.d.) About Us. Retrieved from http://www.csrees.usda.gov/qlinks/Extension.html\#today

U.S. Department of Agriculture, National Institute of Food and Agriculture, Extension. (2000). Salary Analyses of Cooperative Extension Service Positions. Retrieved from http:/www.csrees.usda.gov/about/human_res/pdfs/report2000.pdf 
U.S. Department of Agriculture, National Institute of Food and Agriculture, Extension. (2010). Salary Analyses of Cooperative Extension Service Positions. Retrieved from http://www.csrees.usda.gov/about/human_res/pdfs/report2010.pdf

U.S Department of Commerce, Census Bureau. (2010). 2010 Census: How are census data used? Retrieved from https://ask.census.gov/app/answers/detail/a_id/7388 / /2010-census\%3A-how-are-census-data-used\%3F

U.S Department of Commerce, Census Bureau. (2010). Census Participation. Retrieved from http://2010.census.gov/2010census/take10map/

U.S. Bureau of Labor Statistics (2011). Labor Force Statistics from the Current Population Survey. Retrieved from http://www.bls.gov/cps/lfcharacteristics.htm \#unemp

Ulrich, D. (1997). Human resource champions: The next agenda for adding value and delivering results. Boston, MA: Harvard Business School Press.

Van Maanen, J., \& Schein, E. H. 1979. Towards a theory of organizational socialization. In B. M. Staw (Ed.), Research in organizational behavior, (vol. 1; pp. 209-264). Greenwich, CT: JAI.

Van Tilburg, E.L. (1985). Factors associated with the turnover intention of Ohio Cooperative Extension county agents. Unpublished doctoral dissertation. The Ohio State University, Columbus.

Vernon, S., \& Commander, C. (1998). Stay for pay: A retention solution. HR Focus, 75, $7-8$.

Vlosky, R. P., \& Aguilar, F. X. (2009). A model of employee satisfaction: Gender differences in Cooperative Extension. Journal of Extension, 47, 1-15.

Vlosky, R. P., \& Dunn, M. A. (2009). Cooperative Extension Services employee satisfaction in the workplace: Does race matter? Retrieved from http://www.Ifpdc.lsu.edu/publications/working_papers/wp86.pdf

Wefald, A. J., \& Downey, R. G. (2009). The construct dimensionality of engagement and its relationship with satisfaction. The Journal of Psychology: Interdisciplinarym and Applied, 143, 91-112.

Wiener, Y. (1982). Commitment in organizations: A normative view. The Academy of Management Review, 7, 418-428.

Wellins, R., \& Concelman, J. (2005). Personal engagement: Driving growth at the seelevel. Retrieved from www.ddiworld.com/pdf/ddi_personalengagement_ar.pdf 
Wheeler, A. R., Harris, K. J., \& Harvey, P. (2010). Moderating and mediating the HRM effectiveness-intent to turnover relationship: The roles of supervisors and job embeddedness. Journal of Managerial Issues.

Williams, C. R. (2000). Reward contingency, unemployment, and functional turnover. Human Resource Management Review, 9, 549-576.

Williams, L., \& Anderson, J. (1991). Job satisfaction and organizational commitment as predictors of organizational citizenship and in-role behaviors. Journal of Management, 17, 601-617.

Yankelovich, D., \& Immerwahr, J. (1984). Putting the work ethic to work. Society, 21(2), 58-76.

Yates, D., Moore, D., \& McCabe, G. (1999). The Practice of Statistics. New York, NY: Freeman.

Yu, J., \& Cooper, H. (1983). A quantitative review of the effects on response bias. Journal of Marketing Research, 20, 36-44. 


\section{APPENDIX A \\ U.S. UNEMPLOYMENT RATES \\ (U.S. BUREAU OF LABOR STATISTICS, 2011).}


Labor Force Statistics from the Current Population Surve)

\section{Original Data Value}

\begin{tabular}{|c|c|c|c|c|c|}
\hline $\begin{array}{l}\text { Series Id: } \\
\text { Seasonally Adjusted } \\
\text { Series title: } \\
\text { Labor force status: } \\
\text { Type of data: } \\
\text { Age: } \\
\text { Years: }\end{array}$ & $\begin{array}{l}\text { (Seas) Un } \\
\text { Unemploy } \\
\text { Percent o } \\
16 \text { years } \\
2001 \text { to } 2\end{array}$ & $\begin{array}{l}\text { nployme } \\
\text { ent rate } \\
\text { ate } \\
\text { d over } \\
1\end{array}$ & Rate & & \\
\hline Year & Jan & Feb & Mar & Apr & May \\
\hline 2001 & 4.2 & 4.2 & 4.3 & 4.4 & 4 \\
\hline 2002 & 5.7 & 5.7 & 5.7 & 5.9 & 5. \\
\hline 2003 & 5.8 & 5.9 & 5.9 & 6.0 & 6. \\
\hline 2004 & 5.7 & 5.6 & 5.8 & 5.6 & 5. \\
\hline 2005 & 5.3 & 5.4 & 5.2 & 5.2 & \\
\hline 2006 & 4.7 & 4.8 & 4.7 & 4.7 & 4 \\
\hline 2007 & 4.6 & 4.5 & 4.4 & 4.5 & 4 \\
\hline 2008 & 5.0 & 4.8 & 5.1 & 4.9 & 5 \\
\hline 2009 & 7.8 & 8.2 & 8.6 & 8.9 & 9 \\
\hline 2010 & 9.7 & 9.7 & 9.7 & 9.8 & 9 \\
\hline 2011 & 9.0 & 8.9 & 8.8 & 9.0 & \\
\hline
\end{tabular}

\begin{tabular}{rrrrrrrr}
\multicolumn{1}{c}{ Jun } & \multicolumn{1}{c}{ Jul } & \multicolumn{1}{c}{ Aug } & \multicolumn{1}{c}{ Sep } & \multicolumn{1}{c}{ Oct } & Nov & Dec \\
\hline 4.3 & 4.5 & 4.6 & 4.9 & 5.0 & 5.3 & 5.5 & 5.7 \\
5.8 & 5.8 & 5.8 & 5.7 & 5.7 & 5.7 & 5.9 & 6.0 \\
6.1 & 6.3 & 6.2 & 6.1 & 6.1 & 6.0 & 5.8 & 5.7 \\
5.6 & 5.6 & 5.5 & 5.4 & 5.4 & 5.5 & 5.4 & 5.4 \\
5.1 & 5.0 & 5.0 & 4.9 & 5.0 & 5.0 & 5.0 & 4.9 \\
4.6 & 4.6 & 4.7 & 4.7 & 4.5 & 4.4 & 4.5 & 4.4 \\
4.4 & 4.6 & 4.7 & 4.6 & 4.7 & 4.7 & 4.7 & 5.0 \\
5.4 & 5.6 & 5.8 & 6.1 & 6.2 & 6.6 & 6.8 & 7.3 \\
9.4 & 9.5 & 9.5 & 9.7 & 9.8 & 10.1 & 9.9 & 9.9 \\
9.6 & 9.5 & 9.5 & 9.6 & 9.6 & 9.7 & 9.8 & 9.4 \\
9.1 & 9.2 & 9.1 & 9.1 & 9.1 & & &
\end{tabular}


APPENDIX B

INSTITUTIONAL REVIEW BOARD APPROVAL CONFIRMATION

\section{BRAAN 2- Proceod Aetions - Univenity of Louiswilk}

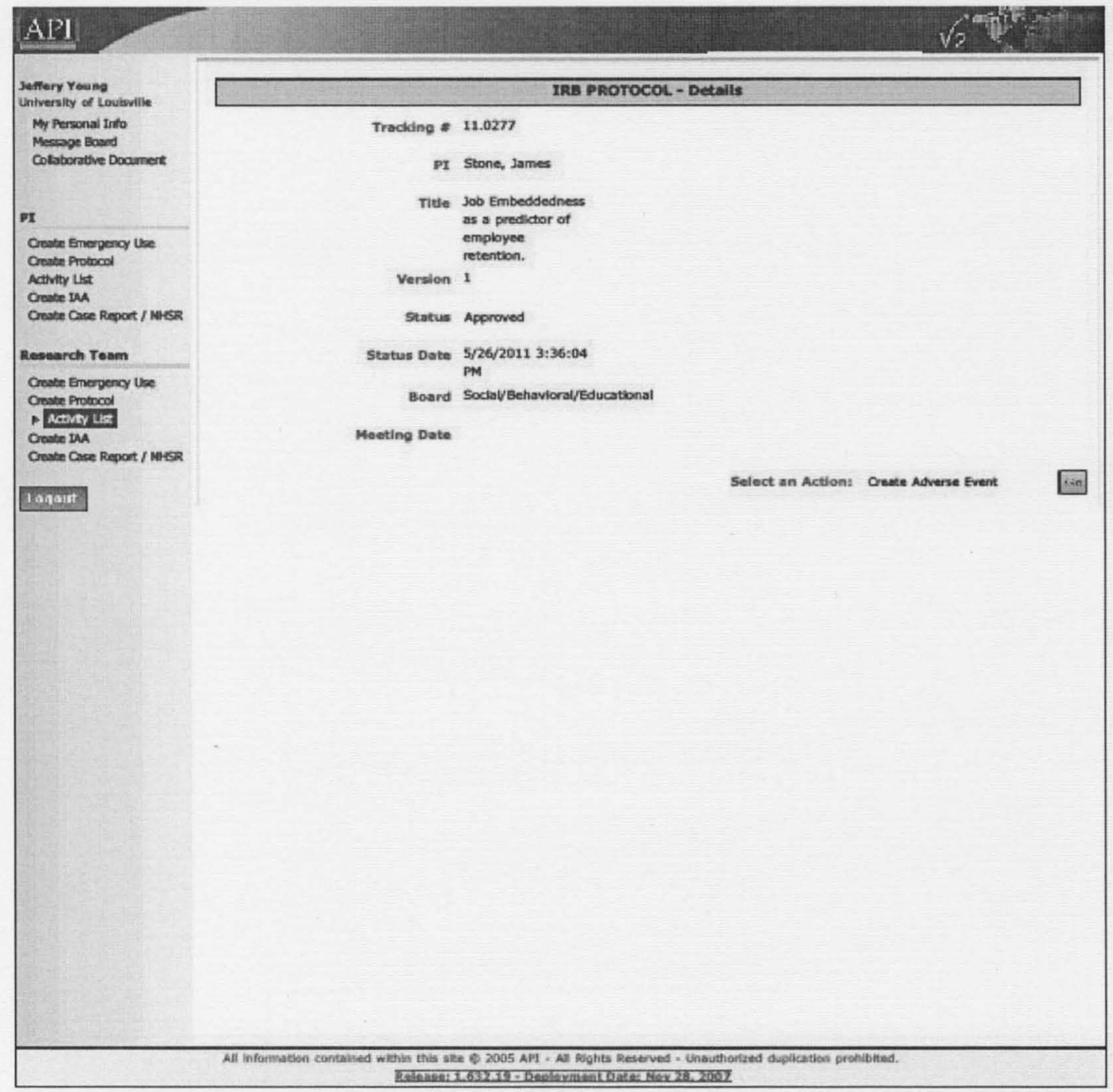




\title{
APPENDIX C
}

\section{SURVEY INSTRUMENT}

Thank you for participating.

\begin{abstract}
Informed Consent Form
Introduction

You are being invited to participate in a research study involving retention of Extension agents at Kansas State University and the University of Kentucky. High turnover (i.e. low retention) rates lead to substantial negative consequences for all organizations.

These costs include the financial expense of recruiting, hiring and retaining employees,
\end{abstract} and the loss of productivity during the time a position is vacant.

Though the exact costs related to turnover are difficult to determine, research estimates range from $\$ 80,000$ per employee (Kutilek, 2000) to $150 \%$ of position salary (Friedman, D., Galinsky, E., \& Plowden, V., 1992). The obvious implication is that as retention rates decrease, the associated costs negatively affect an organization's bottom line.

Individuals from the Department of Leadership, Foundations \& Human Resource Education, the Institutional Review Board (IRB), the Human Subjects Protection Program Office (HSPPO) at the University of Louisville and other regulatory agencies may inspect these records. In all other respects, however, the data will be held in confidence to the extent permitted by law. Should the data be published, your identity will not be disclosed.

Procedures

The survey will take approximately 20 minutes to complete. You will be asked to rate a list of questions on a 5 point Llikert Type or Multiple Choice Scales. All data will be collected electronically (on-line) or hard copy, through the use of this survey instrument. To ensure anonymity, each participant may be assigned a unique identification number, which will be necessary to complete the survey on-line (Dillman, 2009)

Risks/Discomforts

No known risks were identified for involvement in this study.

Benefits

There are no direct benefits for participants. However, it is hoped that through your participation, researchers will learn more about why Extension Agents choice to remain employed with Extension in Kansas and Kentucky..

Confidentiality

All data obtained from participants will be kept confidential and will only be reported in an aggregate format (by reporting only combined results and never reporting individual ones). All questionnaires will be concealed, and no one other than the primary investigator and assistant researches will have access to them. The data collected will be stored in the HIPPA-compliant, Qualtrics-secure database until it has been deleted by the primary investigator.

Compensation

There is no direct compensation for participants

Participation

Participation in this research study is completely voluntary. 
Questions about the Research

If you have questions regarding this study, you may contact Jeffery Young (District Director, University of Kentucky, Cooperative Extension Service, at 859-257-7484, jyoung@uky.edu or Dr. James Stone III at 502-8520639, james.stone@lou isville.edu.

Participation in this study, indicates your understanding and consent.

SC

Please base your answers of the following Likert Type Scale where applicable:

$1=$ Strongly Disagree; $2=$ Disagree; $3=$ Neither Agree nor Disagree, $4=$ Agree; $5=$ Strongly Agree

SC

Leaving my community would be very hard.

\begin{tabular}{|c|c|cc|cc|}
\hline & $\begin{array}{c}\text { Strongly } \\
\text { Disagree }\end{array}$ & Disagree & $\begin{array}{c}\text { Neither Agree } \\
\text { nor Disagree }\end{array}$ & Agree & Strongly Agree \\
\hline Choose One & 0 & 0 & 0 & 0 & 0
\end{tabular}

SC

People respect me a lot in my community.

\begin{tabular}{c|c|ccc|c|c|} 
& $\begin{array}{c}\text { Strongly } \\
\text { Disagree }\end{array}$ & Disagree & $\begin{array}{c}\text { Nether Agree nor } \\
\text { Disagree }\end{array}$ & Agree & Strongly Agree \\
Choose One & 0 & 0 & 0 & 0 & 0
\end{tabular}

SC

My neighborhood is safe.

\begin{tabular}{|l|c|cc|c|c|}
\hline & $\begin{array}{c}\text { Strongly } \\
\text { Disagree }\end{array}$ & Disagree & $\begin{array}{c}\text { Neither Agree } \\
\text { nor Disagree }\end{array}$ & Agree & Strongly Agree \\
\hline Choose One & 0 & 0 & 0 & 0 & 0 \\
\hline
\end{tabular}

SC

If I were to leave the community, I would miss my non-work friends.

\begin{tabular}{c|c|cc|cc|} 
& $\begin{array}{c}\text { Strongly } \\
\text { Disagree }\end{array}$ & Disagree & $\begin{array}{c}\text { Neither Agree } \\
\text { nor Disagree }\end{array}$ & Agree & Strongly Agree \\
\hdashline Choose One & 0 & 0 & 0 & 0 & 0
\end{tabular}

S C

If I were to leave the community, I would miss my neighborhood.

\begin{tabular}{|l|c|cc|cc|c|}
\hline & $\begin{array}{c}\text { Strongly } \\
\text { Disagree }\end{array}$ & Disagree & $\begin{array}{c}\text { Neither Agree } \\
\text { nor Disagree }\end{array}$ & Agree & Strongly Agree \\
\hline Choose One & 0 & 0 & 0 & 0 & 0
\end{tabular}

J S

Generally speaking, I am very satisfied with my job.

\begin{tabular}{|l|c|cc|cc|c|}
\hline & $\begin{array}{c}\text { Strongly } \\
\text { Disagree }\end{array}$ & Disagree & $\begin{array}{c}\text { Neither Agree } \\
\text { nor Disagree }\end{array}$ & Agree & Strongly Agree \\
\hline Choose One & 0 & 0 & 0 & 0 & 0
\end{tabular}


$11 / 23 / 11$

Qualtrics Survey Software

$\mathrm{JS}$

I am generally satisfied with the feeling of worthwhile accomplishment I get from doing my job.

\begin{tabular}{|c|c|c|c|c|c|}
\hline & $\begin{array}{l}\text { Strongly } \\
\text { Disagree }\end{array}$ & Disagree & $\begin{array}{l}\text { Neither Agree } \\
\text { nor Disagree }\end{array}$ & Agree & Strongly Agree \\
\hline Choose One & 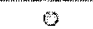 & 0 & 0 & 0 & 0 \\
\hline
\end{tabular}

JS

I am generally satisfied with the kind of work I do in my job.

\begin{tabular}{c|ccccc} 
& $\begin{array}{c}\text { Strongly } \\
\text { Disagree }\end{array}$ & Disagree & $\begin{array}{l}\text { Neither Agree } \\
\text { nor Disagree }\end{array}$ & Agree & Strongly Agree \\
Choose One & 0 & 0 & 0 & 0 & 0
\end{tabular}

A C

I feel a strong sense of belonging to Extension.

\begin{tabular}{|l|ccccc|c|}
\hline & $\begin{array}{c}\text { Strongly } \\
\text { Disagree }\end{array}$ & Disagree & $\begin{array}{c}\text { Neither Agree } \\
\text { nor Disagree }\end{array}$ & Agree & Strongly Agree \\
\hline Choose One & 0 & 0 & 0 & 0 & 0
\end{tabular}

AC

I feel personally attached to Extension.

\begin{tabular}{l|lcccc} 
Strongly & Disagree & $\begin{array}{l}\text { Neither Agree } \\
\text { nor Disagree }\end{array}$ & Agree & Strongly Agree \\
Choose One & 0 & 0 & 0 & 0 & 0
\end{tabular}

A C

I feel proud to tell others I work for Extension.

\begin{tabular}{|l|cc:cc|c|}
\hline & $\begin{array}{c}\text { Strongly } \\
\text { Disagree }\end{array}$ & Disagree & $\begin{array}{c}\text { Neither Agree } \\
\text { nor Disagree }\end{array}$ & Agree & Strongly Agree \\
\hline Choose One & 0 & 0 & 0 & 0 & 0
\end{tabular}

A C

Working in Extension has a great deal of personal meaning to me.

\begin{tabular}{l|ccccc} 
& $\begin{array}{c}\text { Strongly } \\
\text { Disagree }\end{array}$ & Disagree & $\begin{array}{c}\text { Neither Agree } \\
\text { norDisagree }\end{array}$ & Agree & Strongly Agree \\
\hline Choose One & 0 & 0 & 0 & 0 & 0
\end{tabular}

A C

I would be happy to work for Extension until I retire.

\begin{tabular}{l|ccccc} 
& $\begin{array}{c}\text { Strongly } \\
\text { Disagree }\end{array}$ & Disagree & $\begin{array}{l}\text { Neither Agree } \\
\text { nor Disagree }\end{array}$ & Agree & Strongly Agree \\
\hline Choose One & 0 & 0 & 0 & 0 & 0
\end{tabular}

AC

I really feel that problems faced by Extension are also my problems.

\begin{tabular}{l|c|c|cc|c|}
\hline & $\begin{array}{c}\text { Strongly } \\
\text { Disagree }\end{array}$ & Disagree & $\begin{array}{c}\text { Neither Agree } \\
\text { nor Disagree }\end{array}$ & Agree & Strongly Agree \\
\hline Choose One & 0 & 0 & 0 & 0 & 0
\end{tabular}

https:/new qualtrics. com/ControlPanel/PopUp.php?PopType=SurveyPrintPr... 
$\mathrm{F} \cdot \mathrm{C}$.

Please continue to base your answers of the following Likert Type Scale:

$1=$ Strongly Disagree; $2=$ Disagree; $3=$ Neither Agree nor Disagree, $4=$ Agree; $5=$ Strongly Agree

F C

I really love the place where I live.

\begin{tabular}{l|c|c|cc|c|}
\hline & $\begin{array}{c}\text { Strongly } \\
\text { Disagree }\end{array}$ & Disagree & $\begin{array}{c}\text { Neither Agree } \\
\text { nor Disagree }\end{array}$ & Agree & Strongly Agree \\
\hline Choose One & 0 & 0 & 0 & 0 & 0
\end{tabular}

FC

The weather where I live is suitable for me.

\begin{tabular}{c|cccccc} 
& $\begin{array}{c}\text { Strongly } \\
\text { Disagree }\end{array}$ & Disagree & $\begin{array}{c}\text { Neither Agree } \\
\text { nor Disagree }\end{array}$ & Agree & Strongly Agree \\
Choose One & 0 & 0 & 0 & 0 & 0
\end{tabular}

FC

This community (where I live) is a good match for me.

\begin{tabular}{l|ccccc|c}
\hline & $\begin{array}{c}\text { Strongly } \\
\text { Disagree }\end{array}$ & Disagree & $\begin{array}{c}\text { Neither Agree } \\
\text { nor Disagree }\end{array}$ & Agree & Strongly Agree \\
\hline Choose One & 0 & 0 & 0 & 0 & 0
\end{tabular}

FC

I think of the community where I live as home.

\begin{tabular}{l|ccccc} 
& $\begin{array}{c}\text { Strongly } \\
\text { Disagree }\end{array}$ & Disagree & $\begin{array}{c}\text { Neither Agree } \\
\text { nor Disagree }\end{array}$ & Agree & Strongly Agree \\
\hline Choose One & 0 & 0 & 0 & 0 & 0
\end{tabular}

$\mathrm{FC}$

The area where I live offers the leisure activities that I like, (sports, outdoors, cultural, arts)

\begin{tabular}{c|ccccc} 
& $\begin{array}{c}\text { Strongly } \\
\text { Disagree }\end{array}$ & Disagree & $\begin{array}{c}\text { Neither Agree } \\
\text { nor Disagree }\end{array}$ & Agree & Strongly Agree \\
Choose One & 0 & 0 & 0 & 0 & 0
\end{tabular}

$\mathrm{F}-\mathrm{O}$

Please continue to base your answers of the following Likert Type Scale:

1=Strongly Disagree; $2=$ Disagree; $3=$ Neither Agree nor Disagree, $4=$ Agree; $5=$ Strongly Agree

FO

I like the members of my county or district office.

\begin{tabular}{c|cc|ccc|c|} 
& $\begin{array}{c}\text { Strongly } \\
\text { Disagree }\end{array}$ & Disagree & $\begin{array}{c}\text { Neither Agree } \\
\text { nor Disagree }\end{array}$ & Agree & Strongly Agree \\
\hline Choose One & 0 & 0 & 0 & 0 & 0
\end{tabular}

FO 
Qualtrics Survey Software My coworkers (in my county or district office) are similar to me.

\begin{tabular}{|l|cc|ccc|}
\hline & $\begin{array}{c}\text { Strongly } \\
\text { Disagree }\end{array}$ & Disagree & $\begin{array}{c}\text { Neither Agree } \\
\text { norDisagree }\end{array}$ & Agree & Strongly Agree \\
Choose One & 0 & 0 & 0 & 0 & 0
\end{tabular}

$\mathrm{FO}$

My job utilizes my skills and talents well.

\begin{tabular}{|c|cc|ccc|} 
& $\begin{array}{c}\text { Strongty } \\
\text { Disagree }\end{array}$ & Disagree & $\begin{array}{c}\text { Neither Agree } \\
\text { nor Disagree }\end{array}$ & Agree & Strongly Agree \\
\hline Choose One & 0 & 0 & 0 & 0 & 0
\end{tabular}

$\mathrm{FO}$

I feel like l'm a good match for Extension.

\begin{tabular}{|c|c|c|c|c|c|}
\hline & $\begin{array}{l}\text { Strongly } \\
\text { Disagree }\end{array}$ & Disagree & $\begin{array}{l}\text { Neither Agree } \\
\text { nor Disagree }\end{array}$ & Agree & Strongly Agree \\
\hline Choose One & c & 0 & 0 & 0 & 0 \\
\hline
\end{tabular}

FO

My values are compatible with Extension's values.

\begin{tabular}{c|c|c|ccc} 
& $\begin{array}{c}\text { Strongly } \\
\text { Disagree }\end{array}$ & Disagree & $\begin{array}{c}\text { Neither Agree } \\
\text { norDisagree }\end{array}$ & Agree & Strongly Agree \\
\hline Choose One & 0 & 0 & 0 & 0 & 0
\end{tabular}

$\mathrm{F} \mathrm{O}$

I can reach my professional goals working for Extension.

\begin{tabular}{|l|cc|ccc} 
& $\begin{array}{c}\text { Strongly } \\
\text { Disagree }\end{array}$ & Disagree & $\begin{array}{c}\text { Neither Agree } \\
\text { nor Disagree }\end{array}$ & Agree & Strongly Agree \\
\hline Choose One & 0 & 0 & 0 & 0 & 0
\end{tabular}

$\mathrm{FO}$

I feel good about my professional growth and development.

\begin{tabular}{c|cc|ccc} 
& $\begin{array}{c}\text { Strongly } \\
\text { Disagree }\end{array}$ & Disagree & $\begin{array}{c}\text { Neither Agree } \\
\text { nor Disagree }\end{array}$ & Agree & Strongly Agree \\
\hline Choose One & 0 & 0 & 0 & 0 & 0
\end{tabular}

$\mathrm{FO}$

I fit with Extension's culture (shared attitudes, values and goals)

\begin{tabular}{c|c|c|ccc} 
& $\begin{array}{c}\text { Strongly } \\
\text { Disegree }\end{array}$ & Disagree & $\begin{array}{l}\text { Neither Agree } \\
\text { nor Disagree }\end{array}$ & Agree & Strongly Agree \\
\hline Choose One & 0 & 0 & 0 & 0 & 0
\end{tabular}

FO

If I stay with Extension, I will be able to achieve most of my professional goals.

\begin{tabular}{l|c|c|ccc} 
& $\begin{array}{c}\text { Strongly } \\
\text { Disagree }\end{array}$ & Disagree & $\begin{array}{l}\text { Neither Agree } \\
\text { nor Disagree }\end{array}$ & Agree & Strongly Agree \\
Choose One & 0 & 0 & 0 & 0 & 0
\end{tabular}

LO

Please choose the answer that best describes you or your situation. 
LO

How many years have you been in your present position?

$\begin{array}{cccccccc}0-5 & 6-10 & 11-15 & 16-20 & 21-25 & 26-30 & 30-35 & 35+ \\ 0 & 0 & 0 & 0 & 0 & 0 & 0 & 0\end{array}$

L O

How many coworkers (county or district office) do you interact with on a weekly basis?

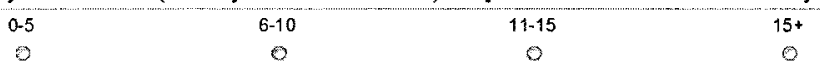

LO

How many coworkers (at county or district office) are highly dependent on you?

$0.566-10 \quad 11-15 \quad 15+$

LO

How many work teams (permanent work groups) are you on?

$\begin{array}{cccc}1-2 & 3-4 & 5-6 & 7+ \\ 0 & 0 & 0 & 0\end{array}$

LO

How many work committees (short term work groups) are you on?

$\begin{array}{cccc}1-2 & 3-4 & 5-6 & 7+ \\ 0 & 0 & 0 & 0\end{array}$

L C Please continue to base your answers of the following Likert Type or Single Answer Scale items where applicable:

$1=$ Strongly Disagree; $2=$ Disagree; $3=$ Neither Agree nor Disagree, $4=$ Agree; $5=$ Strongly Agree

LC

My family roots are in this community.

\begin{tabular}{l|c|cc|c|c}
\hline & $\begin{array}{c}\text { Strongly } \\
\text { Disagree }\end{array}$ & Disagree & $\begin{array}{c}\text { Neither Agree } \\
\text { nor Disagree }\end{array}$ & Agree & Strongly Agree \\
\hline Choose One & 0 & 0 & 0 & 0 & 0
\end{tabular}

LC

I am currently married.

$\begin{array}{cc}\text { Yes } & \text { No } \\ 0 & 0\end{array}$

LC

If married, my spouse works outside the home.

$\begin{array}{ccc}\text { Yes } & \text { No } & \text { N/A } \\ 0 & 0 & 0\end{array}$

LC

I own the home I live in (mortgaged or outright).

https:/new qualtrics.com/ControlPanel/PopUp.php?P op Type=SurveyPrintPr... 
LC How many family members live nearby?

$\begin{array}{ccc} & 4-6 & 6+ \\ 0 & 0 & 0\end{array}$

0

LC

How many of your close friends live nearby?

$\begin{array}{ccc}0-3 & 4-6 & 6+ \\ 0 & 0 & 0\end{array}$

LC

How long have you lived in your community?

$\begin{array}{cccc}0-9 \text { years } & 10-19 \text { years } & 20-29 \text { years } & 30+\text { years } \\ 0 & 0 & 0 & 0\end{array}$

so

Please continue to base your answers of the following Likert Type Scale where applicable:

$1=$ Strongly Disagree; $2=$ Disagree; $3=$ Neither Agree nor Disagree, $4=$ Agree; $5=$ Strongly Agree

so

I have a lot of freedom in my current job to decide how to pursue my goals.

\begin{tabular}{c|ccccc|c|c} 
& $\begin{array}{c}\text { Strongly } \\
\text { Disagree }\end{array}$ & Disagree & $\begin{array}{c}\text { Neither Agree } \\
\text { nor Disagree }\end{array}$ & Agree & Strongly Agree \\
\hline Choose One & 0 & 0 & 0 & 0 & 0
\end{tabular}

So

The benefits of this job are good (retirement, health...).

\begin{tabular}{l|lc|c|c|c} 
& (: $\begin{array}{c}\text { Strongly } \\
\text { Disagree }\end{array}$ & Disagree & $\begin{array}{c}\text { Neither Agree } \\
\text { nor Disagree }\end{array}$ & Agree & Strongly Agree \\
\hline Choose One & 0 & 0 & 0 & 0 & 0
\end{tabular}

SO

I feel that people at work respect me a great deal.

\begin{tabular}{c|cccccc} 
& $\begin{array}{c}\text { Strongly } \\
\text { Disagree }\end{array}$ & Disagree & $\begin{array}{c}\text { Neither Agree } \\
\text { nor Disagree }\end{array}$ & Agree & Strongly Agree \\
Choose One & 0 & 0 & 0 & 0 & 0
\end{tabular}

so

I would sacrifice a lot if | left this job.

\begin{tabular}{c|ccccc|c} 
& $\begin{array}{c}\text { Strongly } \\
\text { Disagree }\end{array}$ & Disagree & $\begin{array}{c}\text { Neither Agree } \\
\text { nor Disagree }\end{array}$ & Agree & Strongly Agree \\
\hline Choose One & 0 & 0 & 0 & 0 & 0
\end{tabular}

so

My promotional opportunities (within Extension) are excellent here. 


\begin{tabular}{|c|c|c|c|c|c|}
\hline \multicolumn{6}{|c|}{ Qualtrics Survey Software } \\
\hline & $\begin{array}{c}\text { Strongy } \\
\text { Disagree }\end{array}$ & Disagree & $\begin{array}{l}\text { Nelmer Agree } \\
\text { nor Disagree }\end{array}$ & Agree & Strongly Agree \\
\hline Choose One & 0 & 0 & 6 & 0 & 0 \\
\hline
\end{tabular}

so

I am well compensated for my level of performance.

\begin{tabular}{|l|c|c|c|c|c|}
\multicolumn{1}{c|}{} & $\begin{array}{c}\text { Strongly } \\
\text { Disagree }\end{array}$ & Disagree & $\begin{array}{c}\text { Neither Agree } \\
\text { nor Disagree }\end{array}$ & Agree & Strongly Agree \\
\hline Choose One & 0 & 0 & 0 & 0 & 0
\end{tabular}

so

The perks on this job are good.

\begin{tabular}{|l|c|c|cc|c|}
\hline & $\begin{array}{c}\text { Strongly } \\
\text { Disagree }\end{array}$ & Disagree & $\begin{array}{c}\text { Neither Agree } \\
\text { nor Disagree }\end{array}$ & Agree & StronglyAgree \\
\hline Choose One & 0 & 0 & 0 & 0 & 0
\end{tabular}

SO

The health-care benefits provided by this organization are excellent.

\begin{tabular}{|l|c|c|c|cc|}
\hline & $\begin{array}{c}\text { Strongly } \\
\text { Disagree }\end{array}$ & Disagree & $\begin{array}{c}\text { Neither Agree } \\
\text { nor Disagree }\end{array}$ & Agree & Strongly Agree \\
\hline Choose One & 0 & 0 & 0 & 0 & 0
\end{tabular}

So

The retirement benefits provided by this organization are excellent.

\begin{tabular}{|c|c|c|c|c|c}
\hline & $\begin{array}{c}\text { Strongly } \\
\text { Disagree }\end{array}$ & Disagree & $\begin{array}{c}\text { Neither Agree } \\
\text { nor Disagree }\end{array}$ & Agree & Strongly Agree \\
\hdashline Choose One & 0 & 0 & 0 & 0 & 0
\end{tabular}

so

I believe the prospects for continuing employment with this organization are excellent.

\begin{tabular}{|c|c|c|c|c|c|}
\hline & $\begin{array}{l}\text { Strongly } \\
\text { Disagree }\end{array}$ & Disagree & $\begin{array}{l}\text { Neither Agree } \\
\text { nor Disagree }\end{array}$ & Agree & Strongly Agree \\
\hline Choose One & 0 & 0 & 0 & 0 & 0 \\
\hline
\end{tabular}

DES

When I work, I really exert myself to the fullest, beyond what is expected.

\begin{tabular}{|l|c|c|c|c|c|}
\hline & $\begin{array}{c}\text { Strongly } \\
\text { Disagree }\end{array}$ & Disagree & $\begin{array}{c}\text { Neither Agree } \\
\text { nor Disagree }\end{array}$ & Agree & Strongly Agree \\
\hline Choose One & 0 & 0 & 0 & 0 & 0
\end{tabular}

DES

I finish a job even if it means sacrificing breaks or lunches.

\begin{tabular}{|c|c|c|ccc|} 
& $\begin{array}{c}\text { Strongly } \\
\text { Disagree }\end{array}$ & Disagree & $\begin{array}{c}\text { Neither Agree } \\
\text { nor Disagree }\end{array}$ & Agree & Strongly Agree \\
\hline Choose One & 0 & 0 & 0 & 0 & 0
\end{tabular}

DES

I do more than is expected of me. 
$11 / 23 / 11$

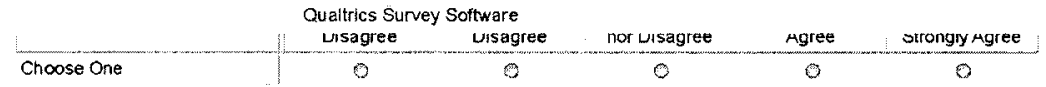

DES

I voluntarily put in extra hours to achieve a result faster.

\begin{tabular}{|l|cc|c|c|c|}
\hline & $\begin{array}{c}\text { Strongly } \\
\text { Disagree }\end{array}$ & Disagree & $\begin{array}{c}\text { Neither Agree } \\
\text { nor Disagree }\end{array}$ & Agree & Strongly Agree \\
\hline Choose One & 0 & 0 & 0 & 0 & 0
\end{tabular}

DES

I persist in overcoming obstacles to complete an important task.

\begin{tabular}{|l|ccccc|c|}
\hline & $\begin{array}{c}\text { Strongly } \\
\text { Disagree }\end{array}$ & Disagree & $\begin{array}{c}\text { Neither Agree } \\
\text { nor Disagree }\end{array}$ & Agree & Strongly Agree \\
\hline Choose One & 0 & 0 & 0 & 0 & 0
\end{tabular}

DES

I put in extra effort when I find it necessary.

\begin{tabular}{|c|c|c|c|c|c|}
\hline & $\begin{array}{l}\text { Strongly } \\
\text { Disagree }\end{array}$ & Disagree & $\begin{array}{l}\text { Neither Agree } \\
\text { nor Disagree }\end{array}$ & Agree & Strongly Agree \\
\hline Choose One & 0 & 0 & 0 & 0 & 8 \\
\hline
\end{tabular}

DES

I work harder than expected to help Extension be successful.

\begin{tabular}{|l|ccccc|c|}
\hline & $\begin{array}{c}\text { Strongly } \\
\text { Disagree }\end{array}$ & Disagree & $\begin{array}{c}\text { Neither Agree } \\
\text { nor Disagree }\end{array}$ & Agree & Strongly Agree \\
\hline Choose One & 0 & 0 & 0 & 0 & $\$$
\end{tabular}

EES

I work with intensity on my job.

\begin{tabular}{|c|ccc|c|c|}
\hline & $\begin{array}{c}\text { Strongly } \\
\text { Disagree }\end{array}$ & Disagree & $\begin{array}{c}\text { Neither Agree } \\
\text { nor Disagree }\end{array}$ & Agree & Strongly Agree \\
\hline Choose One & 0 & 0 & 0 & 0 & 0 \\
\hline
\end{tabular}

E E S

l exert my full effort to my job.

\begin{tabular}{|l|cccc|c|}
\hline & $\begin{array}{c}\text { Strongly } \\
\text { Disagree }\end{array}$ & Disagree & $\begin{array}{c}\text { Neither Agree } \\
\text { ner Disagree }\end{array}$ & Agree & Strongly Agree \\
\hline Choose One & 0 & 0 & 0 & 0 & $\emptyset$
\end{tabular}

E ES

I devote a lot of energy to my job.

\begin{tabular}{|l|cccccc|}
\hline & $\begin{array}{c}\text { Strongly } \\
\text { Disagree }\end{array}$ & Disagree & $\begin{array}{c}\text { Neither Agree } \\
\text { nor Disagree }\end{array}$ & Agree & Strongly Agree \\
\hline Choose One & 0 & 0 & 0 & 0 & 0
\end{tabular}


EES

I try my hardest to perform well on my job.

\begin{tabular}{l|cc|c|c|c|} 
& $\begin{array}{c}\text { Strongly } \\
\text { Disagree }\end{array}$ & Disagree & $\begin{array}{c}\text { Neither Agree } \\
\text { nor Disagree }\end{array}$ & Agree & Strongly Agree \\
\hline Choose One & 0 & 0 & 0 & 0 & $\emptyset$
\end{tabular}

EES

I strive as hard as I can to complete my job.

\begin{tabular}{|c|cc|c|c|c|} 
& $\begin{array}{c}\text { Strongly } \\
\text { Disagree }\end{array}$ & Disagree & $\begin{array}{c}\text { Neither Agree } \\
\text { nor Disagree }\end{array}$ & Agree & Strongly Agree \\
\hline Choose One & 0 & 0 & 0 & 0 & 0
\end{tabular}

E ES

I exert a lot of energy on my job.

\begin{tabular}{|c|c|c|c|c|c|}
\hline & $\begin{array}{l}\text { Strongly } \\
\text { Disagree }\end{array}$ & Disagree & $\begin{array}{l}\text { Neither Agree } \\
\text { nor Disagree }\end{array}$ & Agree & Strongly Agree \\
\hline Choose One & 0 & 0 & 0 & o & 0 \\
\hline
\end{tabular}

EES

I am enthusiastic in my job.

\begin{tabular}{|c|c|c|c|c|c|}
\hline & $\begin{array}{c}\text { Strongly } \\
\text { Disagree }\end{array}$ & Disagree & $\begin{array}{l}\text { Neither Agree } \\
\text { nor Disagree }\end{array}$ & Agree & Strongly Agree \\
\hline Choose One & 0 & P & $\odot$ & 6 & 0 \\
\hline
\end{tabular}

EES

I feel energetic at my job.

\begin{tabular}{l|lcc|c|c} 
& Strongly & Disagree & $\begin{array}{c}\text { Neither Agree } \\
\text { nor Disagree }\end{array}$ & Agree & Strongly Agree \\
\hline Choose One & 0 & 0 & 0 & 0 & 0
\end{tabular}

EES

I am interested in my job.

$\left[\begin{array}{cccccc}\begin{array}{c}\text { Strongly } \\ \text { Disagree }\end{array} & \text { Disagree } & \begin{array}{c}\text { Neither Agree } \\ \text { nor Disagree }\end{array} & \text { Agree } & \text { Strongly Agree } \\ \text { Choose One } & 0 & 0 & 0 & 0 & 0\end{array}\right.$

EES

I am proud of my job.

\begin{tabular}{c|ccccc|c} 
& $\begin{array}{c}\text { Strongly } \\
\text { Disagree }\end{array}$ & Disagree & $\begin{array}{c}\text { Neither Agree } \\
\text { nor Disagree }\end{array}$ & Agree & Strongly Agree \\
\hline Choose One & 0 & 0 & 0 & 0 & 0
\end{tabular}

EES

I feel positive about my job.

\begin{tabular}{c|cccc|c|c|} 
& $\begin{array}{c}\text { Strongly } \\
\text { Disagree }\end{array}$ & Disagree & $\begin{array}{c}\text { Neither Agree } \\
\text { nor Disagree }\end{array}$ & Agree & Strongly Agree \\
\hline Choose One & 0 & 0 & 0 & 0 & 0
\end{tabular}

E ES 


\begin{tabular}{|l|cc|c|c|c|}
\hline & $\begin{array}{c}\text { Strongly } \\
\text { Dlsagree }\end{array}$ & Disagree & $\begin{array}{c}\text { Neither Agree } \\
\text { nor Disagree }\end{array}$ & Agree & Strongly Agree \\
\hline Choose One & 0 & 0 & 0 & 0 & 0
\end{tabular}

EES

At work, my mind is focused on my job.

\begin{tabular}{l|cc|c|c|c} 
& $\begin{array}{c}\text { Strongly } \\
\text { Disagree }\end{array}$ & Disagree & $\begin{array}{c}\text { Neither Agree } \\
\text { nor Disagree }\end{array}$ & Agree & Strongly Agree \\
\hline Choose One & 0 & 0 & 0 & 0 & 5
\end{tabular}

EES

At work, I focus a great deal of attention on my job.

\begin{tabular}{l|cc|ccc} 
& $\begin{array}{c}\text { Strongly } \\
\text { Disagree }\end{array}$ & Disagree & $\begin{array}{c}\text { Neither Agree } \\
\text { nor Disagree }\end{array}$ & Agree & Strongly Agree \\
Choose One & & 0 & 0 & 0 & 0
\end{tabular}

EES

At work, I'm absorbed in my job.

\begin{tabular}{l|cc|c|c|c} 
& $\begin{array}{c}\text { Strongly } \\
\text { Disagree }\end{array}$ & Disagree & $\begin{array}{c}\text { Neither Agree } \\
\text { nor Disagree }\end{array}$ & Agree & Strongly Agree \\
Choose One & 0 & 0 & 0 & 0 & 0
\end{tabular}

EES

At work, I concentrate on my job.

\begin{tabular}{|c|c|c|c|c|c|}
\hline & $\begin{array}{l}\text { Strongly } \\
\text { Disagree }\end{array}$ & Disagree & $\begin{array}{l}\text { Neither Agree } \\
\text { nor Disagree }\end{array}$ & Agree & Strongly Agree \\
\hline Choose One & 0 & 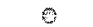 & 0 & 0 & $p$ \\
\hline
\end{tabular}

EES

At work, I devote a lot of attention to my job.

\begin{tabular}{l|ccccc}
\hline & $\begin{array}{c}\text { Strongly } \\
\text { Disagree }\end{array}$ & Disagree & $\begin{array}{c}\text { Neither Agree } \\
\text { nor Disagree }\end{array}$ & Agree & Strongly Agree \\
Choose One & 0 & 0 & 0 & 0 & 0
\end{tabular}

ITS

For the following questions, please choose the answer that best applies: $1=$ Strongly Disagree; $2=$ Disagree; $3=$ Neither Agree nor Disagree, $4=$ Agree; $5=$ Strongly Agree

ITS

In the past, it would have been easy to find a job that would make me consider leaving Extension.

\begin{tabular}{|c|cc|c|c|c} 
& $\begin{array}{c}\text { Strongly } \\
\text { Disagree }\end{array}$ & Disagree & $\begin{array}{c}\text { Neither Agree } \\
\text { nor Disagree }\end{array}$ & Agree & Strongty Agree \\
\hline Choose One & 0 & 0 & 0 & 0 & 0
\end{tabular}

ITS

It would be easy to find a job now that is good enough to consider kaving Extension. 


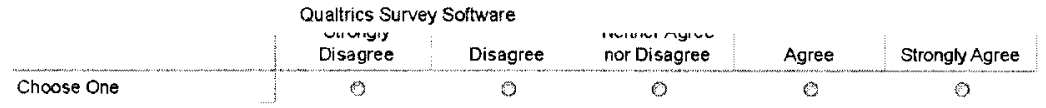

ITS

I have considered accepting a position with another company or organization.

\begin{tabular}{l|c|c|c|c|c|} 
& $\begin{array}{c}\text { Strongly } \\
\text { Disagree }\end{array}$ & Disagree & $\begin{array}{c}\text { Neither Agree } \\
\text { nor Disagree }\end{array}$ & Agree & Strongly Agree \\
\hline Choose One & 0 & 0 & 0 & 0 & 0
\end{tabular}

ITS

In the past, it would be easy to find a job that is better than my current one.

\begin{tabular}{|c|c|cc|c|c|} 
& $\begin{array}{c}\text { Strongly } \\
\text { Disagree }\end{array}$ & Disagree & $\begin{array}{c}\text { Neither Agree } \\
\text { nor Disagree }\end{array}$ & Agree & Strongly Agree \\
\hline Choose One & 0 & 0 & 0 & 0 & 0
\end{tabular}

ITS

It would be easy to find a job now that is better than my current one.

\begin{tabular}{c|c|cccc|c|} 
& $\begin{array}{c}\text { Strongly } \\
\text { Disagree }\end{array}$ & Disagree & $\begin{array}{c}\text { Neither Agree } \\
\text { nor Disagree }\end{array}$ & Agree & Strongly Agree \\
\hline Choose One & 0 & 0 & 0 & 0 & 0
\end{tabular}

ITS

(If younger than 65 years of age) I plan to retire at age 65

\begin{tabular}{c|cc|cc|c|c|c} 
& $\begin{array}{c}\text { Strongly } \\
\text { Disagree }\end{array}$ & Disagree & $\begin{array}{c}\text { Neither Agree } \\
\text { nor Disagree }\end{array}$ & Agree & $\begin{array}{c}\text { Strongly } \\
\text { Agree }\end{array}$ & N/A \\
\hline Choose One & 0 & 0 & 0 & 0 & 0 & 0
\end{tabular}

ITS

(If older than 65 years of age) I have considered retirement.

\begin{tabular}{l|c|c|c|c|c|c} 
& (1) Strongly \\
Disagree & Disagree & $\begin{array}{l}\text { Neither Agree } \\
\text { nor Disagree }\end{array}$ & Agree & $\begin{array}{c}\text { Strongly } \\
\text { Agree }\end{array}$ & Na \\
\hline Choose One & 0 & 0 & 0 & 0 & 0 & 0
\end{tabular}

ITS

I would consider accepting an early retirement opportunity.

\begin{tabular}{|c|c|c|c|c|c|}
\hline & $\begin{array}{l}\text { Strongly } \\
\text { Disagree }\end{array}$ & Disagree & $\begin{array}{l}\text { Neither Agree } \\
\text { nor Disagree }\end{array}$ & Agree & Strongly Agree \\
\hline Choose One & 0 & 0 & 0 & 0 & 0 \\
\hline
\end{tabular}

ITS

I have previously considered accepting an early retirement package.

\begin{tabular}{|c|c|c|c|c|c|} 
& $\begin{array}{c}\text { Strongly } \\
\text { Disagree }\end{array}$ & Disagree & $\begin{array}{c}\text { Neither Agree } \\
\text { nor Disagree }\end{array}$ & Agree & Strongly Agree \\
\hline Choose One & 0 & 0 & 0 & 0 & 0
\end{tabular}

ITS

I have considered quitting without having another job.

\begin{tabular}{|l|c|c|c|c|c|}
\hline & $\begin{array}{c}\text { Strongly } \\
\text { Disagree }\end{array}$ & Disagree & $\begin{array}{c}\text { Neither Agree } \\
\text { nor Disagree }\end{array}$ & Agree & Strongly Agree \\
\hline Chmas Ona & $m$ & $m$ & $\ldots$
\end{tabular}


ITS

I have stayed with Extension because it is the best place to work.

\begin{tabular}{|l|c|c|c|c|c|}
\hline & $\begin{array}{c}\text { Strongly } \\
\text { Disagree }\end{array}$ & Disagree & $\begin{array}{c}\text { Neither Agree } \\
\text { nor Disagree }\end{array}$ & Agree & Strongly Agree \\
\hline Choose One & 0 & 0 & 0 & 0 & 0
\end{tabular}

ITS

I plan to stay with Extension until | stop working.

\begin{tabular}{|c|cc|ccc}
\hline & $\begin{array}{c}\text { Strongly } \\
\text { Disagree }\end{array}$ & Disagree & $\begin{array}{c}\text { Neither Agree } \\
\text { nor Disagree }\end{array}$ & Agree & Strongly Agree \\
\hdashline Choose One & 0 & 0 & 0 & 0 & 0
\end{tabular}

ITS

I used to follow up on job opportunities (outside Extension) as I heard about them.

\begin{tabular}{c|cc|ccc|} 
& $\begin{array}{c}\text { Strongly } \\
\text { Disagree }\end{array}$ & Disagree & $\begin{array}{c}\text { Neither Agree } \\
\text { nor Disagree }\end{array}$ & Agree & Strongly Agree \\
\hline Choose One & 0 & 0 & 0 & 0 & 0
\end{tabular}

ITS

I plan to follow up on job opportunities (outside Extension) as I hear about them.

\begin{tabular}{l|ccccc} 
& Strongly & S & Neither Agree \\
Disagree & Disagree & nor Disagree & Agree & Strongly Agree \\
\hline Choose One & 0 & 0 & 0 & 0 & 0
\end{tabular}

ITS

I have never considered leaving Extension.

\begin{tabular}{l|ccccc|c} 
& $\begin{array}{c}\text { Strongly } \\
\text { Disagree }\end{array}$ & Disagree & $\begin{array}{c}\text { Neither Agree } \\
\text { nor Disagree }\end{array}$ & Agree & Strongly Agree \\
Choose One & 0 & 0 & 0 & 0 & 0
\end{tabular}

Please indicate the state in which you live and work.

Kansas Kentucky

0

0

Please indicate your Gender.

$\begin{array}{ccc}\text { Male } & \text { Female } \\ 0 & 0\end{array}$

Please indicate which best describes you.

$\begin{array}{cccccc}\text { Asian } & \text { Black } & \text { Hispanic } & \text { Indian } & \text { White } & \text { Other } \\ 0 & 0 & 0 & 0 & 0 & 0\end{array}$

Does your job include conducting agent performance reviews?

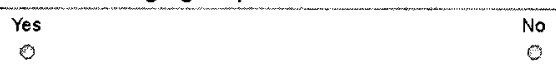

What is the highest education level you have achieved? 
$11 / 23 / 11$ Qualtrics Survey Software

0

voctoral vegree

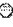

Please indicate which age group best describes you.

$\begin{array}{cccccccc}22-27 & 28-32 & 33-38 & 39-43 & 44-49 & 50-55 & 56-61 & 62+ \\ 0 & 0 & 0 & 0 & 0 & 0 & 0 & 0\end{array}$

Primary program area in which you work.

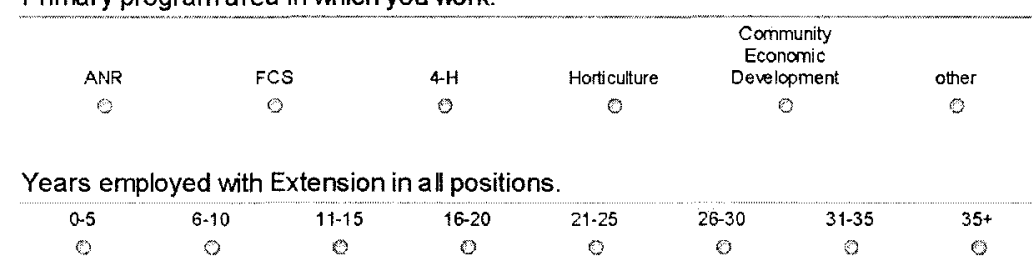

Years of other professional work experience outside Extension.

$\begin{array}{ccc}0-5 & 6-10 & 11+ \\ 0 & 0 & 0\end{array}$

Type of previous work experience.

$\begin{array}{ccc}\text { Public } & \text { Private } & \text { Non-Proft } \\ 0 & 0 & 0\end{array}$

Indicate which best describes the county population in which you work.

$\begin{array}{lllll}\text { under } 10,000 & 10,001-30,000 & 30,001-60,000 & 60,001-100,000 & \text { over } 100,000\end{array}$

$$
8
$$

0

0

e

9

This concludes our survey. Thank you for your help. The results will be available upon request. 


\section{APPENDIX D \\ COPY OF KANSAS STATE UNIVERSITY \\ EXTENSION DIRECTOR'S LETTER}

October 28, 2011

To: Extension Agents

From: Dr. Daryl Buchholz, Associate Director for Extension and Applied Research

Subject: Kansas State University/University of Kentucky Extension Retention Survey

Jeffery Young, University of Kentucky Extension Service, is conducting a research study requiring our assistance. In the next few days all Extension Agents in Kansas and Kentucky will receive an invitation to participate in this study on Extension Agent retention. Your responses to this survey will be very important in helping understand why Extension Agents choose to stay employed with Extension.

I am asking that you take the 15-20 minutes necessary to complete the on-line survey. No identifying questions will be asked and all responses are confidential.

Should you have any further questions or comments, please feel free to contact Jeffery Young at jyoung@uky.edu or (859) 257-7484. 


\section{APPENDIX E \\ KANSAS STATE INVITATION MESSAGE 1}

Good Day!

Last week you received an email from Dr. Daryl Buchholz asking for your cooperation in a research study involving retention of Extension Agents at Kansas State University and the University of Kentucky.

The finding of this survey will help answer many important questions and potentially save thousands of dollars in recruiting and retraining costs and only takes 15 minutes to complete.

\section{A link to the survey website is listed below. Simply click on the link for more information and directions. \$ $\{$ l://SurveyLink $\}$}

A summary of the finding from this research study will be made available upon request. If you have any requests, questions, concerns, or complaints about the research study, please contact me at 502-492-0985 or jyoung@uky.edu.

Sincerely

Jeffery A. Young

University of Kentucky

Cooperative Extension Service

District 3 Director

N-106, Ag. Science North

Lexington, KY 40546 
APPENDIX F

KANSAS STATE UNIVERSITY INVITATION MESSAGE 2

From: Jeffery A. Young (jyoung@uky.edu)

To: Kansas State University Extension Agents

Subject: University of Kentucky/ Kansas State University Retention Survey

We recently sent you an email asking you to respond to a survey Extension Agent retention in Kansas and Kentucky. Your responses to this survey are very important and should take no longer than 10-15 minutes to complete.

If you have already completed the survey, we appreciate your participation. If you have not yet responded, I encourage you to take a few minutes and complete the survey.

\section{A link to the survey website is listed below. Simply click on the link for more information and directions.}

$\$\{1: / /$ SurveyLink $\}$

Your participation is entirely voluntary and all of your responses will be kept confidential. No personally identifiable information will be associated with your responses in any reports of this data. Should you have any further questions or would like to receive a summary of the finding from this research study, please feel free to contact me atjyoung@uky.edu.

Your response is important. Getting direct feedback from agents is crucial in improving Extension in Kansas and Kentucky. Thank you for your help by completing the survey.

Sincerely,

Jeffery A. Young

District Director

Cooperative Extension Service

University of Kentucky

Dr. James Stone III

Director

National Research Center for Career and Technical Education

University of Louisville 


\section{APPENDIX G}

\section{KANSAS STATE UNIVERSITY INVITATION MESSAGE 3}

From: Jeffery A. Young (jyoung@uky.edu)

To: Kansas State University Extension Agents

Subject: Please complete the UK/KSU Retention Survey

Fall is a busy time for agents and we understand how valuable your spare time is during this time of year. We are hoping you may be able to give about 10 minutes of your time to help us collect important information for our KSU/UK Retention Survey.

If you have already completed the survey, we appreciate your participation. If you have not yet responded to the survey, we urge you to take this final opportunity to do so. We plan to end this study soon, so we wanted to email everyone who has not responded to make sure you had a chance to participate.

\section{A link to the survey website is listed below. Simply click on the link for more information and directions.}

Thank you in advance for completing the survey. Your responses are important! Agents are the best sources of information to help shape the Extension Services in Kansas and Kentucky. If you would like a summary of the finding of this research study please send requests to jyoung@uky.edu. Thank you again for your help by completing the survey.

Sincerely,

Jeffery A. Young

District Director

Cooperative Extension Service

University of Kentucky

Dr. James Stone III

Director

National Research Center for Career and Technical Education

University of Louisville 


\section{APPENDIX H \\ KANSAS STATE UNIVERSITY INVITATION MESSAGE 4}

From: Jeffery A. Young (jyoung@uky.edu)

To: Kansas State University Extension Agents

Subject: Please complete the UK/KSU Retention Survey

Fall is a busy time for agents and we understand how valuable your spare time is during this time of year. We are hoping you may be able to give about 10 minutes of your time to help us collect important information for our KSU/UK Retention Survey.

If you have already completed the survey, we appreciate your participation. If you have not yet responded to the survey, we urge you to take this final opportunity to do so. We plan to end this study soon, so we wanted to email everyone who has not responded to make sure you had a chance to participate.

\section{A link to the survey website is listed below. Simply click on the link for more information and directions.}

Thank you in advance for completing the survey. Your responses are important! Agents are the best sources of information to help shape the Extension Services in Kansas and Kentucky. If you would like a summary of the finding of this research study please send requests to jyoung@uky.edu. Thank you again for your help by completing the survey.

Sincerely,

Jeffery A. Young

District Director

Cooperative Extension Service

University of Kentucky

Dr. James Stone III

Director

National Research Center for Career and Technical Education

University of Louisville 


\section{APPENDIX I \\ COPY OF UNIVERSITY OF KENTUCKY \\ EXTENSION DIRECTOR'S LETTER}

From: Dr. Jimmy Henning, Associate Dean for Extension

Director, UK Cooperative Extension Service

To: All Agents

Subject: University of Kentucky/ Kansas State University Extension Retention Survey

October 28, 2011

I am writing to ask for your cooperation in a research study being conducted by Jeff

Young, District 3 Director. In the next few days all Extension Agents in Kentucky and

Kansas will receive an invitation to participate in this study on Extension Agent retention.

Your responses to this survey will be very important in helping understand why

Extension Agents choose to stay employed with the UK Extension Service.

I am asking that you take the 15-20 minutes necessary to complete the on-line survey. No identifying questions will be asked and all responses are confidential.

Should you have any further questions or comments, please feel free to contact Jeff at jyoung@uky.edu or (859) 257-7484.

Jimmy C. Henning

Associate Dean and Director for

UK Cooperative Extension

S107 Ag Science Building North

Lexington, KY 40546-0091

859.257.4302 PH

859.257.3501 FAX

Jimmy.henning@uky.edu

www.ca.uky.edu/CES 


\section{APPENDIX J \\ UNIVERSITY OF KENTUCKY INVITATION MESSAGE 1}

Good Day!

Last week you received an email from Dr. Jimmy Henning asking for your cooperation in a research study involving retention of Extension Agents at Kansas State University and the University of Kentucky.

The finding of this survey will help answer many important questions and potentially save thousands of dollars in recruiting and retraining costs and only takes 15 minutes to complete.

\section{A link to the survey website is listed below. Simply click on the link for more information and directions. \$ $\{$ ://SurveyLink $\}$}

A summary of the finding from this research study will be made available upon request. If you have any requests, questions, concerns, or complaints about the research study, please contact me at 502-492-0985 or jyoung@uky.edu.

Sincerely

Jeffery A. Young

University of Kentucky

Cooperative Extension Service

District 3 Director

N-106, Ag. Science North

Lexington, KY 40546 


\section{APPENDIX K \\ UNIVERSITY OF KENTUCKY INVITATION MESSAGE 2}

From: Jeffery A. Young (jyoung@uky.edu)

To: University of Kentucky Extension Agents

Subject: University of Kentucky/ Kansas State University Retention Survey

We recently sent you an email asking you to respond to a survey Extension Agent retention in Kansas and Kentucky. Previous responses show that this survey takes no longer than 10-15 minutes to complete.

If you have already completed the survey, we appreciate your participation. If you have not yet responded to the survey, we encourage you to take a few minutes and complete the survey.

A link to the survey website is listed below. Simply click on the link for more information and directions.

Your participation in the survey is entirely voluntary and all of your responses will be kept confidential. No personally identifiable information will be associated with your responses in any reports of this data. Should you have any further questions or would like to receive a summary of the finding from this research study, please feel free to contact me atjyoung@uky.edu.

Your response is important. Getting direct feedback from agents is crucial in improving Extension in Kansas and Kentucky. Thank you for your help by completing the survey

Sincerely,

Jeffery A. Young

District Director

Cooperative Extension Service

University of Kentucky

Dr. James Stone III

Director

National Research Center for Career and Technical Education

University of Louisville 


\section{APPENDIX L \\ UNIVERSITY OF KENTUCKY INVITATION MESSAGE 3}

From: Jeffery A. Young (jyoung@uky.edu)

To: University of Kentucky Extension Agents

Subject: Please complete the UK/KSU Retention Survey

Fall is a busy time for agents and we understand how valuable your spare time is during this time of year. We are hoping you may be able to give about 15-20 minutes of your time to help us collect important information for our KSU/UK Retention Survey.

If you have already completed the survey, we appreciate your participation. If you have not yet responded to the survey, we urge you to take a few minutes and complete the survey. We plan to end this study soon, so we wanted to email everyone who has not responded to make sure you had a chance to participate.

\section{A link to the survey website is listed below. Simply click on the link for more information and directions.}

Thank you in advance for completing the survey. Your responses are important! Agents are the best sources of information to help shape the Extension Services in Kansas and Kentucky. If you would like a summary of the finding of this research study please send requests to jyoung@uky.edu. Thank you again for your help by completing the survey.

Sincerely,

Jeffery A. Young

District Director

Cooperative Extension Service

University of Kentucky

Dr. James Stone III

Director

National Research Center for Career and Technical Education

University of Louisville 


\section{APPENDIX M \\ UNIVERSITY OF KENTUCKY INVITATION MESSAGE 4}

From: Jeffery A. Young (jyoung@uky.edu)

To: University of Kentucky Extension Agents

Subject: Please complete the UK/KSU Retention Survey

Fall is a busy time for agents and we understand how valuable your spare time is during this time of year. We are hoping you may be able to give about 10 minutes of your time to help us collect important information for our KSU/UK Retention Survey.

If you have already completed the survey, we appreciate your participation. If you have not yet responded to the survey, we urge you to take this final opportunity to do so. We plan to end this study soon, so we wanted to email everyone who has not responded to make sure you had a chance to participate.

\section{A link to the survey website is listed below. Simply click on the link for more information and directions.}

Thank you in advance for completing the survey. Your responses are important! Agents are the best sources of information to help shape the Extension Services in Kansas and Kentucky. If you would like a summary of the finding of this research study please send requests to jyoung@uky.edu. Thank you again for your help by completing the survey.

Sincerely,

Jeffery A. Young

District Director

Cooperative Extension Service

University of Kentucky

Dr. James Stone III

Director

National Research Center for Career and Technical Education

University of Louisville 
APPENDIX N

NIFA LAND-GRANT COLLEGES AND UNIVERSITIES MAP 
USDA United States National Institute Deparment of of Food and
Agricuture

NIFA LAND-GRANT COLLEGES AND UNIVERSITIES

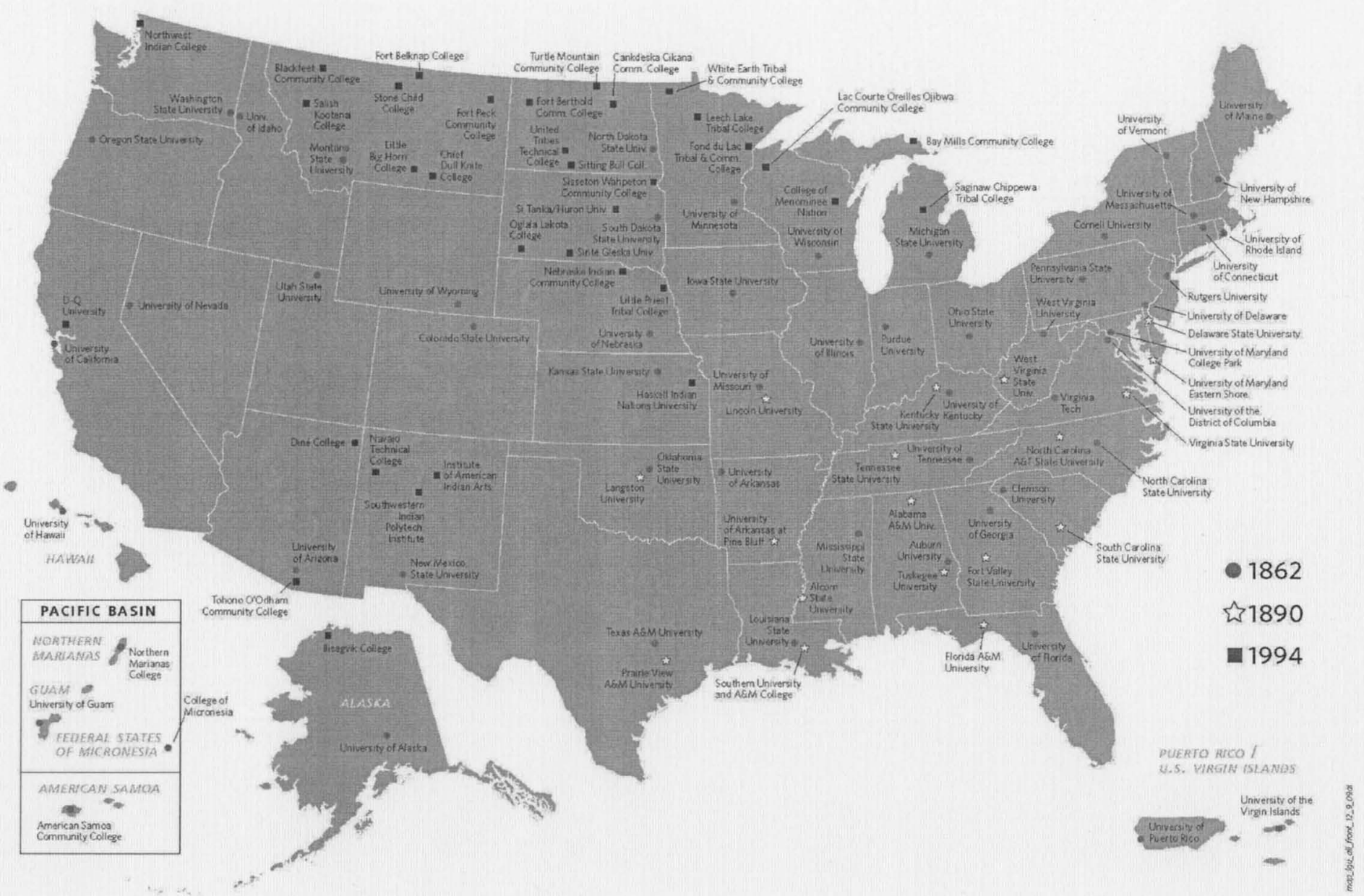


APPENDIX O

\section{NIFA LAND-GRANT COLLEGES AND UNIVERSITIES LIST}

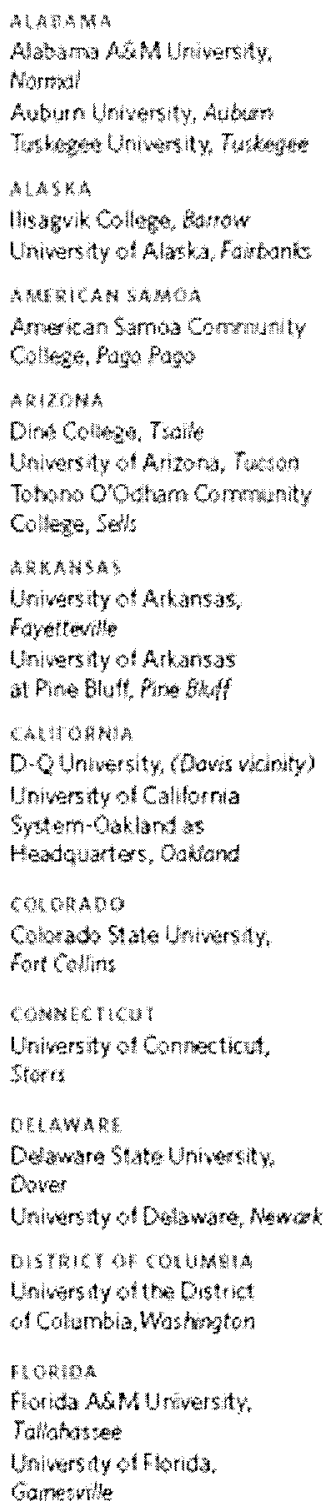

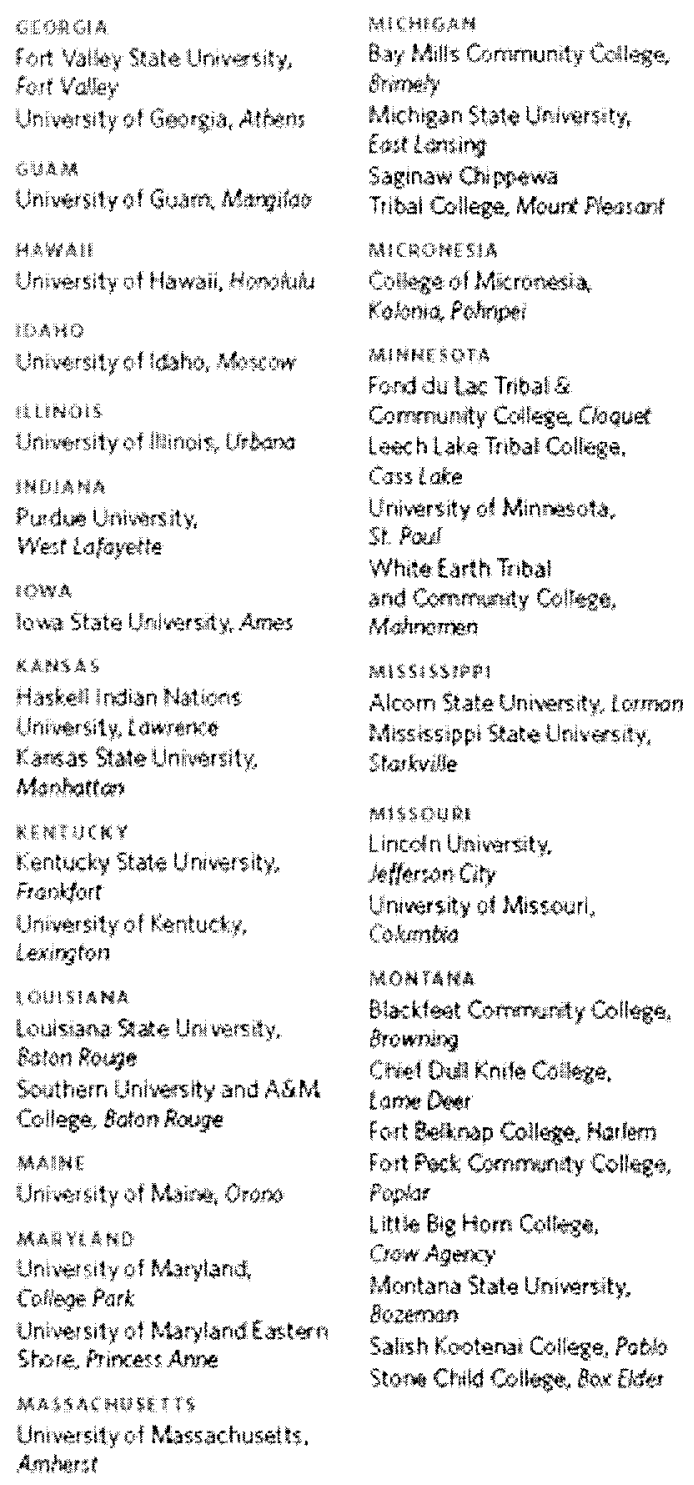

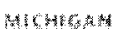

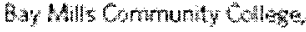
Whaty

Mchigan ste Universty

Ext Loring

Sagnaw Chpwa

Tibal Collegs Mour Peasar

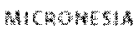

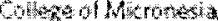

romia purthe

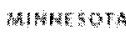

Fond dula Tribls

Cormmaty Codege Coous

lech a are Tribal Colkge.

Cosstore

Uriversty of Ninesets.

St. Pous

White enth That

and pompraty Golvow

Motromen

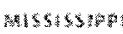

Alom Stata Uniterstu lown

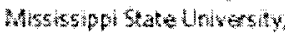

Sarblile

Mroscum:

Lintedn Universty

kfferencty

Unwersity of Missour.

conentwo

Montast

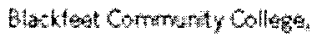

Brownis

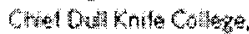

Larwe Dow

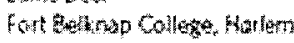

Fot Post Gormuty Collow

Pondar

Litts Big Hon Cothisest

Cys Agery

Mortand State Uriwarky.

Bezomon

Salish hootena College, Pobs

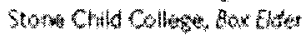




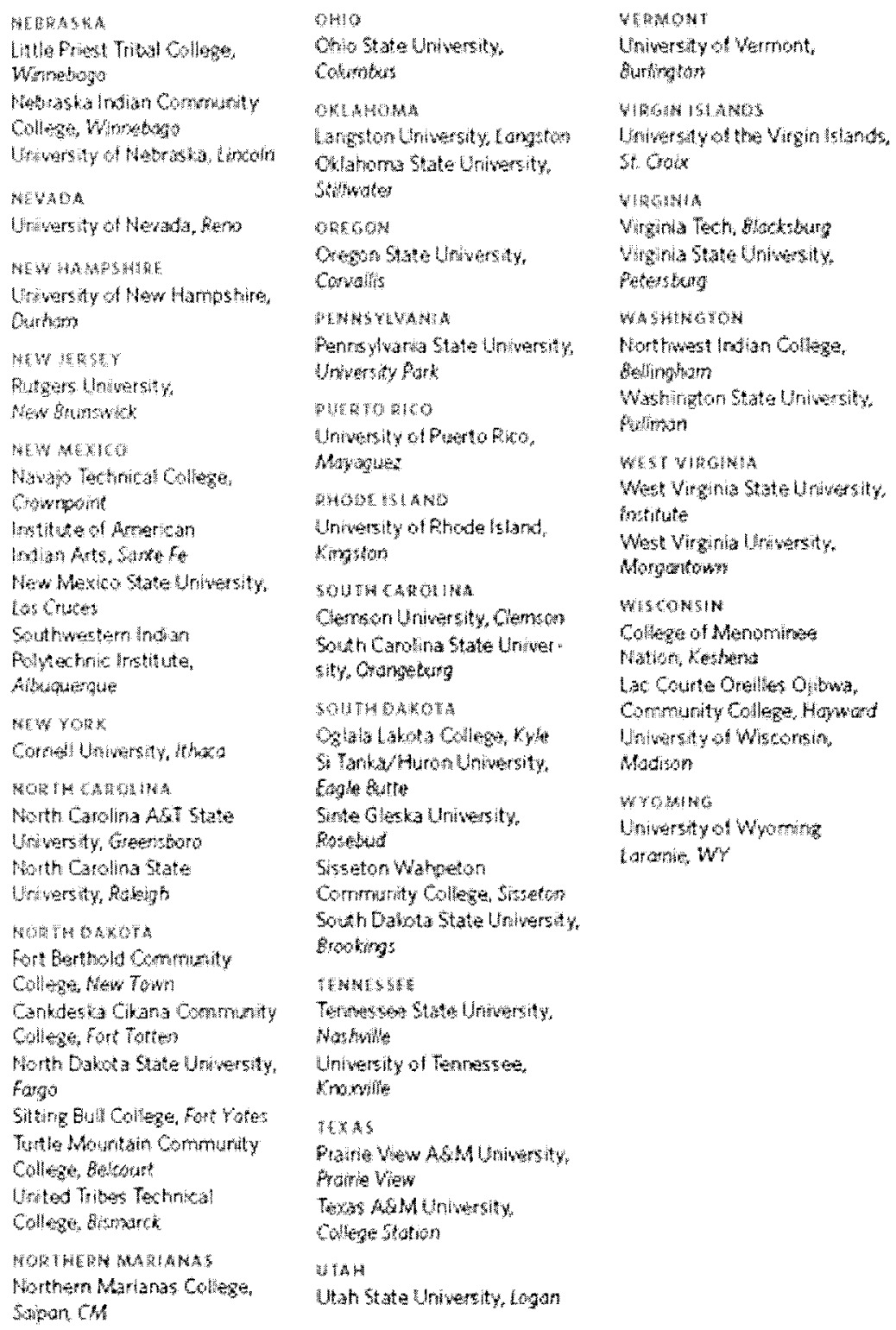




\section{APPENDIX P}

NIFA Salary Analysis of Cooperative Extension Service Positions

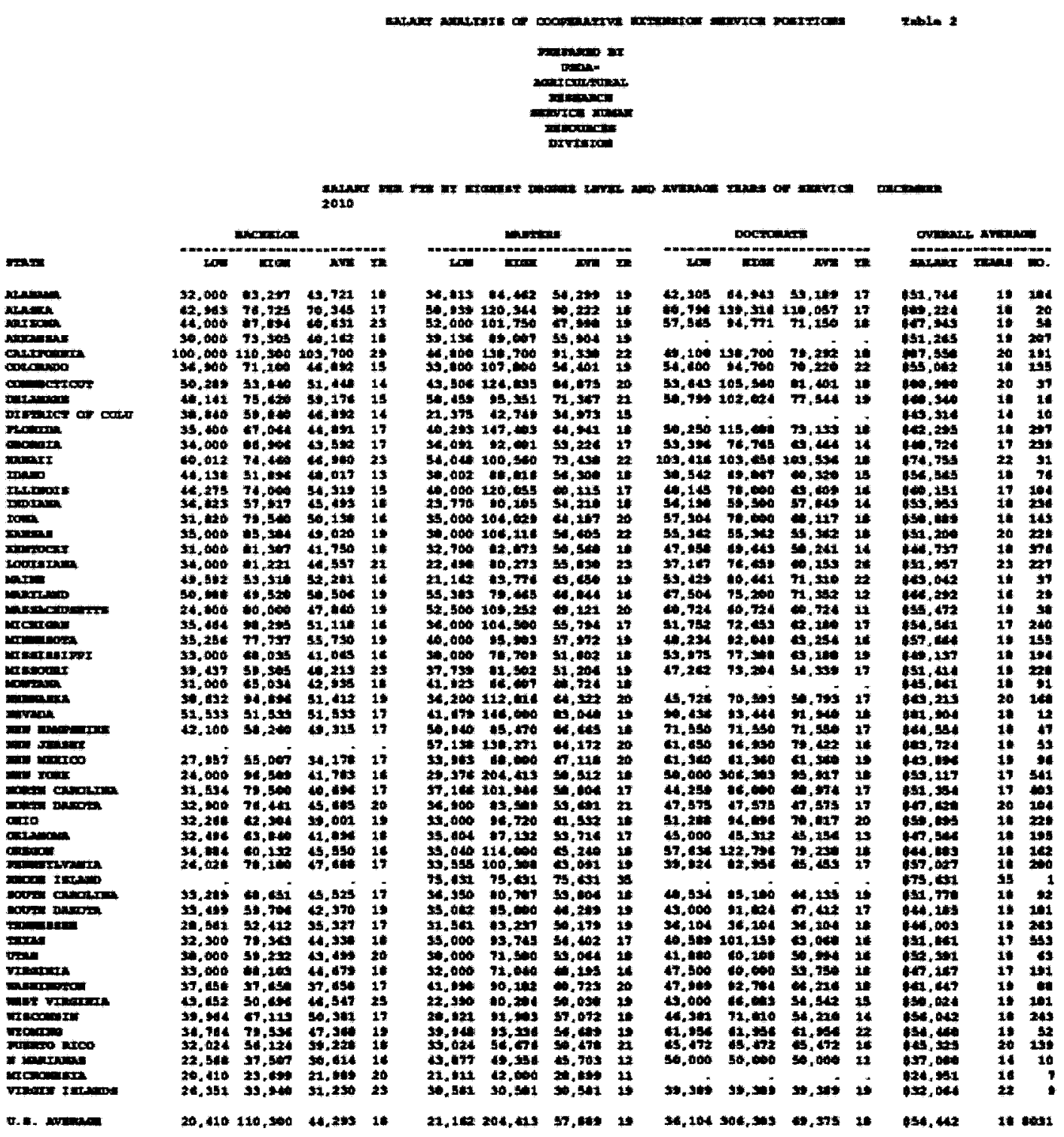


APPENDIX Q

\section{CORRELATIONS ALL VARIABLES}


Correlations: Part 1

\begin{tabular}{|c|c|c|c|c|c|c|c|c|c|c|c|c|}
\hline & EmbTot & IntStay & DES & Black & Indian & Masters & Doctoral & PAFCS & $\mathrm{PA} 4 \mathrm{H}$ & PAhort & PAced & PAother \\
\hline $\begin{array}{l}\text { EmbTot } \\
\text { IntStay } \\
\text { DES } \\
\text { Black } \\
\text { Indian } \\
\text { Masters } \\
\text { Doctoral } \\
\text { PAFCS } \\
\text { PA4H } \\
\text { PAhort } \\
\text { PAced } \\
\text { PAother } \\
\text { Age 28-32 } \\
\text { Age 33-38 } \\
\text { Age 39-43 } \\
\text { Age 44-49 } \\
\text { Age 50-55 } \\
\text { Age 56-61 } \\
\text { Age 62+ } \\
\text { Yrs Ext 6-10 } \\
\text { Yrs Ext 11-15 } \\
\text { Yrs Ext 16-20 } \\
\text { Yrs Ext 21-25 } \\
\text { Yrs Ext 26-30 } \\
\text { Yrs Ext 31-35 } \\
\text { Yrs Ext 36+ } \\
\text { Yrssother 6-10 } \\
\text { Yrssother 11+ } \\
\text { YrsPrivate } \\
\text { Yrsnonprof } \\
\text { CoPop10-30 } \\
\text { CoPop30-60 } \\
\text { CoPop60-100 } \\
\text { CoPop100+ } \\
\text { Female }\end{array}$ & - & $\frac{.217^{* *}}{-}$ & $\begin{array}{c}.334^{* *} \\
.005 \\
-\end{array}$ & $\begin{array}{r}-.047 \\
-.046 \\
-.064 \\
-\end{array}$ & $\begin{array}{l}-.199^{* *} \\
-.038 \\
-.068 \\
-.010 \\
-\end{array}$ & $\begin{array}{c}.012 \\
-.038 \\
.212^{* *} \\
-.027 \\
-.080 \\
-\end{array}$ & $\begin{array}{r}-.010 \\
.28^{*} \\
.03^{*} \\
.080 \\
-.99^{*} \\
.210 \\
-\end{array}$ & $\begin{array}{c}-.025 \\
.107^{*} \\
.045 \\
.078 \\
.035 \\
.019 \\
.02^{*} \\
-\end{array}$ & $\begin{array}{c}.000 \\
.002 \\
.062 \\
.068 \\
-.043 \\
.079 \\
.070 \\
-.391^{* *} \\
-\end{array}$ & $\begin{array}{c}-.008 \\
-.020 \\
-.034 \\
-.041 \\
-.018 \\
-.076 \\
.060 \\
-.164^{* *} \\
-.175^{* *} \\
-\end{array}$ & $\begin{array}{r}.054 \\
.084 \\
-.021 \\
.010 \\
.004 \\
.056 \\
. .050 \\
-.040 \\
. .043 \\
. .018 \\
-\end{array}$ & $\begin{array}{c}.054 \\
.084 \\
-.021 \\
-.010 \\
-.004 \\
.056 \\
.020 \\
-.040 \\
-.043 \\
-.018 \\
1.000^{* *} \\
-\end{array}$ \\
\hline
\end{tabular}

${ }^{\text {a }}$ Cannot be computed because at least one of the variables is constant.

* Correlation is significant at the 0.05 level (2-tailed). ${ }^{* *}$ Correlation is significant at the 0.01 level (2-tailed). 
Correlations: Part 2

\begin{tabular}{|c|c|c|c|c|c|c|c|c|c|c|c|c|}
\hline & $\begin{array}{c}\text { Age } \\
28-32\end{array}$ & $\begin{array}{c}\text { Age } \\
33-38 \\
\end{array}$ & $\begin{array}{c}\text { Age } \\
39-43\end{array}$ & $\begin{array}{c}\text { Age } \\
44-49 \\
\end{array}$ & $\begin{array}{c}\text { Age } \\
50-55 \\
\end{array}$ & $\begin{array}{c}\text { Age } \\
56-61 \\
\end{array}$ & $\begin{array}{l}\text { Age } \\
62+ \\
\end{array}$ & $\begin{array}{c}\text { Yrs ext } \\
6-10 \\
\end{array}$ & $\begin{array}{c}\text { Yrs ext } \\
11-15 \\
\end{array}$ & $\begin{array}{c}\text { Yrs ext } \\
16-20 \\
\end{array}$ & $\begin{array}{c}\text { Yrs ext } \\
21-25 \\
\end{array}$ & $\begin{array}{c}\text { Yrs ext } \\
26-30 \\
\end{array}$ \\
\hline EmbTot & -.019 & -.002 & -.044 & -.027 & .045 & .058 & -.027 & .004 & .016 & -.035 & .020 & -.016 \\
\hline IntStay & -.039 & -.054 & -.033 & -.017 & $.129^{* *}$ & .040 & -.017 & -.018 & -.087 & -.001 & .006 & -.009 \\
\hline DES & -.048 & -.026 & .022 & .036 & .046 & .026 & .036 & .005 & .010 & -.003 & -.031 & .066 \\
\hline Black & -.002 & -.061 & -.005 & .019 & -.067 & -.022 & .019 & .036 & .007 & .046 & -.053 & -.045 \\
\hline Indian & -.023 & .068 & -.023 & -.028 & -.030 & .064 & -.028 & -.034 & -.031 & -.023 & -.024 & $.102^{*}$ \\
\hline Masters & .005 & .042 & .079 & $.121^{* *}$ & .015 & -.003 & $.121^{* *}$ & -.020 & $.140^{* *}$ & .025 & .028 & .052 \\
\hline Doctoral & .010 & .050 & -.070 & $-.11 *$ & $-.02 *$ & -.010 & .220 & .010 & -.130 & -.020 & -.040 & $-.05 *$ \\
\hline PAFCS & -.042 & -.049 & -.070 & .003 & .022 & $.127^{* *}$ & .003 & -.024 & -.029 & -.014 & .021 & .001 \\
\hline PA4H & $.098^{*}$ & .026 & .004 & .032 & -.044 & $-.115^{*}$ & .032 & .055 & .044 & -.002 & -.077 & -.016 \\
\hline PAhort & -.006 & .039 & .017 & .006 & -.028 & .006 & .006 & .036 & .030 & -.064 & -.013 & -.017 \\
\hline PAced & -.023 & -.027 & $.189^{* *}$ & -.028 & -.030 & -.028 & -.028 & -.034 & -.031 & $.193^{* *}$ & -.024 & .020 \\
\hline PAother & -.023 & -.027 & $.189^{* *}$ & -.028 & -.030 & -.028 & -.028 & -.034 & -.031 & $.193^{* *}$ & -.024 & -.020 \\
\hline Age $28-32$ & - & $-.139^{* *}$ & $-.119^{*}$ & $-.145^{n *}$ & $-.152^{* *}$ & $-145^{* *}$ & $-.145^{* *}$ & $.383^{* *}$ & $-160^{* *}$ & $-.117^{*}$ & $-.121^{*}$ & $-.101^{\circ}$ \\
\hline Age 33-38 & & - & $-.143^{* *}$ & $-.174^{* *}$ & $-.183^{* *}$ & $-.174^{* *}$ & $-.174^{* *}$ & $.120^{*}$ & $.295^{* *}$ & $-.140^{* *}$ & $-.145^{* *}$ & $-.121^{* *}$ \\
\hline Age $39-43$ & & & - & $-.150^{* *}$ & $-.157^{* *}$ & $-150^{* *}$ & $-.150^{* *}$ & -.021 & $.162^{* *}$ & $.291^{* *}$ & $-.103^{*}$ & $-.105^{*}$ \\
\hline Age $44-49$ & & & & - & $-.191^{* *}$ & $-.182^{* *}$ & $1.000^{* *}$ & .010 & .019 & .072 & $.312^{* *}$ & -.038 \\
\hline Age $50-55$ & & & & & - & $-.191^{* *}$ & $-.191^{* *}$ & $-.139^{* *}$ & -.089 & .000 & $.102^{*}$ & $.212^{* *}$ \\
\hline Age 56-61 & & & & & & 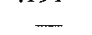 & $-.182^{* *}$ & $.156^{* *}$ & -.028 & .012 & .022 & $.141^{* *}$ \\
\hline Age $62+$ & & & & & & & - & .010 & .019 & .072 & $.312^{* *}$ & -.038 \\
\hline Yrs Ext 6-10 & & & & & & & & - & $-.239^{* *}$ & $-.174^{* *}$ & $-.180^{* *}$ & $-.151^{* *}$ \\
\hline Yrs Ext 11-15 & & & & & & & & & - & $-.162^{* *}$ & $-.168^{* *}$ & $-.141^{* *}$ \\
\hline Yrs Ext $16-20$ & & & & & & & & & & - & $-.122^{* *}$ & $-.102^{*}$ \\
\hline Yrs Ext 21-25 & & & & & & & & & & & - & $-.106^{\circ}$ \\
\hline Yrs Ext 26-30 & & & & & & & & & & & & - \\
\hline \multicolumn{13}{|l|}{ Yrs Ext 31-35 } \\
\hline \multicolumn{13}{|l|}{ Yrs Ext 36+ } \\
\hline \multicolumn{13}{|l|}{ Yrssother 6-10 } \\
\hline \multicolumn{13}{|l|}{ Yrssother 11+ } \\
\hline \multicolumn{13}{|l|}{ YrsPrivate } \\
\hline \multicolumn{13}{|l|}{ Yrsnonprof } \\
\hline \multicolumn{13}{|l|}{ CoPop10-30 } \\
\hline \multicolumn{13}{|l|}{ CoPop30-60 } \\
\hline \multicolumn{13}{|l|}{ CoPop60-100 } \\
\hline CoPop100+ & & & & & & & & & & & & \\
\hline Female & & & & & & & & & & & & \\
\hline
\end{tabular}

${ }^{*}$ Correlation is significant at the 0.05 level (2-tailed). ${ }^{* *}$ Correlation is significant at the 0.01 level ( 2 -tailed). 
Correlations: Part 3

\begin{tabular}{|c|c|c|c|c|c|c|c|c|c|c|c|}
\hline & $\begin{array}{c}\text { Yrs ext } 31- \\
35 \\
\end{array}$ & Yrs ext $36+$ & $\begin{array}{c}\text { Yrssother 6- } \\
10 \\
\end{array}$ & $\begin{array}{c}\text { Yrssother } \\
11+\end{array}$ & $\begin{array}{c}\text { Yrs } \\
\text { Private } \\
\end{array}$ & $\begin{array}{c}\text { Yrs } \\
\text { Nonprof } \\
\end{array}$ & $\begin{array}{c}\text { CoPop } \\
10-30 \\
\end{array}$ & $\begin{array}{l}\text { CoPop } \\
30-60 \\
\end{array}$ & $\begin{array}{l}\text { CoPop } \\
60-100 \\
\end{array}$ & $\begin{array}{c}\text { CoPop } \\
100+\end{array}$ & Female \\
\hline EmbTot & $.101^{*}$ & .020 & -.061 & -.010 & -.052 & .010 & $.118^{*}$ & -.008 & .057 & .008 & -.057 \\
\hline IntStay & .079 & .006 & -.027 & -.030 & -.045 & -.120 & .011 & -.022 & .066 & -.039 & .082 \\
\hline DES & .051 & -.031 & -.035 & .040 & $-.112^{*}$ & .030 & .067 & -.023 & .036 & -.029 & $.103^{*}$ \\
\hline Black & -.043 & -.053 & -.063 & -.020 & -.077 & .010 & $-.113^{*}$ & .049 & .010 & $.203^{* *}$ & .067 \\
\hline Indian & -.019 & -.024 & .065 & .010 & .022 & .080 & -.050 & .057 & -.020 & -.026 & -.011 \\
\hline Masters & -.010 & .028 & .037 & .010 & -.018 & -.080 & .004 & .010 & -.046 & .071 & .050 \\
\hline Doctoral & .010 & $.22 *$ & -.030 & -.060 & .020 & .170 & .080 & -.010 & .050 & .030 & .040 \\
\hline PAFCS & .011 & .021 & .025 & .120 & $-.228^{* *}$ & .020 & -.010 & -.006 & -.017 & -.038 & $.515^{* *}$ \\
\hline $\mathrm{PA} 4 \mathrm{H}$ & -.006 & -.077 & -.014 & -.050 & $-.121^{* *}$ & -.090 & .027 & .056 & .002 & .039 & $.169^{* *}$ \\
\hline PAhort & -.013 & -.013 & .009 & .040 & $.172^{* *}$ & .010 & $-.112^{*}$ & .036 & $.111^{*}$ & $.172^{* *}$ & -.053 \\
\hline PAced & -.019 & -.024 & -.028 & -.040 & -.048 & -.120 & -.050 & -.031 & $.102^{*}$ & .070 & -.011 \\
\hline PAother & -.019 & -.024 & -.028 & .140 & -.048 & -.010 & -.050 & -.031 & $.102^{*}$ & .070 & -.011 \\
\hline Age $28-32$ & $-.098^{*}$ & $-.121^{*}$ & -.021 & .020 & -.063 & .010 & .016 & -.024 & -.048 & -.009 & $.098^{*}$ \\
\hline Age $33-38$ & $-.118^{*}$ & $-.145^{* *}$ & .075 & .020 & -.004 & .060 & .007 & .026 & .016 & -.052 & .016 \\
\hline Age $39-43$ & $-.101^{*}$ & $-.103^{*}$ & -.009 & -.030 & -.002 & .080 & .014 & .041 & -.002 & -.037 & -.014 \\
\hline Age $44-49$ & $-.123^{* *}$ & $.312^{* *}$ & -.008 & -.010 & .038 & .020 & .010 & .043 & -.060 & .026 & .045 \\
\hline Age $50-55$ & $.313^{* *}$ & $.102^{*}$ & .044 & .210 & -.001 & .030 & -.005 & .041 & -.025 & .063 & -.037 \\
\hline Age 56-61 & $.174^{* *}$ & .022 & .043 & -.240 & .051 & -.030 & -.054 & $-.101^{\circ}$ & $.096^{*}$ & .044 & -.032 \\
\hline Age $62+$ & $-.123^{* *}$ & $.312^{* *}$ & -.008 & -.120 & .038 & .010 & .010 & .043 & -.060 & .026 & -.045 \\
\hline Yrs Ext 6-10 & $-.146^{* *}$ & $-.180^{* *}$ & -.014 & -.010 & -.022 & .040 & .028 & .038 & -.091 & .053 & .000 \\
\hline Yrs Ext $11-15$ & $-.136^{* *}$ & $-.168^{* *}$ & -.006 & -.030 & -.017 & .020 & -.011 & .021 & .068 & -.022 & .044 \\
\hline Yrs Ext $16-20$ & $-.099^{*}$ & $-.122^{* *}$ & .017 & .010 & .023 & .010 & -.064 & .029 & .029 & -.011 & -.056 \\
\hline Yrs Ext 21.25 & $-.103^{*}$ & $1.000^{* *}$ & .046 & .030 & .081 & .010 & .052 & -.018 & .073 & -.019 & -.065 \\
\hline Yrs Ext 26-30 & -.086 & $-.106^{\circ}$ & -.012 & .090 & .005 & .000 & .028 & .032 & -.059 & .046 & .089 \\
\hline Yrs Ext 31-35 & - & $-.103^{*}$ & .018 & .010 & -.035 & .050 & .041 & -.025 & .005 & -.043 & -.039 \\
\hline Yrs Ext 36+ & & - & .046 & -.570 & .081 & .050 & .052 & -.018 & .073 & -.019 & -.065 \\
\hline Yrssother 6-10 & & & - & .010 & -.056 & .010 & -.045 & .017 & -.080 & -.041 & .007 \\
\hline Yrssother 11+ & & & & - & .020 & -.710 & .030 & .050 & .050 & .020 & .050 \\
\hline YrsPrivate & & & & & - & .020 & -.089 & .019 & .039 & .010 & $-324^{* *}$ \\
\hline Yrsnonprof & & & & & & - & .220 & .220 & .230 & .120 & .150 \\
\hline CoPop10-30 & & & & & & & - & $-.347^{* *}$ & $.223^{* *}$ & $-.298^{* *}$ & -.029 \\
\hline CoPop30-60 & & & & & & & & - & $-.137^{* *}$ & $-183^{* *}$ & .007 \\
\hline CoPop60-100 & & & & & & & & & - & $-.118^{*}$ & -.008 \\
\hline CoPop100+ & & & & & & & & & & - & .039 \\
\hline Female & & & & & & & & & & & - \\
\hline
\end{tabular}

* Correlation is significant at the 0.05 level (2-tailed). ${ }^{*}$ Correlation is significant at the 0.01 level (2-tailed). 
CURRICULUM VITAE

\author{
JEFFERY ALLEN YOUNG \\ 132 MILLWOOD DRIVE \\ SHEPHERDSVILLE, KY 40165
}

\title{
ACADEMIC BACKGROUND
}

\section{Graduate}

- Doctor of Philosophy

Dissertation Title: Job Embeddedness Theory: Can it Help Explain

Employee Retention?

Major: Education Leadership and Organizational Development

UNIVERSITY OF LOUISVILLE, LOUISVILLE, KENTUCKY

- Master of Public Administration

Major: Public Policy and Administration

UNIVERSITY OF LOUISVILLE, LOUISVILLE, KENTUCKY

\section{Undergraduate}

- Bachelor of Science

Major: Agricultural Economics

UNIVERSITY OF KENTUCKY, LEXINGTON, KENTUCKY

\section{WORK EXPERIENCE}

- District 3 Director, University of Kentucky, Cooperative Extension Service 2007-Present

- County Extension Agent for 4-H Youth Development, University of Kentucky Cooperative Extension Service

1990-2007

- Location Manager, Goodyear Tire and Rubber Co., Richmond, Virginia 1987-1990

- Assistant Location Manager, Southern States Cooperative, Goochland, Virginia 1985-1987 


\section{EXPERIENCES AND TRAINING}

- Multi-Area/Regional Extension Conference Planning Committees

- Southern Region Volunteer Forum, Planning Committee and Presenter

- Kentucky Volunteer Leader Forum, Planning Committee and Presenter

- Youth Protection Risk Management, trainer, writer and planning committee member

- County Review Team member (multiple)

- Regional Issues and Program Committee

- Turning Lemons, Into Lemonade, Dr. Ron Hustedde, University of Kentucky

- Extension Mentor Training

- Managerial Assessment of Proficiency (MAP), UK April, 2004

- Managing to EXCEL - UK November, 2004

- Equipping Emerging Leaders - Situational Leadership Program

- "How to Handle Difficult People," Rockhurst College

- Human Resources and the Law - Rockhurst College

- Managing Multiple Projects, Rockhurst College

- Communicating with Confidence, Clarity and Credibility, Rockhurst College

- Managing Emotions in the Workplace, Rockhurst College

- Conflict Resolution Training, Just Solutions of Louisville

- National Issues Forum, University of Miami-Ohio

- Myers-Briggs Type Indicator - Qualified Presenter

- Common-health Citizens Forums Facilitator

- Living Leadership, Maximum Impact Group

- Management Training Program, Southern States Cooperative

- Management Training and Continuing Education, Goodyear Tire and Rubber Co.

- Managed retail sales operation with annual sales of over $\$ 1$ million and 8 employees 